\title{
Modulation of thiols and pulmonary immune responses due to diesel exhaust particle (DEP) exposure
}

\author{
Nabil Hussain Al-Humadi \\ West Virginia University
}

Follow this and additional works at: https://researchrepository.wvu.edu/etd

\section{Recommended Citation}

Al-Humadi, Nabil Hussain, "Modulation of thiols and pulmonary immune responses due to diesel exhaust particle (DEP) exposure" (2002). Graduate Theses, Dissertations, and Problem Reports. 1572.

https://researchrepository.wvu.edu/etd/1572

This Dissertation is protected by copyright and/or related rights. It has been brought to you by the The Research Repository @ WVU with permission from the rights-holder(s). You are free to use this Dissertation in any way that is permitted by the copyright and related rights legislation that applies to your use. For other uses you must obtain permission from the rights-holder(s) directly, unless additional rights are indicated by a Creative Commons license in the record and/ or on the work itself. This Dissertation has been accepted for inclusion in WVU Graduate Theses, Dissertations, and Problem Reports collection by an authorized administrator of The Research Repository @ WVU.

For more information, please contact researchrepository@mail.wvu.edu. 


\title{
Dissertation
}

Modulation of Thiols and Pulmonary Immune Responses due to Diesel Exhaust Particle (DEP) Exposure

\author{
Nabil H. Al-Humadi \\ Dissertation submitted to the \\ School of Pharmacy \\ at West Virginia University \\ in Partial fulfillment of the requirements \\ for the degree of \\ Doctor of Philosophy \\ In Pharmaceutical Sciences
}

\author{
Joseph K.H. Ma, Ph.D., Chair \\ Paul D. Siegel, Ph.D. \\ Daniel M. Lewis, Ph.D. \\ Vincent Castranova, Ph.D. \\ Yongyut Rojanaskul, Ph.D. \\ Department of Basic Pharmaceutical Science
}

Morgantown, West Virginia

2002

Keywords: Diesel Exhaust Particles, Glutathione, Cysteine, HPLC, IgE, IgG, IL-4 mRNA, IFN- $\gamma$ mRNA, Inflammatory Markers, Lymph Node Cells, Alveolar Macrophage, Glutahione Reductase

Copyright 2002 Nabil H. Al-Humadi 


\begin{abstract}
Modulation of Thiols and Pulmonary Immune Responses due to DEP Exposure
\end{abstract}

\begin{abstract}
Nabil Al-Huamdi
Environmental exposure to diesel exhaust particles (DEP) has been of concern because of its potential contribution to the increased prevalence of acute and chronic airway diseases. The objective of this study was to investigate the role of thiol changes (due to DEP exposure) in immune responses. Rats were exposed to OVA, DEP, or both by intratracheal instillation (IT) and/or inhalation. IT-DEP exposure significantly increased the inflammatory parameters and thiol levels in both Sprague Dawley and Brown Norway rats. Exposure to DEP and/or OVA resulted in significant increases in neutrophils, $\mathrm{LDH}$, total protein, and albumin content in lavage fluid. Alveolar macrophage (AM) from DEP-exposed rats showed a time-dependent increase in intracellular cysteine (CYSH) and glutathione (GSH). In lymph node cells (LNC), the intracellular GSH increased significantly at 24 hours, and declined at 72 hours post exposure. LNC-CYSH, and AM-CYSH and-GSH were increased at both 24 and 72 hours. DEP acutely enhanced cystine uptake and reduction in both AM and LNC. In contrast, the intracellular level of GSH in DEP-exposed LNC was significantly reduced despite the increased CYSH level and GSH-Reductase ${ }^{\circledR}$ activity when these cells were cultured with cystine. The DEP exposure stimulated GSH-R activity and resulted in increased conversion of cystine to CYSH in both cell types. Notable restoration of cystine uptake, reduction and GSH production was seen in AM of DEP-exposed OVA-challenged rats. Threshold effect on both CYSH and GSH levels in BAL and AM was seen after exposure to different concentrations of OVA alone. CB and DEP tended to increase lung IFN- $\gamma$ and IL-4 $m$ RNA. The significant increases in serum OVA-specific IgG and $\operatorname{IgE}$ and the increase in IL-4 $m$ RNA in lung tissue were consistent with an adjuvant effect of DEP or CB for OVA sensitization. In summary, DEP caused lung inflammation and thiol changes (in both AM and LNC) and that these effects are particulate mediated.
\end{abstract}




\section{Dedicated to}

My Wife, Hind and Children, Ala, Reem and Nasma My Mother, Amina Al-Humadi

My Beloved Deceased Brother, Ala Al-Humadi 


\section{ACKNOWLEDGMENTS}

My advisor, Dr. Joseph Ma, thank you for your wise guidance, patience, contribution, and for promoting my professional growth during my graduate studies. My mentor, Dr. Paul Siegel, I would like to express my special thanks to you for being a second advisor and not just a boss but also a friend and a brother. I gained a lot of experience by working with you, watching you, and listening to your advises. I would like to express my special thanks to Dr. Dan Lewis who was very helpful in giving me his professional advises. I would also like to thank my committee members Drs. Vincent Castranova, and Yongyut Rojanasakul for your comments and suggestions to my research and for promoting my career development.

I would not have done all my research in a timely and organized way with out the help of Mr. Mark Barger. The National Institute of Occupational Safety and Health (NIOSH) are and will be always special knowledge ship where I get my experience. NIOSH has provided me the opportunity to work with the most wonderful and helpful people like Dr. David Weissman, Dr. Bao-Zhin Zhong, Ms. Judy Mull, Mrs. Zhen-Zhin Zhuang, and Dr. Jane Ma. NIOSH library staff were always very efficient in their help especially Melanie Vunjak.

In the memory of my beloved brother Ala who I have missed his smile, encouragement, and support. You have been always the sunshine of our family and you will be always like that. My wife, Hind, for being very patient, understandable, and helpful during all my years of study. The most important person in my life is my mother Amina Al-Humadi, thank you for your warm hands in every touch of my steps. To my brothers and sisters for the help and encouragement. 


\section{TABLE OF CONTENTS}

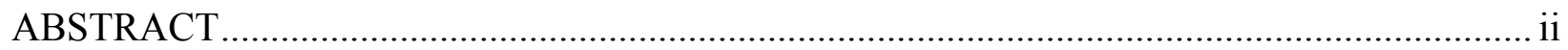

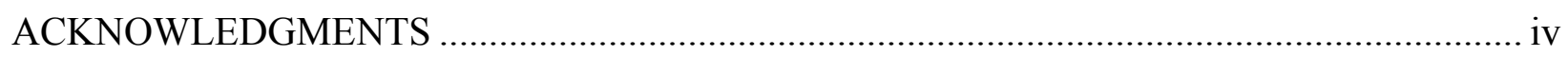

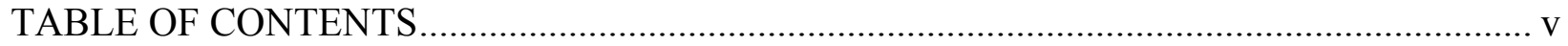

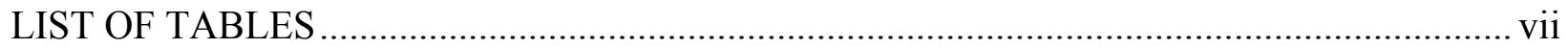

LIST OF FIGURES .................................................................................................... vii

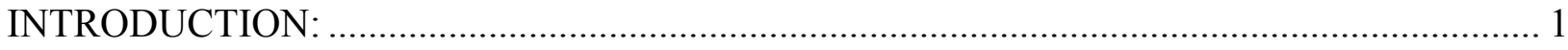

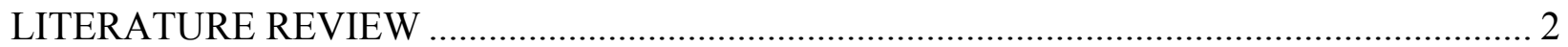

Diesel Exhaust Particles (DEP): ................................................................................... 2

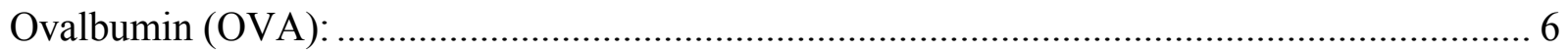

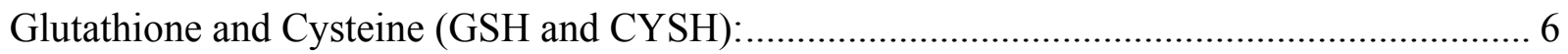

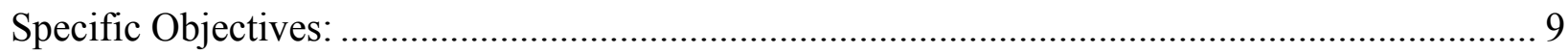

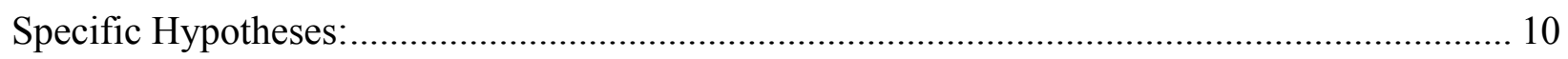

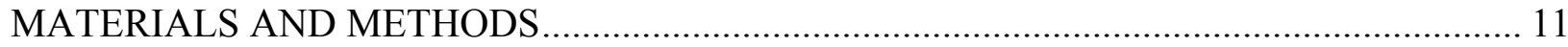

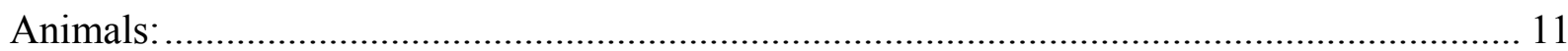

Particulate Sample Preparations: ................................................................................ 11

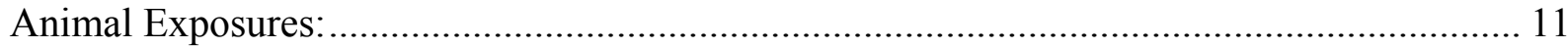

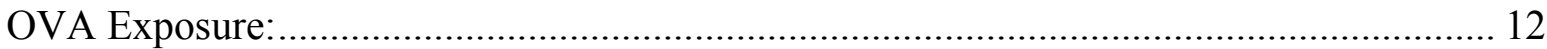

DEP Exposure by Intratracheal Instillation or Inhalation:........................................... 12

IT-DEP Exposure and ex vivo16hr incubation of LNC or AM with or with out Cystine:... 12

Combined IT-DEP or CB and OVA Exposure:............................................................ 13

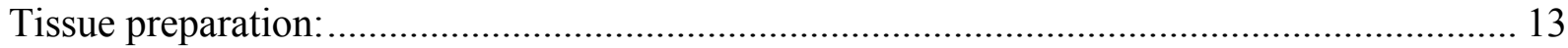

Bronchoalveolar Lavage (BAL) and Biochemical Assays: .......................................... 13

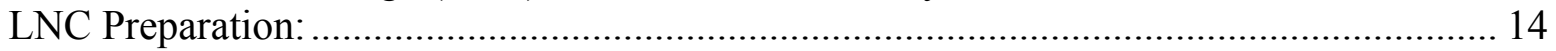

Cell Cultures for Cysteine (CYSH) and GSH Synthesis in AM and Lymphocytes: ........... 14

BAL Cellular Evaluation (granulocytes and alveolar macrophages): ................................. 15

BAL LDH, Total Protein, and Albumin Determination: ............................................... 15

Thiol Conjugation with Monobromobimane (MBB):..................................................... 16

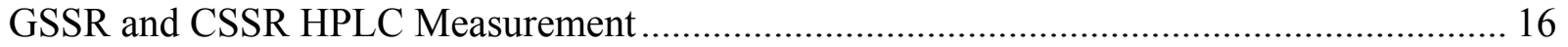

HPLC Conditions for Glutathione and Cysteine Determination: ...................................... 16 
Preliminary Method:

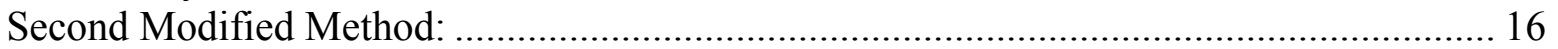

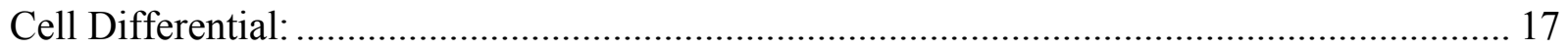

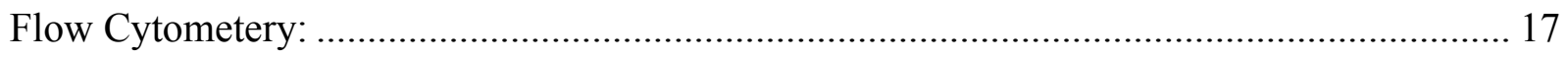

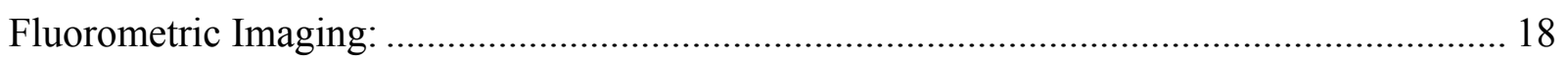

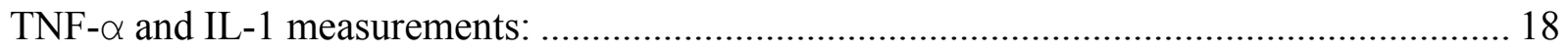

Glutathione Reductase (GSH-R) Activity: ....................................................................... 19

Cytokine Reverse Transcription - Polymerase Chain Reaction (RT-PCR): .............................. 19

Serum OVA Specific IgE and IgG Measurements: ............................................................ 20

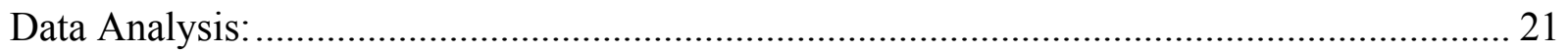

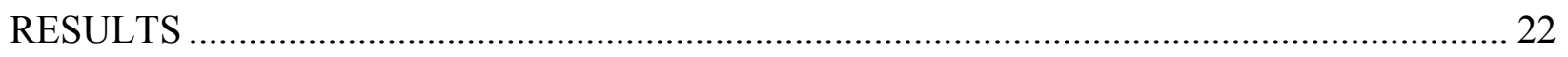

Thiol Measurement Methods Development......................................................................... 22

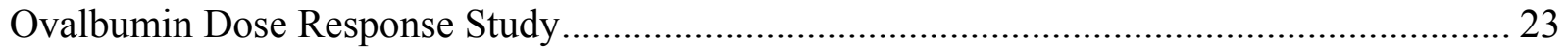

Comparison of Pulmonary response to Inhaled and Intratracheally Instilled Diesel Exhaust

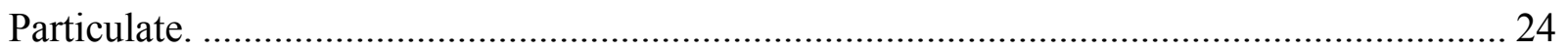

Alteration of Intracellular Cysteine and Glutathione Levels in Alveolar Macrophages and Lymphocytes by Diesel Exhaust Particle Exposure ……………………………………..... 25

The Effect of Diesel Exhaust Particles (DEP) and Carbon Black (CB) On Thiol Changes in Pulmonary Ovalbumin Allergic Sensitized Brown Norway Rats............................................. 27

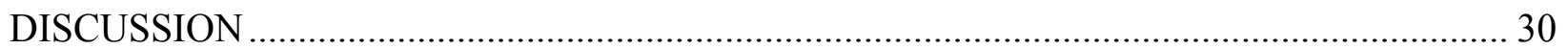

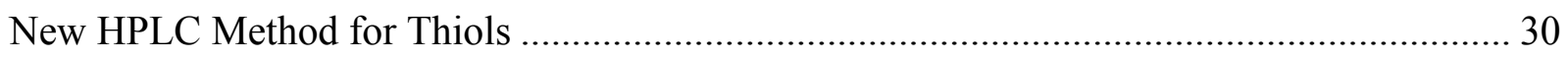

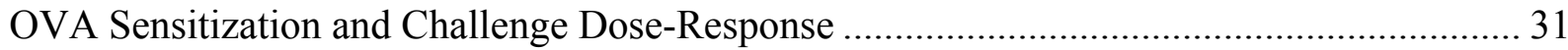

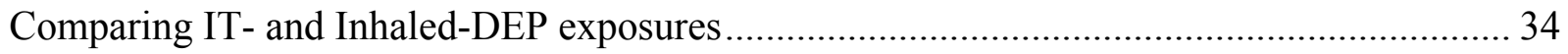

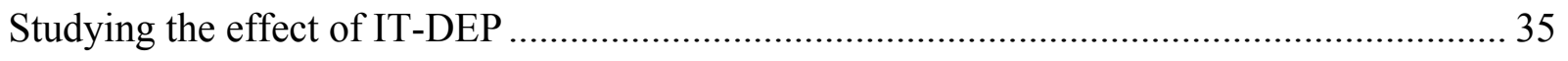

Combined IT-DEP and Inhaled-OVA exposure effect...................................................... 38

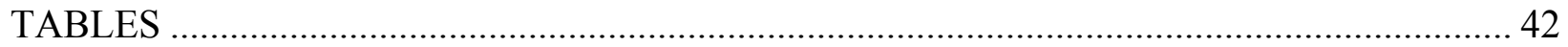

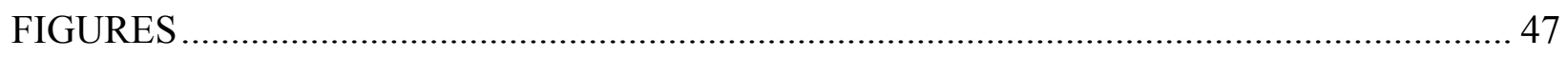

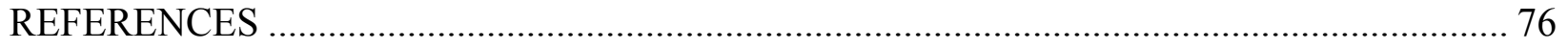

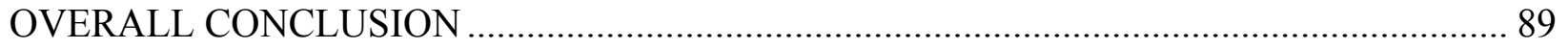

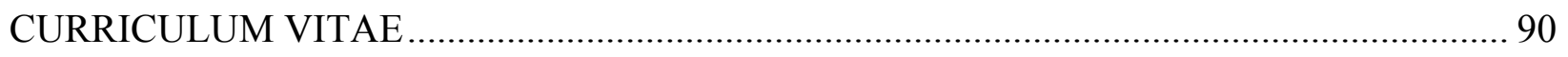




\section{LIST OF TABLES}

\section{SECTION I}

Table 1. Percent $\mathrm{CD}^{+}$and $\mathrm{CD} 8^{+}$Cells in Selected Lymph Nodes ............................................. 42

Table 2. Cysteine and Glutathione Levels in the Pulmonary Associated and Axiliary Lymph

Nodes and Alveolar Macrophages of Sprague Dawly Rats......................................................... 43

Table 3. Comparison of Lymph Node and BAL Cells at 72 hours after either IT or Inhaled DEP

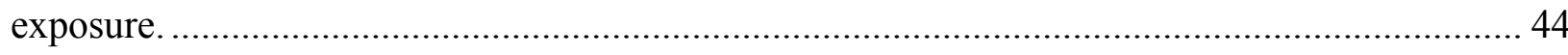

Table 4. Comparison of Brown Norway (BN) and Sprague-Dawley (SD) Rat Responses to DEP

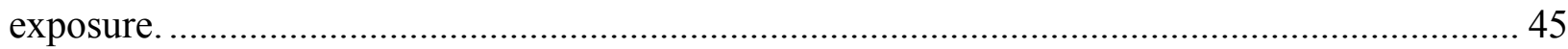

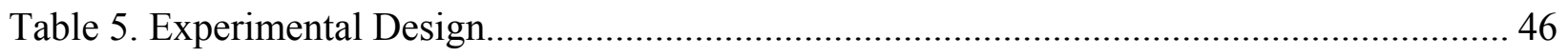




\section{LIST OF FIGURES}

Fig 1. Fluorescent microscopic images of MBB stained rat alveolar macrophage 47

Fig 2. Standard curves for oxidized and reduced glutathione and cysteine 48

Fig 3. Glutathione and cysteine HPLC-Chromatograms 49

Fig 4. The OVA dose response effect on inflammatory responses in Brown Norway rats as indicated by elevations of granulocytes (A), lactate dehydrogenase activity (B), total protein content and albumin (C) in the bronchoalveolar lavage fluid (BAL). 50

Fig 5. The relative serum anti-OVA IgE (A) and anti-OVA $\operatorname{IgG}(\mathrm{B})$ concentrations in response to saline, and different doses of OVA-sensitized rats.

Fig 6. OVA dose dependent effect on Cysteine (A) and GSH (B) levels in rat cell free bronchoalveolar lavage fluid (BAL) at sacrifice. 52

Fig 7. OVA dose dependent effect on intracellular Cysteine (A) and GSH (B) levels in rat AM at sacrifice. 53

Fig 8. OVA dose dependent effect on intracellular cysteine (A) and GSH (B) levels in rat parathymic and tracheal lymph node lymphocytes at sacrifice.

Fig 10. OVA dose dependent effect on the levels of intra- and extra- cellular CYSH (A) and GSH (B) in the alveolar macrophage after 16 hour's ex vivo incubation in thiol free medium. .. 56 Fig 11. OVA dose dependent effect on the levels of intra- and extra- cellular CYSH (A) and GSH (B) in lymph node cells after 16 hour's ex vivo incubation in thiol free medium. 57

Fig 12. Nose only inhalation system for diesel exhaust particles 58

Fig 13. Electron micrographs of CB and DEP. 59

Fig 14. The effect of IT-DEP at 4, 24, 72 hr's on the levels of cysteine and GSH in lymph node and BAL cells 60

Fig 15. The effect of IT-DEP on PMN, LDH and Total Protein levels in BAL

Fig 16. The effect of IT-DEP on the levels of TNF-alpha and IL-1 in AM conditioned medium with and without ex vivo LPS stimulation 62 Fig 17. The effect of (intratracheally instilled) DEP on neutrophil count (A), lactate dehydrogenase (B), total protein (C), and albumin (D) in BAL of Sprague-Dawley rats. 
Fig 18. The effect of (intratracheally instilled) DEP on the levels of AM-cysteine ( ) and GSH $(\square)$ and LNC-cysteine $(\triangle)$ and GSH $(\bigcirc)$ at 4,24 , and 72 hours post exposure in Sprague-Dawley rats. Average \% Control SE for the three time points $=7.16,10.4$, and 14.5 for AM-GSH, AM-CYSH, and LNC-GSH, respectively.

Fig 19. Intracellular Cysteine (A) and GSH (B) levels in alveolar macrophages of SpragueDawley rats after in vivo IT-DEP and 16 hours ex vivo incubation with or without cystine treatment.

Fig 20. Intracellular Cysteine (A) and GSH (B) level in para-thymic and tracheal lymph node cells of Sprague-Dawley rats after in vivo IT-DEP and 16 hours ex vivo incubation with or without cystine treatment.

Fig 21. Percent absorption of Cysteine, Cystine, GSH, and GSSG in acellular culture media (no cells added) after 4 hours incubation with $(50 \mathrm{ug} / \mathrm{ml})$ DEP.

Fig 22. The effect of DEP (3 days after intratracheal instillation) on glutathione reductase activity in alveolar macrophage (A) and para-thymic and tracheal lymph node (B) cells of Sprague-Dawley rats.

Fig 23. The effect of combined exposure to DEP or CB and OVA on the pulmonary inflammatory responses in Brown Norway rats as indicated by elevations of PMN (A) lactate dehydrogenase (B) activity and total protein (C) content in the bronchoalveolar lavage fluid (BAL).

Fig 24. The relative serum anti-OVA IgE (A) and anti-OVA IgG (B) concentration following saline, DEP, or CB exposure in non-sensitized (exposed to saline) and OVA-sensitized rats.... 70 Fig 25. Effect of DEP or CB with or without OVA exposure on $m$ RNA expression for IFN- $\gamma$ (A) and IL-4 (B) in lung tissue. $n=5$ /group. Each point represents average \pm SEM. Note: Agaros gel pictures have been included to show the variation between the individual animals. .71 Fig 26. Measurement of intracellular cysteine (A) and GSH (B) levels in AM harvested from rats exposed to saline, CB, DEP, OVA, or both particles (CB or DEP) and OVA, after ex vivo incubation for $16 \mathrm{hr}$. 72

Fig 27. Measurement of intracellular cysteine (A) and GSH (B) levels in para-thymic and tracheal lymph node lymphocytes harvested from rats exposed to saline, $\mathrm{CB}, \mathrm{DEP}, \mathrm{OVA}$, or both 
particles (CB or DEP) and OVA, after isolation with ficoll-hypaque and ex vivo incubation for $16 \mathrm{hr}$.

Fig 28. Measurement of intracellular cysteine (A) and GSH (B) levels in AM harvested from rats exposed to saline, CB, DEP, OVA, or both particles (CB or DEP) and OVA, after ex vivo incubation with $24 \mu \mathrm{g} / \mathrm{ml}$ cystine for $16 \mathrm{hr}$......

Fig 29. Measurement of intracellular cysteine (A) and GSH (B) levels in para-thymic and tracheal lymph node lymphocytes harvested from rats exposed to saline, CB, DEP, OVA, or both particles (CB or DEP) and OVA, after isolation with ficoll-hypaque and ex vivo incubation with $24 \mu \mathrm{g} / \mathrm{ml}$ cystine for $16 \mathrm{hr}$. 75 


\section{INTRODUCTION:}

Because of the rapid growth in world population and the increasing worldwide migration from rural to urban areas pollution is becoming an important political issue and public health concern (Salvi et al., 1999). Exposure to motor vehicle generated air pollutants, like diesel exhaust particles (DEP), has been associated with various health outcomes (mentioned in a large number of epidemiological studies), like exacerbation of asthma, chronic bronchitis, respiratory tract infections, ischaemic heart disease and stroke (Salvi and Holgate, 1999). Incomplete combustion and formation of various gases, liquids and solid particles can result from the use of diesel in motor vehicles. Submicron soot particles have been shown to mediate several adverse effects. The concentration and size of the inhaled particles play an important role in the dose deposited in the lung. Particles larger than $5 \mu \mathrm{m}$ reach the proximal airways and are eliminated by mucociliary clearance, whereas particles with a diameter $<5 \mu \mathrm{m}$ reach the alveoli (Brain and Valberg, 1979; Chow, 1995). An estimated 18,000 different high-molecular-weight organic compounds are adsorbed to the carbonaceous core of DEP. Electron microscopic studies demonstrated that over $80 \%$ of these particles have a size of $\leq 0.1 \mu \mathrm{m}$ (Salvi and Holgate, 1999). Recent focus has been on ultrafine particles (diameter $<0.05-0.10 \mu \mathrm{m}$ ) because of their ability to penetrate the epithelium and vascular walls and enter the bloodstream (Sydbom et al., 2001). Increased carcinogenicity (Cammer et al., 1988), potentiation of autoimmune disorders (Yoshino and Sagai, 1999), alterations in blood coagulability and increased cardiovascular disorders (Schwartz et al., 1996; Seaton et al., 1995) are some of the biological health effects associated with ultrafine DEP particles.

The crucial roles of glutathione (GSH) to cell survival and function have been well studied. These roles include, serving as a cofactor for several enzymes; reduction of protein disulfides and thus regulating sulfhydryl-dependent enzymes; required for the synthesis of DNA precursors; and reduction of intracellular oxidants (free radicals, reactive metabolic intermediates) thereby protecting cell from damage by these agents (Kosower and Kosower, 1969; Dolphin et al., 1989; and Taniguchi et al., 1989). Furthermore, thiols such as GSH and CYSH have been reported to play an important role in the alteration of immune responses. Lymphocytes exhibit strong membrane transport activity for CYSH, but only a weak transport 
activity for cystine (Ishii et al., 1987). In contrast, AM have a strong capacity for cystine uptake and the conversion of cystine into CYSH (Watanabe and Bannai, 1987). It has also been shown that macrophages function as CYSH pumps that take up cystine and release CYSH upon stimulation. This in turn results in an increase in the intracellular GSH level of activated lymphocytes in the vicinity (Gmunder et al., 1990). These studies suggest that AM may regulate T lymphocyte responses through thiol regulation. Thus any change in the thiol levels of AM, may have an effect on $\mathrm{T}$ lymphocyte activity and in turn on immune responses. The objective of this study was to investigate the role of thiol changes in the immune system after exposure to DEP with and without ovalbumin (OVA) sensitization. In order to achieve our goal, three experimental designs were included in which, rats were exposed to DEP, OVA, and combined DEP and OVA.

\section{LITERATURE REVIEW}

\section{Diesel Exhaust Particles (DEP):}

The prevalence and severity of asthma has increased worldwide in the last 20 years (Eggleston et al., 1999; Koren and Utell, 1997). The reasons for this increase are not well understood, but are likely to involve the complex interplay of genetic, social-economic, behavioral, and environmental factors. Environmental factors include combined exposure to airborne particulates (PM 10, PM 2.5) and a variety of allergens such as house dust mites and pollens. The most prevalent form of asthma is allergic asthma. An allergic immune response to an allergen, is characterized by the production of interleukin (IL)-4, IL-5, and IL-10 by the Th2 subset of CD4+ T lymphocytes (American thoracic society workshop, 1999). These cytokines trigger IgE production by B cells and the recruitment of eosinophils (American thoracic society workshop, 1999). Inflammation orchestrated by Th2 cytokines (IL-4, IL-5 and IL-13), and thickening of all layers of the airway walls are common pathological observations in asthmatics (Woolcock et al., 1997).

Diesel engine exhaust is an occupational and environmental health concern. Diesel vehicles emit 2 to 20 times more nitrogen oxides and 30 to 100 times more particles than do gasoline engine cars (Sagai et al., 1993). Diesel exhaust particles (DEP) are a complex mixture 
of polycyclic aromatic hydrocarbons (PAH), ash, transition metals, and a carbon core. Major PAH components of DEP include phenanthrenes 52\%, fluorens 15\%, naphthalenes 13\%, fluoranthrenes $10 \%$ and pyrenes $10 \%$ (Nel et al., 1998). The particulate phase of diesel engine exhaust (DEP) is thought to contribute to the increased prevalence of acute and chronic airway diseases. Exposure to DEP of more than $2 \mathrm{mg} / \mathrm{m}^{3}$ has been documented in underground mines, railroad, construction, and in auto repair industries (Cass and Gray, 1995). Such exposures have been associated with pulmonary inflammation, fibrosis, lung cancer, increased rate of respiratory infections, and enhanced allergic sensitization (Iwai et al., 2000; Diaz-Sanchez et al., 1994; Yang et al., 1997; Yang et al., 1999; Yang et al., 2001). Previously, work in this laboratory demonstrated that both the organic and the particulate components play a major role in DEPinduced pulmonary toxicity. While the particulate is known to induce acute inflammatory responses, the organic component has been shown to suppress AM secretion of proinflammatory cytokines and cell-mediated immunity in response to bacterial infection (Yang et al., 1997; Yang et al., 1999; Yang et al., 2001). In addition, DEP exposure has been linked to increased $\operatorname{IgE}$ production (Diaz-Sanchez et al., 1994) and isotype switching in B cells to produce $\operatorname{IgE}$ in humans (Fujieda et al., 1998) and in animals (Muranaka et al., 1986). These studies suggest that DEP may suppress cellular, but enhance allergic immune responses.

Recently, a number of studies have shown that short-term exposure to diesel exhaust particles (DEP) may exert a strong effect on the respiratory and immune system, suggesting that DEP and perhaps, other particles as well, may be key environmental factors in augmenting pulmonary allergic reactions. Indeed, the ability of DEP to enhance an immune response to intranasally administered allergen and DEP has been demonstrated in both humans and rodents. Diaz Sanchez et al., (1994 and 1995), showed that in vivo nasal challenge with $300 \mu \mathrm{g}$ of DEP to both healthy and allergic subjects enhances the amount of total IgE (but not of other immunoglobulin isotypes) in human upper airways and increased the number of local $\operatorname{IgE}$ secreting cells. This DEP exposure also increased both Th1- and Th2-type cytokines (including IL-4, IL-6, IL-13, and interferon $\gamma$ ) in the nasal mucosa. In later studies, the same author (DiazSanchez et al. 1997) showed that combined exposure of ragweed allergen and DEP resulted in a marked enhancement in the production of ragweed-specific IgE and $m$ RNA for Th2-type 
cytokines by cells in the nasal mucosa, when compared to challenge with ragweed allergen or DEP alone of subjects with ragweed allergy.

The adjuvant effect of DEP on allergic sensitization has also been demonstrated in mice using ovalbumin (OVA) as the allergen. Takano et al., (1997) showed that intranasally instilled DEP aggravated OVA-induced airway inflammation, and markedly increased IL-5 levels and the $m$ RNA levels of IL-4, IL-2, and granulocyte macrophage-colony stimulating factor in lung tissue. DEP exposure also exhibited adjuvant activity for anti-OVA specific IgG and IgE production. In addition, the combined exposure of mice to DEP $\left(3\right.$ or $\left.6 \mathrm{mg} / \mathrm{m}^{3}\right)$ by inhalation for 6 weeks and to intranasally administered OVA, resulted in higher anti-OVA IgE antibody titers than mice exposed to DEP or OVA alone.

The cellular reactions to DEP and/or their particulate and organic components leading to increased Th2 response are not yet clear. Studies in our laboratory have shown that DEP suppresses pulmonary bacteria clearance and bacteria-induced macrophage production of TNF- $\alpha$ (Yang et al. 1999; Yang et al., 2001). This effect was attributed to the organic component of DEP. However, a number of studies have shown that various particles, including carbon black (CB), which resembles the carbonaceous core of DEP, can enhance allergic sensitization (Maejima et al., 1997; Lambert et al., 1999; Lambert et al., 2000). Carbon black, in particular, has been demonstrated to enhance proliferation of antibody forming cells and both $\operatorname{IgE}$ and $\operatorname{IgG}$ levels (Lovik et al., 1997; Van Zijverden et al., 2000). These studies suggested that DEP might skew the immune response toward the Th2 side, whereas CB stimulates both Th1 and Th2 responses.

The inflammatory responses associated with particle stimulation involve oxidative stress in the lung and possible alteration of thiol levels that are critical to the cytokine production and cytotoxic activities of lymphocytes. Glutathione (GSH), for example, is known to affect NF- $\mathrm{BB}$ activation and regulate lymphocyte immune responses (Droge et al., 1994; Haddad et al., 2000; Takizawa et al., 1999). Studies by Shukla et al., (2000) have shown that inhalation of CB (300 $\mu \mathrm{g} / \mathrm{m}^{3}$ air for $6 \mathrm{hr}$ followed by $24 \mathrm{hr}$ clean air exposure) causes an early increase in intracellular oxidants and the $m$ RNA levels of a number of NFkB-regulated genes, including TNF- $\alpha$, IL-6, 
and interferon. These studies suggest that GSH may play a role in DEP and/or CB induced immune responses.

DEP is thought to be mutagenic and/or carcinogenic as well as cytotoxic to bacteria and mammalian cells (Kotin et al., 1995; Huisingh et al., 1978; Li AP 1981; Pederson TC 1981; Schuetzle D 1983). It has been shown that the most mutagenic chemical fractions of DEP extracted by organic solvents contain primarily oxygenated PAH derivatives including compounds with hydroxy, ketone, quinone, acid anhydride, dihydroxy, and acid substituents on parent PAH (Schuetzle et al., 1980; Pederson TC and Siak J-S 1981). It has also been suggested that active oxygen species participate in the DEP toxicity (Sagai et al., 1993). The induction of 8hydroxydeoxyguanosine, which is produced by hydroxyl radicals (Kasai $\mathrm{H}$ and Nishimura $\mathrm{S}$ 1984) has been demonstrated in mice exposed to DEP (Nagashima et al., 1995). It has been also reported that DEP components, probably quinoid or nitroaromatic structures, promote DNA damage through redox cycling based generation of superoxide (Kumagai et al., 1997). Sagai et al., (1993) reported that most of DEP induced acute lung toxicity is due to active oxygen radicals, such as $\mathrm{O}_{2}{ }^{-}$and $\cdot \mathrm{OH}$, and that DEP lethality is due to pulmonary edema associated with endothelial cell damage. DEP-induced endothelial cell damage, during early exposure, is caused by NO, superoxide, and related active oxygen species, including peroxynitrite (Bai et al., 2001). It has been suggested by the Bai et al., (2001) that scavenging these active oxygen species would be an efficient therapy for DEP-mediated cardiopulmonary diseases.

Fahy et al., (2000) reported that simultaneous exposure of allergic patients to DEP and allergens could result in high local chemokine levels via MAP kinase pathway activation, which could in turn increase the likelihood of reaching a critical threshold that would lead to the initiation of respiratory allergic symptoms. DEP and their associated PAHs were shown to enhance the recruitment of inflammatory cells and to trigger the release of numerous mediators of inflammation, such as cytokines and adhesion molecules in both in vitro and in vivo studies (Boland et al., 1999; Salvi et al., 1999). Exposure to low doses of diesel exhaust has been shown to adversely affect the cytokine and antibody production in mice by altering CD4+ and CD $8+\mathrm{T}$ cell functions (Fujimaki et al., 2001). 


\section{OVALBUMin (OVA):}

In the last decades allergic disorders in affluent countries has steadily increased (Peat, 1994). In food processing industry (e.g. egg proteins), workers could be occupationally exposed and sensitized. Workers at egg processing plants could be exposed for $8 \mathrm{~h}$ or more daily to as high as $360 \mu \mathrm{m} / \mathrm{m}^{3}$ of ovalbumin (NIOSH, 1988). The association between the increased levels of immunoglobulins ( $\operatorname{IgE}$ and $\operatorname{IgG}$ ) and the exposure to ovalbumin in different animal models has been reported (Andersson, 1980; Sedgwick and Holt, 1983; McMenamin et al., 1992; Renz et al., 1992; Siegel et al., 1997; Siegel et al., 2000). Further more, ovalbumin has been used to investigate the facilitation of the development of respiratory and intestinal allergies by the occupational and environmental factors (Siegel et al., 2000; Watzl et al., 1999; Al-Humadi et al., 2002-2). The low toxicity and documented antigenicity of this protein make it a popular choice as an antigen of allergy and asthma modeling studies.

\section{GLUTATHIONE AND CYSTEINE (GSH AND CYSH):}

Glutathione is a tripeptide ( $\gamma$-L-glutamyl-L-cysteinylglycine) which plays an important roles in physiological homeostasis. One of these roles may be to help regulate lymphocyte functions. Depletion of intracellular GSH by buthionine sulfoximine (BSO) caused a decrease in CD $8^{+}$ cells and, inhibited, both the generation of large blast-like $\mathrm{CD} 8^{+}$cells and cytotoxic $\mathrm{T}$ lymphocyte (CTL) activity (Gmunder and Droge, 1991). Several other important reported biological functions for the glutathione include functioning as a coenzyme (Knox, 1960), activation of thiol requiring enzymes (Fanger et al., 1970) and protection of cells against oxidative damage (Fanger et al., 1970, Reed, 1969).

Glutathione, which has long been known for its protective function against oxidative cell damage (Fanger et al., 1970), is thought to play a regulatory role in various lymphocyte functions. Gmunder et al., (1990) reported that exogenously added CYSH increases the intracellular GSH level and DNA synthesis in mitogen-stimulated lymphocytes, suggesting that CYSH may also play a regulatory role in mediating immunologically relevant functions of lymphocytes. The same author (Gmunder et al., 1991) showed that GSH mediated cytokine- 
dependent DNA synthesis in T lymphocytes and depletion of intracellular GSH inhibited the relevant DNA synthesis resulting in altered T lymphocyte activity.

Cysteine also has a regulatory role in the immune system and constitutes the majority of the acid-soluble thiol content in cells. Exogenously added cysteine, or (syngeneic) macrophages increases intracellular glutathione level and DNA synthesis activity in mitogenically stimulated lymphocytes (Gmunder et al., 1990). Lymphocytes have strong membrane transport activity for cysteine, but only a weak transport activity for cystine (Ishii et al., 1987). In contrast to lymphocytes, macrophages have a strong membrane transport activity for cystine and also release thiol compounds into the extracellular space (Watanabe and Bannai, 1987). It has also been reported by Gmunder H et al., (1990) that: 1- Macrophages when stimulated generate substantial amounts of cysteine and consume approximately equivalent amounts of cystine, 2Macrophages, when stimulated, function as a cysteine pump that take up cystine and releases reduced cysteine, and 3- Macrophages causes an increase in the intracellular glutathione level of activated lymphocytes in their vicinity.

Reactive oxygen species (ROS) plays an important role in immune responses (Watzl et al., 1999; Oliveira et al., 1995; Wolfreys and Oliveira, 1997). The imbalance between antioxidants, such as glutathione, and ROS levels may lead to oxidative stress. Thus, any decrease in the GSH level could account at least in part for an increase in ROS levels. Indirectly, this may affect immune responses. It has been suggested that GSH itself may play a critical role in immune functions. Macrophages, dendritic cells, and B cells (as antigen presenting cells) are central to the development of either Th1 or Th2 immunity, because antigen presentation and recognition are required to initiate responses (Peterson et al., 1998). Also, Peterson et al, (1998) reported that a selective inhibition of the cytokine production in response to Th1-associated, but not Th2-associated antigens, was due to GSH depletion in APC. Other studies showed that APC ability to reduce antigen disulfide bonds required before antigen processing was impaired when GSH was severely depleted (Short et al., 1996). Also, this severe depletion decreased the activity of thiol proteases crucial to antigen processing and cleavage of invariant chains in the major 
histocompatibility complex class II (Mizuochi et al., 1994). However, many factors, other than the extracellualr supply of thiols, have been recognized as modulators of the direction and the magnitude of T-dependent responses such as; dose and route of antigen administration, type of APC, presence of particular hormones, co-stimulatory molecule expression, and peptide affinity for MHC determinants (Droge et al., 1994; O'Garra and Muphy, 1996; Constant and Bottomly, 1997). Lawrence et al., (2000) suggested that impairment of APC functions may be caused by the reduction of GSH levels including antigen processing and presentation and that the thiols are necessary for complete $\mathrm{T}$ cell activation. 


\section{SPECIFIC OBJECTIVES:}

The objectives of this study are to:

1- Develop a sensitive method for the quantification of specific thiols from biological samples

including BAL, alveolar macrophages, thymic, tracheal, and axiliary lymph nodes in rats.

2- Study the dose-response relationship between inhaled OVA and CYSH and GSH in BAL, AM and $\mathrm{LNC}$, and on immunoglobulin production.

3- Compare the pulmonary cellular response to intratracheal instillation vs inhalation of DEP.

4- Study the effects of DEP exposure on thiol levels, inflammatory response, and alveolar macrophage functions in a Brown Norway rat model.

5- Study the effects of DEP exposure on cellular uptake and utilization of cystine, glutathione reductase (GSH-R) activity, and the production of CYSH and GSH in AM and LNC.

6- Study the adjuvant activities of DEP and CB on OVA sensitization in Brown Norway rats, and the potential role of GSH in OVA- and/or particle-mediated Th2 lymphocyte responses. 


\section{SPECIFIC HYPOTHESES:}

1- OVA affects thiol regulation in AM and LNC resulting in a perturbation of immunoglobuline (Th2 induced allergic response) levels.

2- DEP exposure alters thiol levels in lymph node cells and bronchoalveolar lavage cells.

3- The adjuvant effect of DEP on IgE and pulmonary allergic responses is, at least in part, mediated through its effects on thiol levels. 


\section{MATERIALS AND METHODS}

\section{Animals:}

Male Sprague-Dawley (200-250 gm, Hilltop, Scottsdale, PA) rats were used. Brown Norway (BN) were obtained from area K93 (200-250 gm), Charles River laboratories (Stoneridge, NY) and were free of all respiratory viruses. Rats were maintained at $23 \pm 1{ }^{\circ} \mathrm{C}$ with $50 \%$ relative humidity and a 12-hr light/dark cycle, and acclimated for 2 weeks before use. Food and water were given ad libitum. All procedures were performed in accordance with the American Association for Accreditation of Laboratory Animal Care (AAALAC) standards and under approved National Institute of Occupational Safety and Health (NIOSH) and West Virginia University (WVU) ACUC protocol.

\section{Particulate Sample Preparations:}

CB particles (Fisher Scientific, Fair Lawn, NJ) were autoclaved at $120{ }^{\circ} \mathrm{C}$ for 4 hours before use. DEP (Standard reference material 1650, representing heavy duty engine with a mass median aerodynamic diameter of $0.5 \mu \mathrm{m}$ ) were purchased from the National Institute of Standards and Technology (Gaithersburg, MD). Endotoxin free sterile saline (Baxter Healthcare Corporation, Deerfield, IL) was used to suspend the particles. The suspensions of CB and DEP were sonicated for 1 min using an ultrasonic processor with a micro tip (Heat SystemUltrasonics, Plainview, NY) prior to intratracheal instillation.

\section{ANimAL EXPOSURES:}

In order to achieve the outlined objectives, the following experimental design were used: 


\section{OVA Exposure:}

Five different concentrations of OVA (Sigma Chemical, St. Louis, MO) in endotoxin free saline were aerosolized using a DeVilbiss-646 (DeVilbiss, Somerset, PA) nebulizer. A constant feed of the OVA solution to the nebulizer was achieved using a syringe pump (Model \# 901, Harvard Apparatus, Dover, MA) at a flow rate of $1.22 \mathrm{ml} / \mathrm{min}$. To achieve the desired concentrations of $7.2,68,93,111$, and $156 \mathrm{mg} / \mathrm{m}^{3}$, filtered air was passed through the nebulizer, and used as a diluent for the aerosolized OVA. The chamber OVA aerosol concentration was determined by collecting samples onto $0.45 \mu \mathrm{m}$ (Polycarbonate Membrane, Poretics Corporation, Livermore, CA) filters from a chamber side port at a rate of 1 liter/minute. Filters were washed with $10 \mathrm{ml}$ of endotoxin free saline and analyzed for protein using the Coomassie blue dye reagent (Bio-Rad Laboratories, Hercules, CA) against OVA standards. Rats were exposed to OVA for $30 \mathrm{~min}$ on days $0,7,14$ and 28. Control animals were exposed to aerosolized endotoxin free saline.

\section{DEP Exposure by Intratracheal Instillation or Inhalation:}

Brown Norway rats weighing (200-250 gm) were dosed by either intratracheal instillation (IT) with $5 \mathrm{mg} / \mathrm{kg}$ (saline suspension) of DEP or exposed acutely using a nose-only chamber for 4 hours to $17 \mathrm{mg} / \mathrm{m}^{3}$ DEP aerosol (Figure 12). Tissue was collected at 4, 24, and 72 hours following IT and at 72 hours following aerosol exposure. Control rats were instilled with saline or given a clean air sham exposure for the respective exposure routes.

\section{IT-DEP Exposure and ex vivo16hr incubation of LNC or AM with or with out Cystine:}

Male Sprague-Dawley (200-250 gm, Hilltop, Scottsdale, PA) rats were used. Brown Norway (BN) (200-250 gm, Charles River, Stoneridge, NY) rats were used for strain comparison purposes. Methohexital sodium (35 mg/kg body weight, ip; Eli Lilly Co., Indianapolis, IN) was used to lightly anesthetize the animals prior to their placement in a vertical position for intratracheal instillation (IT). A curved ball-tipped cannula (18 gauge) was used to briskly inject the DEP-particulate suspension ( $5 \mathrm{mg} / \mathrm{kg}$ body weight) into the trachea. Control animals received 
sterile saline vehicle. The instillation volume was $2 \mathrm{ml} / \mathrm{kg}$ body weight. AM and LNC were collected at 4, 24, and 72 hours after exposure and used for CYSH and GSH determination. In separate experiments, cell samples were collected at 72 hours post exposure for either GSH-R activity measurements or cultured in Hepes (for $16 \mathrm{~h}$ ) with or without cystine $(24 \mu \mathrm{g} / \mathrm{ml}$ ) for CYSH and GSH assessment.

\section{Combined IT-DEP or CB and OVA Exposure:}

Male Brown Norway rats (Charles River, Stoneridge, NY), weighing 200-250 g, were used. IT and inhalation procedures were performed as described above. Rats were exposed to OVA for $30 \mathrm{~min}$ at day 1 after IT-exposure (on day 0 ) to DEP, CB, or saline, and then once a week for 30 min on days 8,15 and 29 (Table 5). The OVA chamber concentration was $90 \mathrm{mg} / \mathrm{m}^{3}$ \pm 18 . Control animals were exposed to aerosolized endotoxin free saline. All rats were sacrificed at day 30. Rats were sacrificed $24 \mathrm{~h}$ after the last OVA challenge exposure to maximize potential for identifying alteration in pulmonary inflammatory responses.

\section{TISSUE PREPARATION:}

\section{Bronchoalveolar Lavage (BAL) and Biochemical Assays:}

Rats were anesthetized with sodium pentobarbital (50 mg/kg, ip; Butler, Columbus, OH) and euthanized by exsanguination of the abdominal aorta one day after the last inhalation exposure. The trachea was cannulated and the lungs were lavaged with $\mathrm{Ca}^{2+} / \mathrm{Mg}^{2+}$-free phosphate-buffered saline (PBS, $45 \mathrm{mM} \mathrm{NaCl}, 5 \mathrm{mM} \mathrm{KCl}, 1.9 \mathrm{mM} \mathrm{NaH} \mathrm{PO}_{4}, 9.35 \mathrm{mM}$ $\mathrm{Na}_{2} \mathrm{HPO}_{4}$, and $5.5 \mathrm{mM}$ glucose; $\mathrm{pH} 7.4$ ), at a volume of $6 \mathrm{ml}$ for the first lavage and $8 \mathrm{ml}$ for the subsequent lavages. The total lavage volume was $80 \mathrm{ml}$. The BAL fluid was centrifuged at 500 $\mathrm{g}$ for $10 \mathrm{~min}$ at $4{ }^{\circ} \mathrm{C}$. The supernatant fluid from the first lavage was saved separately for the determination of protein content and lactate dehydrogenase (LDH) activity using an automated Cobas Fara II analyzer (Roche Diagnostic Systems, Montclair, NJ) with standard diagnostic reagents and manufacturers procedures. Cell pellets from all lavage fluids of an individual rat were combined and suspended in $1 \mathrm{ml}$ of PBS to determine the total cell and differential cell 
counts using an electronic cell counter (Coulter Electronics, Hialeah, FL) equipped with a cellsizing unit (Lane and Mehta, 1990). Alveolar macrophages (AM) and granulocytes were determined by their unique cell diameters and used in primary cell culture experiments.

\section{LNC Preparation:}

Lymph nodes (para-thymic and tracheal, and axiliary) were collected in $1 \mathrm{ml}, \mathrm{pH} 7.4$, Hepes buffer. The lymph node capsules were broken with a glass bar using a tissue culture screen. LN cells were washed, transferred into a $15-\mathrm{ml}$ tube, and centrifuged at $2000 \mathrm{rpm}$ for 10 min. Cell pellets were reconstituted with $1 \mathrm{ml}$ Hepes buffer for cell counts, cell differentiation, flow cytometry, and cell culture experiments. The cell samples showed a lymphocyte content of greater than $98 \%$. Lymphocytes were used without further purification except for combined ITDEP and OVA exposure study. In this study lymphocytes were further isolated using Histopaque ${ }^{\circledR}(\mathrm{d}=1.083$, Sigma Chemicals, St. Louis, MO). In brief, the samples were centrifuged for $30 \mathrm{~min}$ at $2500 \mathrm{rpm}$, and lymphocytes were collected, washed twice, and resuspended in $1 \mathrm{ml}$ of Hepes buffer prior to assay.

\section{Cell Cultures for Cysteine (CYSH) and GSH Synthesis in AM and Lymphocytes:}

AM isolated from each rat were suspended in eagle minimum essential medium (EMEM) culture medium (EMEM, Sigma Chemical Co.) containing $1 \mathrm{mM}$ glutamine, $100 \mu \mathrm{g} / \mathrm{ml}$ streptomycin, 100 units $/ \mathrm{ml}$ penicillin, $10 \%$ heat-inactivated fetal bovine serum, and $10 \mathrm{mM}$ Hepes. Aliquots of $1 \mathrm{ml}$ cell suspension, adjusted to $1 \times 10^{6} \mathrm{AM}$, were added to each well of a 12-well tissue culture plate. AM were allowed to adhere to the plastic plate for $2 \mathrm{~h}$ in a humidified incubator $\left(37^{\circ} \mathrm{C}\right.$ and $5 \% \mathrm{CO}_{2}$ ) (Driscoll et al., 1990). The non-adherent cells were removed by rinsing the monolayers three times with Hepes buffer. The AM-enriched cells were then either analyzed immediately for CYSH and GSH content and GSH-R activity or further incubated $\left(37^{\circ} \mathrm{C}\right.$ and $\left.5 \% \mathrm{CO}_{2}\right)$ in fresh Hepes buffer with, or without, cystine $(24 \mu \mathrm{g} / \mathrm{ml})$ for 16 hours. After centrifugation at $500 \mathrm{~g}$ for $5 \mathrm{~min}$, the cell pellet was washed twice, resuspended in $1 \mathrm{ml}$ Hepes buffer, and analyzed for CYSH and GSH contents according to the following method. One $\mu$ l of a solution containing $80 \mathrm{mM}$ monobromobimane (mbb) was added to $100 \mu \mathrm{l}$ of the cell suspension. The fluorescence derivitization of the reduced thiols was allowed to proceed at $4{ }^{\circ} \mathrm{C}$ 
overnight. The cells were then lysed by sonication for 30 seconds using a sonic dismembrator (Fisher Scientific, Pittsburgh, PA), with a frequency of $20 \mathrm{~Hz}$ and an output of $40 \% \max , 10$ pulses (75 pulses/minute), on ice. Lysates were then centrifuged at 10,000 rpm for $10 \mathrm{~min}$, and filtered through a $0.2 \mu \mathrm{m}$ filter (Microspin Nylon Filter, PGC, Frederick, MD) to remove cell membranes and debris. Analysis of CYSH and GSH levels in the solution was carried out using the reverse phase high performance liquid chromatography (HPLC) method described later.

For lymphocytes, aliquots of $2 \times 10^{6}$ cells were either analyzed immediately for CYSH and GSH contents and GSH-R activity or further incubated with, or without, cystine $(24 \mu \mathrm{g} / \mathrm{ml})$ for $16 \mathrm{~h}$ in a humidified incubator $\left(37{ }^{\circ} \mathrm{C}\right.$ and $\left.5 \% \mathrm{CO}_{2}\right)$. Following incubation, cultures were centrifuged at $500 \mathrm{~g}$ for $5 \mathrm{~min}$ and washed twice with Hepes. The pellets were re-suspended in $1 \mathrm{ml}$ Hepes buffer and analyzed for CYSH and GSH following the method described above.

\section{BAL Cellular EVAluAtion (GRANUloCytes AND ALVEOLAR MACROPHAGES):}

A Coulter multisizer II with AccuComp software (Coulter Electronics, Hialeah, Fl) was used to quantify BAL granulocytes and alveolar macrophages.

\section{Bal LDH, Total Protein, and Albumin Determination:}

An automated Cobas FARA II (Roche Diagnostic Systems, Montclair, NJ) was used to determine total acellular protein and LDH in BALF from the first wash. The protein content was measured colorimetrically at $540 \mathrm{~nm}$ by using biuret reagent (Layne 1957) with Sigma Diagnostic reagents and procedures (Sigma Chemical Company, St. Louis, Mo.). LDH was measured by monitoring the formation of NADH spectrophotometrically at $340 \mathrm{~nm}$ using Roche Diagnostic reagents and procedures (Roche Diagnostic Systems, Indianapolis, Ind.) and expressed as units per liter according to the method described by Gay et al. (1968).

Albumin content in the acellular BALF from the first wash was monitored at $628 \mathrm{~nm}$ based on the binding to bromcresol green. An automated Cobas Fara II analyzer (Roche Diagnostic Systems, Montclair, NJ), and Sigma Diagnostic reagents and procedures (Sigma Chemical Company, St. Louis, Mo.) were used. Results were expressed as milligrams per milliliter BALF. 


\section{Thiol Conjugation with Monobromobimane (MBB):}

Stock solutions of $80 \mathrm{mM}$ of MBB (Molecular Probe, Eugene, OR) were prepared in acetonitrile. One $\mathrm{ml}$ of culture supernatant fluid, or live cell suspension $\left(1-5 \times 10^{6}\right.$ cells $\left./ \mathrm{ml}\right)$ was derivetized either for $2 \mathrm{hr}$ 's at room temperature or at $4 \mathrm{C}^{\circ}$ overnight with $10 \mathrm{ul}$ of the MBB stock solution. Following derivitization cells were lysed using an ultra sonic cell disruptor, centrifuged (10000 rpm) for $10 \mathrm{~min}$ and supernatant fluid filtered through $0.2 \mu \mathrm{m}$ filter (Microspin Nylon Filter, PGC, Frederick, MD) for subsequent HPLC/Fluorescent analysis.

\section{GSSR AND CSSR HPLC MEASUREMENT}

One microliter of $80 \mathrm{mM}$ Tributylphosphine were added to each $10 \mu 1$ sample. Samples then incubated for $1 \mathrm{hr}$ at $50 \mathrm{C}^{\circ}$. After cooling samples down, MBB were added following the abovementioned procedure. Samples were frozen at $-20 \mathrm{C}^{\circ}$ until ready for HPLC analysis.

\section{HPLC CONDitions for Glutathione AND CySTEINE Determination:}

\section{Preliminary Method:}

Shimadzu ez chrom (VP version) HPLC system and RF-551 fluorometer detector were used. Phenomenex (Luna, 5u) C18 column and a mobile phase of $11 \%$ Acetonitrile (ACN) and 89\% of $1.5 \mathrm{mM}$ phosphoric acid- $1.7 \mathrm{mM}$ acetic acid buffer ( $\mathrm{pH} 2.7$ ) with flow rate of $1 \mathrm{ml} /$ minute were used for separation. Gradient of $11 \%$ ACN over 6 minutes to $15 \%$ over 10 minutes and $25 \%$ over 15 minutes and $35 \%$ over 18 minutes and then back to $11 \%$ over 21 minutes and then reequilibrated at $11 \%$ for 5 minutes (to 26 minutes). Glutathione and cysteine peaks were detected with an excitation of 380 and emission of 480 with limits of detection of 1 fmole.

\section{Second Modified Method:}

A Shimadzu HPLC system equipped with a RF-551 fluorometric detector and a C18 reverse phase column (Phenomenex, Luna, $5 \mu \mathrm{m}$ ) was used for the analysis of CYSH and GSH. 
Separation of the mbb-thiol derivatives was achieved using a gradient system of acetonitrile in $0.1 \mathrm{M}$ sodium acetate $(\mathrm{pH} \mathrm{5.0})$, delivered at a flow rate of $1 \mathrm{ml} / \mathrm{min}$. The gradient system consisted of a mobile phase of $7 \%$ acetonitrile for the first 6 minutes, and stepped increases to 15, 25, and 40\% after 10, 15, and 18 minutes, respectively. The CYSH and GSH derivatives were detected at an excitation of $380 \mathrm{~nm}$ and an emission of $480 \mathrm{~nm}$, with retention times at 8.0 and $10.2 \mathrm{~min}$, respectively.

\section{Cell Differential:}

Slides were fixed with methanol for 5 minutes and dried. Slide staining were done by using Diff-Quik Solution 1 (7 dips) and solution II (Baxter Healthcare Corp., McGaw Park, IL) (4 dips) and slide then washed with distilled water and dried.

\section{Flow CYTOMETERY:}

To enumerate T cell subsets (CD4+ helper and CD8+ suppressor T-cells), each of the lymph node cells were labeled with an appropriate monoclonal antibody, conjugated with a fluorescent probe for visualization (Luster et al., 1988). Single cell suspensions were prepared from excised lymph nodes. The cells were collected by centrifugation and suspended in phosphate buffered saline, $\mathrm{pH} 7.4$, containing $1 \%$ bovine serum albumin and $0.1 \%$ sodium azide to a cell density of $1.5 \times 10^{6} / \mathrm{ml}$. For the T cell subsets, the cells were incubated with $100 \mathrm{ml}$ anti-rat CD4+ monoclonal antibody conjugated with PE (H 129.19, Pharmingen, San Jose, CA) and $100 \mu$ of anti-mouse CD8+ monoclonal antibody conjugated with PE (53-6.7, Pharmingen, San Jose, CA). The cells were also incubated with their respective isotype control to correct for autofluorescence. After incubation with the conjugated monoclonal antibodies, the cells were washed once with staining buffer and incubated for 5 minutes with $1 \mathrm{mg} / \mathrm{ml}$ propidium iodide as a viability stain. The cells were again washed and then enumerated on a Becton Dickinson FacsVantage Flow Cytometer. Fluorescence was gated on propidium iodide to eliminate dead cells. The values are expressed as the percent of gated live cells. 


\section{FLUOROMETRIC IMAGING:}

Cellular fluorometric images were taken by an Olympus AX7 microscope system with epiflourescence by using filter cube in the UV range and excitation of 360-370 with barrier filter of 420. The images were captured with a Sony DXC 9000 video camera.

\section{TNF- $\alpha$ AND IL-1 MEASUREMENTS:}

IL-1 in alveolar macrophage culture medium was analyzed using mouse thymocyte proliferation assay (Kang et al., 1992). Briefly, thymocytes were obtained from male CD-1 mice (6-10 weeks of age) and suspended in RPMI-1640 medium with $2 \mathrm{mM}$ glutamine, $100 \mathrm{U} / \mathrm{ml}$ penicillin, $100 \mu \mathrm{g} / \mathrm{ml}$ streptomycin, $10 \%$ heat-inactivated fetal bovine serum, and $2 \times 10^{-5} \mathrm{M}$

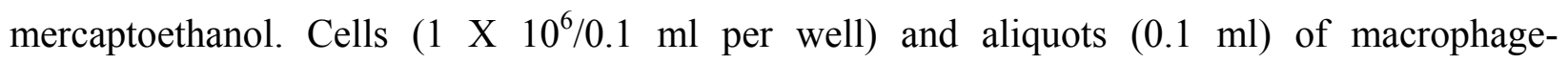
conditioned medium were added in quadruplicate to 96-well microculture plates. Cell cultures were incubated at $37{ }^{\circ} \mathrm{C}$ in an atmosphere containing $5 \% \mathrm{CO}_{2}$ for 30 hours. The cultures were pulsed for 22 hours with $\left[{ }^{3} \mathrm{H}\right]$ thymidine $(1.0 \mu \mathrm{Ci} /$ well, activity $11.3 \mathrm{Ci} / \mathrm{mmol}$; Dupont NEN Products, Boston, Mass.), and the thymocytes harvested using a Harvester 96-cell harvester (Tomtech, Orange, Conn.). The cell radioactivity in the collecting glass fiber filters was measured using a liquid scintillation counter (1214 Rackbeta, Wallac, Finland). The amount of IL-1 like activity in the tested macrophage supernatants was expressed as disintegrations per minute. Antibodies of anti-rat IL- $\alpha$ and anti-rat IL- $\beta$ (Endogen, Cambridge, Mass.) were used to confirm IL-1 activity measured by the thymocyte proliferation assay. These antibodies completely neutralized the activity in the macrophage-conditioned supernatant, thus indicating that the increase in thymocyte proliferation was due to the presence of IL-1 in the macrophageconditioned culture medium.

TNF- $\alpha$ in macrophage-conditioned medium was determined using an enzyme-linked immunosorbent assay (ELISA; Biosource International, Camarillo, Calif.) according to the manufacturer's instructions. ELISA was first described by Engvall and Perlmann (1971) and the biotin-avidin system was described by Bayer and Wilchek (1978). 


\section{GLUTATHIONE REDUCTASE (GSH-R) ACTIVITY:}

The GSH-R activity was determined by measuring the reduction of GSSG to GSH. In brief, a $200 \mu \mathrm{l}$ sample was added to a cuvette containing $400 \mu \mathrm{l}$ of $2.4 \mathrm{mM}$ GSSG reagent (Sigma Chemicals, St. Louis, MO) and $200 \mu \mathrm{l}$ of 3mM 5,5'-dithio-bis(2-nitrobenzoic acid) (DTNB, Sigma Chemicals, St. Louis, MO). At zero time, $400 \mu \mathrm{l}$ of NADPH was added and the rate of changes in UV absorbance, at $412 \mathrm{~nm}$, over six minutes was recorded. The enzyme activity was determined and expressed as $\mu$ mole GSH/minute/million cells.

\section{Cytokine Reverse Transcription - Polymerase Chain Reaction (RT- PCR):}

IL-4 and INF- $\checkmark$ mRNA normalized to G3PDH mRNA was measured using RT-PCR. The RT-PCR experiments were carried out using the method of Noble (Noble et al., 1995). Total RNA was extracted from lung and lung-associated lymph node (LALN) tissue by guanidine isothiocyanate lysis (Trizol; Life Technologies, Rockville, MD). Tissues were processed immediately after sacrifice. Reverse transcription was performed using $5 \mu \mathrm{g}$ total RNA, oligo (dT) 12-18 primers, and M-MLV reverse transcriptase (Superscript First-Strand cDNA Synthesis Kit, Life Technologies, Rockville, MD).

PCR reactions were performed using cDNA derived from $0.4 \mu \mathrm{g}$ RNA, primers listed below, Taq polymerase (Sigma-Aldrich, St. Louis, MO), dNTP mix, 10x PCR buffer, $\mathrm{MgCl}_{2}$, and $\mathrm{H}_{2} \mathrm{O}$. The PCR conditions involved denaturation at $94^{\circ} \mathrm{C}$ for $30 \mathrm{sec}$, annealing at $55^{\circ} \mathrm{C}$ for $30 \mathrm{sec}$, and extension at $72{ }^{\circ} \mathrm{C}$ for $90 \mathrm{sec}$. The initial cycle contained a 4-minute denaturation at $94{ }^{\circ} \mathrm{C}$ and the final cycle contained a 7 -minute extension at $72{ }^{\circ} \mathrm{C}$. 37 cycles were performed.

Primers used for RT-PCR were as follows: IFN- $\gamma$, 5' ATCTGGAGGAACTGGCAAAAGGACG-3' and 5'-CCTTAGGCTAGATTCTGGTGACAGC3', which amplify a 288-bp fragment; IL-4, 5'-ACCTTGCTGTCACCCTGTTCTGC-3' and 5'GTTGTGAGCGTGGACTCATTCACG-3', which amplify a 352 bp fragment [23]; TNF- $\alpha, 5$ 'TACTGAACTTCGGGGTGATTGGTCC-3' and 5'-CAGGCTTGTCCCTTGAAGAGAACC- 3', which amplify a 295-bp fragment; IL-6, 5'-CAAGAGACTTCCAGCCAGTTGC - 3' and 5'TTGCCGAGTAGACCTCATAGTGACC-3', which amplify a 614-bp fragment; and G3PDH, 
CATGTAGGCCATGAGGTCCACCAC-3', which amplify a 983-bp fragment. With the exception of IL-4, all primer sequences were obtained commercially (Clontech, Palo Alto, CA).

PCR products were separated on 1.5\% agarose gels in TBE buffer. Gels were stained with ethidium bromide and digital images captured using a still video system (Eagle Eye II; Stratagene, La Jolla, CA). For gels used to semiquantitate PCR product, samples were loaded in volumes that equalized the size of bands for glyceraldehyde-3-phosphate dehydrogenase (G3PDH) PCR product as determined by visual inspection. Band densities of captured digital images made from these gels were then quantified by densitometry (Eagle Eye II; Stratagene, La Jolla, CA).

\section{SERUM OVA SPECIFIC IgE AND IgG MeASUREMENTS:}

Blood samples were collected from the vena cava at sacrifice. Four sera dilutions with $5 \%$ horse serum albumin (HOSA)/PBS of 1/100, 1/500,1/1000, and 1/10,000 were analyzed for OVA-specific IgE. The OVA-specific IgG determinations were obtained on sera dilutions of $1 / 10,000,1 / 50,000,1 / 100,000$, and 1/500,000. Diluted sera (100ul) were added to a 96-well plate (ICN Biomedicals, Inc., Horsham, PA) that had been previously coated with $200 \mu 1$ of $1 \%$ OVA carbonate coating buffer and blocked with a 5\% HOSA/coating buffer according to the method of Voller and Bidwell, (1986). The plates were incubated overnight at $4{ }^{\circ} \mathrm{C}$ and subsequently incubated with sheep IgG, anti-rat $\operatorname{IgE}(100 \mu 1,1 / 5,000$ dilution in HOSA/PBS; Cat. No. 64-352, ICN Biomedicals, Inc., Costa Mesa, CA) and horseradish peroxidase-bound donkey IgG, antisheep IgG $(100 \mu 1,1 / 10,000$ dilution in HOSA/PBS; Cat. No. 67541, ICN Biomedicals, Inc., Costa Mesa, CA) for $2 \mathrm{hr}$ each at room temperature. The plates were washed three times following each incubation. Plates were developed with tetramethylbenzidine (TMB, Sigma Chemical Co., Saint Louis, MO), and read at $570 \mathrm{~nm}$. OVA-specific IgG were determined using Goat IgG, anti-rat IgG (1/1,000 dilution in HOSA/PBS; Cat. No. R5005, Sigma Chemical Co., Saint Louis, MO) and peroxidase-labeled rabbit IgG anti-goat IgG (1/25,000 dilution in HOSA/PBS; Cat. No. A-3540, Sigma Chemical Co., Saint Louis, MO) as detection antibodies following the same protocol described above. Pooled sera from sensitized rats to OVA was 
extensively tittered (Dilutions of $1 / 10,000$ and $1 / 50,000$ for $\operatorname{IgE}$ and $\operatorname{IgG}$ respectively was assigned a value of 100) and concentration/response curves were obtained. These curves were then used as references to obtain relative concentrations for the OVA-specific IgE and IgG of different exposure groups.

\section{Data Analysis:}

All data were expressed as mean \pm standard error of 2-4 separate experiments. Each measurement was run in duplicate or triplicate per experiment. Statistical analysis of data was performed using Sigma Stat (version 2.0, Jandel Scientific Software, San Rafael, CA) statistical software for Windows 95, NT, and 3.1. ANOVA (Tukey or Dunn's), t-test, and Chi-square was conducted and values of $\mathrm{p}<0.05$ were considered statistically significant. 


\section{RESULTS}

Thiols such as CYSH and GSH are presented in LNC and AM. The first step in our study was to develop a HPLC method to detect and quantify specific thiols in LNC and AM at pmole levels. The second step was to expose the rats to OVA, DEP, and Combined OVA and DEP and study their effect on the thiol levels and the immune responses. Thus, this section will be divided into five subsections in which the results of each study will be reported.

\section{Thiol Measurement Methods Development}

Lymph nodes (LN) (Axiliary and Tracheal) and Bronchial alveolar lavage (BAL) cells were collected in $1 \mathrm{ml}$ of pH 7.4 (PBS+ 500mM BHT+50mM EDTA) from Sprague-Dawley, Hill Top (250-275 gram) rats and used for the HPLC method development. As it has been mentioned in methods section, monobromobimane (MBB) has been used as a thiol derivitizing reagent.

Bronchial alveolar lavage cells were $>90 \%$ macrophages. Axiliary lymph node preparations contained 70 to $80 \%$ lymphocytes, $15-20 \%$ macrophages and a few red blood cells.

Table 1 shows the levels of the $\mathrm{CD} 4+$ and $\mathrm{CD} 8+$ in the tracheal and para-thymic and axiliary LN cells. Approximately $32 \%$ of the lymphocytes were CD4+ and 17\%, CD8+ cells.

The uptake of MBB by alveolar macrophages and lymphocytes and the fluorescence derivatization procedure were completed within two hours of incubation at room temperature (Fig. 1). MBB reacted directly with intracellular thiols in intact live cells preventing oxidative loss during lysis and filtration for subsequent HPLC analysis. The preliminary HPLC method has been used in this study and the second modified HPLC method (which provided better peak resolution) was used for all subsequent studies.

Standard curves with $\mathrm{R}=0.998$ were obtained by the HPLC analysis (Fig 2). The limit of detection was less than 1 pmole/injection. The retention time for Cysteine and GSH were 6 and 10 minutes respectively (Fig 3).

Cysteine and GSH levels were determined in pooled tracheal and para-thymic (LNC), and axiliary lymph node cells and alveolar macrophages of the Spraque Dawly rats (Table 2). There were no big differences in the levels of CYSH and GSH between the axiliary and the tracheal and para-thymic LN cells. The range of cysteine and glutathione from the axiliary lymph 
node cells were 80.9 to 92 and 123.1 to 195.98 pmole $/ 10^{6}$ cells, respectively, and tracheal lymph node cells were 60.48 to 186.6 and 171.76 to 198.4 pmole $/ 10^{6}$ cells, respectively.

Cysteine and glutathione levels in the alveolar macrophages were 30, and 2.5 times higher than lymphocytes, respectively. Comparison of total MBB induced fluorescence with chromatographic total GSH and cysteine measurements suggest that these thiols constitute only a small fraction to total cellular reduced thiol content.

\section{OvalbuMin Dose RESPONSE STUdY}

Granulocytes, LDH activity, total protein content, and albumin levels are shown in Figure 4. An OVA dose response relationship was seen for $\mathrm{LDH}$, total protein, and albumin in BAL fluid. These results show that exposure to high concentrations of aerosolized OVA causes pulmonary epithelial damage and cell toxicity. However, the significance of these changes depends on the OVA exposure concentration.

Figure 5 shows the dose response relationship between OVA and serum specific antibody levels. There was a significant production of antigen-specific IgE and IgG in rats exposed to $\geq$ $68 \mathrm{mg} / \mathrm{m}^{3}$ OVA. The same trend of increases was seen in the specific IgG levels (Panel B). Dose-dependent tolerance was noted in the production of OVA-specific IgE.

The levels of cysteine and GSH were determined in bronchoalveolar lavage fluids (Figure 6). Both cysteine and GSH levels were increased significantly (50 times, at the highest exposure dose) with increasing dose.

The effects of OVA sensitization and challenge on cellular concentrations of cysteine and GSH were studied in AM and lymphocyte taken immediately after sacrifice. Figure 7 shows the intracellular cysteine and GSH levels in AM from various exposure groups. Cysteine at the lowest OVA exposure dose increased slightly followed by a sharp decrease ( $\sim 10$ times) at the higher OVA exposure doses. Glutathione levels were increased slightly at $7.2 \mathrm{mg} / \mathrm{m}^{3}$ and significantly (1.25 times) at $68 \mathrm{mg} / \mathrm{m}^{3}$ dose. A marked decrease (10 times) in the Glutathione levels was seen at higher OVA exposure doses. 
Figure 8 shows the cysteine and glutathione levels in LNC. There was a significant increase ( 1.6 times) in the cysteine levels at high OVA exposure doses. Glutathione levels in these cells were not changed.

Both AM and LNC were incubated for 16 hr's (ex-vivo) in thiol free medium to study their ability to regulate the CYSH and the GSH levels. AM from OVA exposed $\left(93 \mathrm{mg} / \mathrm{m}^{3}\right.$ and higher) animals showed a significant increase in the intracellular levels of both CYSH and GSH. In contrast, these cells showed a significant reduction in the extracellular levels of both CYSH and GSH (Fig 10). LNC showed the same trend of behavior when incubated in the same thiol free medium (Fig 11).

\section{Comparison of Pulmonary Response to Inhaled and Intratracheally Instilled Diesel Exhaust Particulate.}

Chamber samples of both DEP and CB revealed similarities in shape and size between them when examined microscopically (Fig. 13). DEP collected from an environment in which a diesel engine was in use has a fluffy appearance by electron microscopy. In comparison, DEP retained into the air in the laboratory appeared a little more compact. Our analyses for the generated particles also showed that more than $90 \%$ of the particles generated were in the submicron range (data not shown).

The effect of IT-DEP on the levels of glutathione (GSH) and cysteine (CYSH) in both BAL cells and LN cells were studied at 4, 24, and 72 hours (Fig 14). Both GSH and CYSH levels in BAL cells were increased significantly at all time points. Concurrently, the increase in the GSH levels in LN cells was seen at 24 and 72 hours but not at 4 hours post IT-DEP exposure.

The inflammatory markers represented by PMN, LDH, and total protein was also studied (Fig. 15). IT-DEP exposure caused pulmonary inflammation in the lung at 4 hours following exposure as noted by the increase in neutrophils count. This inflammation was also manifested by a significant increase in lavage and LDH proteins.

TNF- $\alpha$ and IL-1 were determined in AM cultured medium with, and without, ex vivo LPS stimulation (Fig. 16). One day post IT-DEP exposure a significant increase in the level of TNF- $\alpha$ was noted. TNF- $\alpha$ was also enhanced in LPS stimulated mac's from DEP exposed rats 
vs LPS stimulated control rat mac's. At three days post IT-DEP exposure a significant decrease of AM TNF- $\alpha$, after ex vivo endotoxin challenge, was observed. Interlukin-1 was significantly elevated in IT-DEP from saline control group at both 1 and 3 days post exposure. In addition, LPS stimulation caused an enhanced increase in the IL-1 levels of the AM at 1-day post IT-DEP exposure.

Table 3 contains a comparison of lymph node and BAL cells at 72 hours post either IT or inhaled DEP exposure. Inhaled DEP caused a significant increase in the levels of GSH in the LNC. CYSH, but not GSH increased significantly in the BAL cells. Both inhaled and IT DEP exposure caused a significant decreases in the AM TNF- $\alpha$ levels after ex vivo endotoxin challenge. The major difference between IT and inhalation routs of exposure is that inhaled DEP did not cause a measurable pulmonary inflammatory response.

\section{Alteration of Intracellular Cysteine and Glutathione Levels in Alveolar Macrophages and Lymphocytes by Diesel Exhaust Particle EXPOSURE}

Figure 17 shows the pulmonary inflammatory responses to DEP exposure. A timedependent increase in neutrophil infiltration, LDH level, total protein and albumin content in the lavage fluid was noted. The neutrophil count peaked (6-fold over control) by 24 hours and was still elevated at 72 hours following exposure. Significant lung damage, as indicated by BALF LDH activity, protein, and albumin content, was observed at 4, 24 and 72 hours post exposure. Changes in intracellular CYSH and GSH in AM and LNC, in relation to the saline control, are shown in Figure 18. In response to DEP exposure, AM had an acute elevation in CYSH (10-fold) and GSH (3-fold) levels (at 24 hours post exposure), which was still elevated at 72 hours post exposure. In comparison, CYSH in LNC was increased starting at 4 hours and remained elevated at 24 and 72 hours post DEP exposure. There was a delay in the increase of GSH levels in LNC with a peak concentration (1.5-fold over control) at 24 hours. The elevation of the GSH level in DEP-exposed lymphocytes declined toward control values by 72 hours post exposure. 
Figure 19 shows the effects of DEP exposure on the capacity of AM to generate CYSH and GSH from cystine. Cells from rats exposed to IT-DEP or saline for 72 hours were incubated ex vivo with $24 \mu \mathrm{g} / \mathrm{ml}$ cystine for 16 hours. In saline-exposed cells, the CYSH level was increased 6-fold over the control by the presence of cystine, indicating that AM exhibit a strong capacity to take up cystine and reduce it to CYSH. DEP exposure enhanced AM capacity to convert cystine to CYSH (panel A). The addition of cystine (in DEP-exposed AM) resulted in a 10-fold increase in the cellular level of CYSH. The level of GSH in AM from control rats was not affected by ex vivo incubation with cystine for 16 hours despite of the increase in CYSH, but was significantly increased by DEP exposure, particularly in the presence of cystine (panel B). These results show that although CYSH is required for the synthesis of GSH, increased level of intracellular CYSH did not necessarily result in greater GSH levels in cells from saline exposed control animals at this 16 hour time point. The cells from DEP-exposed rats, on the other hand, exhibited increased uptake and conversion of cystine to CYSH and significantly elevated GSH level, suggesting an enhanced GSH synthesis.

Figure 20 shows the effects of DEP exposure on the thiol regulation in LNC. The ex vivo incubation with cystine resulted in a 2-fold increase in CYSH production, suggesting that these cells have the capacity to take up and convert cystine to CYSH. In comparison, the DEP exposure resulted in a 6-fold enhancement of CYSH production in LNC. This response was further augmented by the addition of cystine (panel A) to the culture medium. Panel B shows that the GSH levels in LNC were not affected by ex vivo cystine, but were significantly reduced $(60 \%)$ by the DEP exposure when cultured for 16 hours in thiol free media.

The possibility that DEP may affect solution concentrations of various thiols through particle absorption was investigated. Figure 21 shows that DEP exhibited relatively strong affinities toward cystine, moderate absorptive capacity toward CYSH and GSH, but no effect on GSSG. DEP did not directly alter glutathione reductase activity (data not shown).

Figure 22 shows the effect of DEP on the glutathione reductase (GSH-R) activity in AM (panel A) and lymphocytes (panel B). Cells from rats exposed to saline or DEP for 72 hours were used. The GSH-R activities in DEP-exposed AM and lymphocytes were found to be 1.8and 4.0-fold that of the saline controls, respectively. 
Since the Brown Norway rats have been extensively used as a model for allergic sensitization, we have carried out similar studies to evaluate thiol changes in the Brown Norway rat model. Table 4 show the comparison of DEP-induced inflammatory responses in the SpragueDawley and Brown Norway rats. These results show that while they differ in magnitude, both rat models show similar trends of inflammatory responses to DEP exposure. Thiol regulation also showed similar trends in both strains. It is interesting to note that DEP thiol alteration in the AM of SD rats was notably much greater than that seen in $\mathrm{AM}$ from the $\mathrm{BN}$ rats.

\section{The Effect of Diesel Exhaust Particles (DEP) and Carbon Black (CB) On Thiol Changes in Pulmonary Ovalbumin Allergic Sensitized Brown NORWAY RATS.}

Brown Norway rats were exposed by IT to either DEP or CB on day zero followed by OVA sensitization and challenge as described earlier. Figure 23 shows that rats, at four weeks post IT exposure to DEP or CB alone, exhibit normal levels of total protein and LDH in the BAL fluid, as compared to the saline control. Rats exposed to OVA for four weeks also exhibit normal levels of total protein and LDH in the lavage fluid. These results show that OVA or the particles alone did not cause persistent pulmonary epithelial damage or cell toxicity. There was also no increase in BAL inflammatory cells in these groups. In the combined exposures with OVA, however, both DEP and CB resulted in significantly elevated levels of inflammatory cells, total protein and LDH as compared to OVA or particle exposure alone, indicating that both DEP and CB aggravated the airway allergic inflammatory responses to OVA.

Figure 24 shows the effect of DEP or CB on OVA-induced serum specific antibody levels. An antigen-specific IgE and IgG antibody responses in rats exposed to OVA alone were found, and a marked enhancement in antibody production in rats exposed to either particles (DEP or CB) or OVA. The increase in anti-OVA IgE production due to particle interplay was 4 and 3.5 fold that of the OVA control for the CB- and DEP-exposed groups, respectively. The increase in serum anti-OVA IgG production by CB or DEP was $5-6$ fold higher than OVA exposure alone. These results show that both DEP and CB exhibit adjuvant effect on OVA 
sensitization, and that particle composition, in this case the organic content in DEP, is not critical in inducing the adjuvant effect.

Figure 25 shows the effect of CB or DEP on IFN- $\gamma$ and IL-4 (panels A and B) $m$ RNA expressions in lung tissues of non-sensitized and OVA-sensitized rats. In non-sensitized animals, both DEP and CB appear to enhance IFN $-\gamma m$ RNA content as compared to saline controls, but this enhancement was not statistically significant. In contrast, there is a significant increase in IL-4 $m$ RNA by DEP exposure. OVA-sensitization alone did not alter IFN- $\gamma$ and IL-4 $m$ RNA levels in the lung tissue. In the combined exposures, while the IFN- $\gamma m$ RNA levels remain unchanged in all groups, both CB- and DEP-exposed rats showed elevated levels of IL-4 $m$ RNA when compared to rats exposed to OVA alone. The enhancement of IL-4 $m$ RNA by DEP is significant and is consistent with the fact that DEP alone induced an increase in IL-4 $m$ RNA in lung tissue. There was no significant difference in TNF- $\alpha m$ RNA in lung tissue of all exposure groups (data not shown).

The effects of particle and OVA exposures on cellular concentrations of CYSH and GSH were studied in AM and lymphocyte primary cultures incubated for $16 \mathrm{hr}$ in thiol free medium. Figure 26 shows the intracellular CYSH (panel A) and GSH (panel B) levels in AM from various exposure groups. DEP or CB exposure alone did not alter the thiol levels at four weeks post exposure. The OVA exposure slightly increased the CYSH concentration, but markedly decreased the intracellular GSH concentration. In the combined exposure, AM from all groups exhibited elevated concentration of $\mathrm{CYSH}$, but lowered $\mathrm{GSH}$, when compared to the saline control. Figure 27 shows that DEP or CB exposure alone did not significantly affect either CYSH or GSH levels in lymphocytes. Exposure to OVA, on the other hand, resulted in a substantial decrease in both CYSH and GSH concentrations. Figure 27B also shows that DEP may augment the OVA effect in lowering the intracellular GSH in lymphocytes. The difference in effect of OVA challenges to sensitized rats between this study and the OVA dose-response study is addressed in the discussion.

The abilities of AM and lymphocytes from various exposure groups to utilize cystine in CYSH and GSH synthesis are shown in Figures 28 and 29, respectively. Alveolar macrophages had a strong capacity for the uptake and conversion of cystine to CYSH (Figure 28A). This 
ability, however, was significantly suppressed by OVA exposure. Both DEP and CB exposures, on the other hand, enhance CYSH production by AM, even in cells from OVA-sensitized rats. The addition of cystine to AM culture did not result in a significant increase in GSH synthesis in all exposure groups (Figure 28B). GSH was not assessed in the extracellular medium and it is possible that the AM transported much of the GSH out of the cell. Figure 28B further shows that OVA decrease GSH concentration in AM. Figure 29A shows that lymphocytes have the capacity to take up and convert cystine to CYSH. This capacity was not significantly altered by DEP or CB exposure, but was strongly inhibited by OVA. The addition of cystine to lymphocyte culture resulted in a slight increase in GSH synthesis in all exposure groups. As shown in Figures 26 and 27, OVA exposure resulted in lowered cellular levels of GSH in AM and lymphocytes. Figures 28 and 29 further show that even under elevated concentrations of CYSH (through cystine utilization), the GSH levels in AM and lymphocytes remain suppressed by OVA sensitization and challenge. 


\section{DISCUSSION}

This study has been divided to four subsections in order to discuss each section in more detailed way. Our objectives were to study the effect of animal sensitization (with OVA), DEP exposure, and combined DEP and OVA exposure on the thiol (GSH and CYSH) levels and the consequences of this effect on the pulmonary immune responses. A comparison between IT- and Inhaled-DEP exposure was also included to show the difference in the effect on thiols when exposed by these two routs. In the following sections each of these exposures will be discussed according to its appearance in the result section:

\section{NEW HPLC METHOD FOR THIOLS}

Many published methods exist for the measurement of thiols in their oxidized and reduced forms (Cysteine and Glutathione) from different biological samples. Many of these methods are either non specific or not sensitive enough to detect the low levels of the thiols in biological samples.

A rapid and sensitive method for the quantification of CYSH and GSH in intact macrophages and lymphocytes and of intracellular cysteine and GSH levels via HPLC was developed. Monobromobimane (MBB) has been used as a label for both protein and non protein thiols by a glutathione S-transferase-independent mechanism. MBB penetrates the cellular membrane and reacts with the cellular-thiols in live intact cells. Cellular (macrophages and lymphocytes) cysteine and glutathione content were easily derivetized with MBB and the resultant fluorescence was detected by a newly developed HPLC method. The HPLC method has a limit of detection of less than 1 pmole/injection. Both reduced and total (reduced plus oxidized forms) free CYSH and GSH levels can be measured in intact cells directly by this method. Some major advantages of our method include; (1) Simultaneous measurement of both CYSH and GSH, (2) No loss of reduced form during processing of tissues for thiol measurement, (3) Production of a stable derivative that can be stored for later analysis, and (4) Measurement of total GSH includes reduced plus all G-S-S-R forms, including membrane bound, protein and non-protein species. Total CYSH determination has the same advantage. Most other methods only include acid soluble thiols in their measurements. 


\section{OVA Sensitization And Challenge Dose-Response}

Allergic sensitization due to occupational exposure to egg protein has been reported (NIOSH, 1988). Immune response changes due to antigen (such as OVA) exposure have been connected to thiol changes in the cell and its surrounding environment. A direct relationship between T cell GSH levels and T cell function has been reported in GSH depletion experiments. Suppression of T cell activation (Droge et al., 1991; Kavanagh et a., 1993; Staal et al., 1994; Otsuji et al., 1996; Wilhelm et al., 1997; Potter et al., 1997), proliferation (Fidelus et al., 1987; Suthanthiran et al., 1990; Gmunder et al., 1990; Smyth 1991; Walsh et al., 1995; Taylor et al., 1997), level of IL-2R expression (Liang et al., 1992), cytokine production (Peterson et al., 1998; Lawrence et al., 2000), and the generation of CTL responses (Gmunder and Droge 1991; Multhoff et al., 1995) have been reported.

We used Brown Norway rats to investigate the effect of a wide range of OVA exposure and challenge concentrations $\left(7-156 \mathrm{mg} / \mathrm{m}^{3}\right)$ on thiol levels and antibody (Th2) production. Dose-dependent effects of the aerosolized OVA on inflammatory markers (LDH, total protein, and albumin) were seen (Fig 4).

Because it is required for the reduction of disulfide bonds, GSH if depleted has been shown to impair the ability of APC (such as AM) to process and present antigens, which are rich in cystine (Gainey et al., 1996; Short et al., 1996). In this regard, our results show a severe depletion in both CYSH and GSH levels in AM (Fig 7). This depletion was concomitant with the biphasic IgE serum titer. A threshold of these changes could be recognized in the thiol levels in BAL and AM. These results were in agreement with Fahy et al., (2000) who reported that DEPs and allergens could result in high local chemokine levels via MAP kinase pathways activation in allergic patients. This in turn could increase the likelihood of reaching a critical threshold leading to the initiation of respiratory allergic symptoms. Our results show that exposure to allergen alone (such as OVA) in high levels (68 $\mathrm{mg} / \mathrm{m}^{3}$ and higher) were needed to reach this threshold and cause the initiation of allergic symptoms.

It is interesting to note that allergic challenge of sensitized BNR cause a large increase in BAL fluid CYSH and GSH (Fig 6) even though alveolar macrophage thiol levels were severely 
depleted (Fig 7) and the AM attempting to conserve the remainder of their intracellular thiols (Fig 10). In addition, our previous work showed that OVA exposure at $90 \mathrm{mg} / \mathrm{m}^{3}$ impaired the ability of AM in taking up the ex vivo supplemented cystine and using it as a thiol source (AlHumadi et al., 2002-2). Together these results suggest that AM were not the source of the BALF thiols. The reduction of the thiols in AM starts at the $68 \mathrm{mg} / \mathrm{m}^{3}$ and was reduced even more at the $93 \mathrm{mg} / \mathrm{m}^{3}$.

An increase of cysteine in LNC (Fig 8) is needed to maintain the levels of GSH, required for T-cell proliferation and differentiation after the antigenic stimulation (Wilhelm et al., 1997; Fidelus et al., 1987; Suthanthiran et al., 1990). LNC tended to conserve thiols intracellularly when incubated ex vivo for 16 hr's (Fig 11). LNC response to high OVA exposure was different than that of AM as an increasing in the total (intra- and extra- cellular) GSH was noted (Fig 11). Even though cysteine levels were significantly increased in LNC, our previous results shows that these cells lost its ability in taking up cystine and reduce it to cysteine (ex vivo) after exposure to OVA (Al-Humadi et al., 2002-2). In addition, the same study showed the reducing ability of these cells in increasing the GSH level. Methodology may also be very important in assessing the thiol response in LNC. At high OVA challenge an increase in LNC thiols was noted in this study (Fig 8). The LNC were used directly after breaking the LN capsule, without further purification. A sever loss of thiols from LNC of OVA sensitized and challenged BNR was noted in a subsequent study. The major difference between the two experiments was that LNC were processed with ficoll hypague prior to use in the latter study. The sensitized LNC may have been hyper reactive, causing a loss of thiols when placed in this hyperosmotic environment.

Both OVA specific IgE and IgG sera levels were dose-dependent. The IgE response was biphasic, with the development of tolerance at the higher doses (Fig 5). Cytokine production in response to Th1-associated, but not Th2-associated antigens, was reported to be selectively inhibited with GSH depletion (Peterson et al., 1998). The relationship between thiol and immune regulation may be very complex. As noted with the alveolar macrophage, one cell type may become dysfunctional with respect to its thiol regulation, even while it's surroundings become thiol rich. Allergic sensitization is a multifactorial, pleocellular process. It cannot be determined if the AM reflects all APC's or if it is atypical since they exist outside the body in alveolar 
spaces. It is interesting to note, however, the parallel occurrence of AM thiol regulation dysfunction and $\operatorname{IgE}$ tolerance in this study.

Antibody production requires the activation of the $\mathrm{kB}$ nuclear factor $(\mathrm{NFkB})$. Both high and low levels of GSH affect the process of activation (Droge et al., 1994). A cascade of membrane-bound and cystoplasmic protein kinases including tyrosine kinases of the src family are required to trigger the activation of NFkB (Finco and Baldwin 1993; Schicven et al., 1993; Hayashi et al., 1993). P56 ${ }^{\text {lck }}$ (associated with CD4+ and CD8+ molecules and IL-2 receptor Bchains) and P59 fyn (associated with T cell receptor/CD3 complex),(both are members of the src family)were found to be activated by thiol oxidizing agent diamide (Schicven et al., 1993; Hayashi et al., 1993; Nakamurz et al., 1993). The activation of both tyrosine kinases have to be by cross-linking of the corresponding surface receptor molecules and plays an important role as signal transducing molecules in T cell-mediated immune responses. A reactive cysteine residue, the active site of protein tyrosine-phosphatases, must be in the reduced form for catalytic activity (Stevens and Jones 1989). These are some of the important roles that thiol plays in the activation of an immune response. The initial increase followed by the severe reduction in CYSH and GSH levels in AM might explain the biphasic IgE response in our results.

The correlation between CYSH levels and antibody (IgE) production were analyzed (Fig 9). The highest correlation were found between $\mathrm{CYSH}$ in BAL and $\mathrm{AM}(\mathrm{R}=0.96$ and $=0.91$, respectively) and IgE production. This might be an indication of the dependence of IgE (which is part of the humoral immunity) production on the CYSH level changes happening in the lungs.

The ability of both AM and LNC in maintaining the optimal levels of CYSH and GSH in the intra- and the extra- cellular environment were studied (Figures 10 and 11). OVA-exposed AM tended to keep all the thiols intracellularly, when incubated for $16 \mathrm{hr}$ 's in thiol free medium, despite the fact that the basal level of these thiols was reduced significantly. LNC increased their levels of CYSH. They also conserved CYSH and GSH over control cells as noted by the percent released to the culture media during a $16 \mathrm{hr}$ incubation.

AM and LNC tendency to conserve thiols intracellularly might be a measures to delay or prevent apoptotic initiation. It has been reported that Fas-mediated apoptosis is modulated by intracellular glutathione in human T cells (Chiba T., et al., 1996). Potentially thiols may be 
shifted to the mitochondrial compartment (a non-releasable pool) (Gainey et al., 1996) as a measure of preventing cytochrome $\mathrm{C}$ from being released and thus preventing apoptotic initiation.

Two steps are required to breakdown GSH extracellualrly and this process will be catalyzed by $\gamma$-glutamyl transpeptidase and dipeptidase. As a result the GSH will be degraded to its constituent amino acids and made available for the (weak GSH uptake) cells. Our results show that AM and LNC transferred the GSH to the extracellular space without the need to break it down. Whether they transferred GSH was by exocytosis or by a special tripeptide transporter system is not clear yet. The overall conclusions are:

1- IgG antibody displayed a dose dependent increase while the IgE response is biphasic (Fig 5), within the exposure range and time employed.

2- In vitro studies suggest that the dose dependent increase in BAL thiols was not dependent on alveolar macrophages thiol regulation (Fig 6).

3- Dose dependent loss of alveolar macrophage ability to regulate thiols (Fig 7) was suggested by; a- loss of intracellular CYSH and GSH in AM, b- decrease ability to take up and reduce thiols (Al-Humadi et al., 2002-2), and c- decrease in secretion of thiols (Fig 10).

4- Increase in lymphocyte CYSH at higher OVA exposure to sensitized rats was possibly due, at least in part, to conservation of intracellular thiols (Fig 8).

5- The relationship between antibody responses to inhaled antigens and thiol changes in the lung is not clear. If there is any, this relationship could be indirect through the effect of thiols on signal transduction (e.g. NFkB) as suggested by other studies.

\section{COMPARING IT - AND INHALED-DEP EXPOSURES}

Pulmonary inflammation as noted by influx of PMN, and increases in BAL LDH, protein and albumin levels was found following IT-DEP, but not inhaled-DEP. Both IT and inhaled-DEP caused a significant increase in intracellular thiol levels in LN and BAL cells $72 \mathrm{hrs}$ following exposure. Inhaled CB did not produce significant changes in parameters measured. 
Exposure of rats to DEP by IT caused significant decrease in TNF- $\alpha$ production by AM in response to LPS stimulation, but LPS stimulated TNF- $\alpha$ production was not decreased by inhaled DEP $72 \mathrm{hrs}$ following exposure.

Intratracheal and acute inhalation exposures are difficult to compare due to the differences in distribution, deposition, and internal dose, any or all of which may have contributed to the differences noted above.

\section{STUDYING THE EFFECT OF IT-DEP}

IT-DEP exposure is known to induce pulmonary inflammation, including elevated levels of neutrophils, LDH, and total protein in the airways (Yang et al., 1999; Al-Humadi et al., 20021). These increases have been associated with increased production in oxygen free radicals in the alveolar space (Hiura et al., 2000). Alveolar macrophages from DEP-exposed rats show decreased response to lipopolysaccharide and bacterial stimulation in the production of IL-1 and TNF- $\alpha$ (Yang et al., 1999; Yang et al., 2001), suggesting that DEP can alter innate immune responses, which may lead to increased susceptibility to bacterial infection. In addition, several recent studies have linked DEP exposure to allergic inflammation (Saxon and Diaz-Sanchez, 2000; Rudell et al., 1999; Nordenhall et al., 2000; Fahy et al., 2000) and increased $\operatorname{IgE}$ production (Diaz-Sanchez et al., 1994). Other studies have shown that DEP exposure promotes isotype switching to IgE in humans (Fujieda et al., 1998) and in animals (Muranaka et al., 1986). Together, these studies indicate that DEP may suppress cellular, but enhance humoral pulmonary immune responses.

The present study is consistent with the concept that CYSH and GSH may play a dual role in DEP-induced pulmonary immune/inflammatory responses. The increase in CYSH and GSH levels in AM (Figure 18) appears to be an acute response to DEP exposure. As antioxidants, these molecules are produced and secreted by AM and other cells to protect the lung from particle-induced oxidative stress and injury. Interestingly, our results showed that DEP are capable of absorbing cystine and CYSH and possibly altering the extracellular thiol balance through a non-inflammatory mechanism. During the inflammatory process, oxidized thiols such as cystine may be internalized by AM and converted to CYSH. The fact that the DEP 
induces GSH-R activity in AM (Figure 22) is also consistent with an increased production of CYSH. The DEP exposure also resulted in a significant increase in AM production of GSH at 24 hours post-exposure, and a persistent increase of GSH levels at longer post-exposure times (72 hr). The effect of DEP on GSH in AM (ex vivo) may be attributed at least in part to increased GSH-R activity.

As shown in Figure 18, the GSH level in LNC was increased at 24 hours and declined at 72 hours post DEP exposure. When cultured ex vivo, LNC from DEP exposed animals had a significant decrease in GSH. In comparison to AM, there was a delayed increase in GSH level in LNC and no increase in GSH from control LNC cultured with cystine. In all cases lymphocytes were the predominant ( $>95 \%$ ) LNC. These data suggest that lymphocytes may depend on extracellular GSH released from cells such as macrophages.

To provide more insight into the DEP effects on cellular regulation of thiols, AM and lymphocytes from saline and DEP-exposed animals (72 hrs post exposure) were isolated and tested for their reduction of CYSH and production of GSH (Figures 19 and 20). These results show a clear difference between AM and lymphocytes in their responses to DEP exposure. Alveolar macrophages exhibited a strong capacity in the uptake and conversion of cystine to CYSH (Figure 19). This is in line with the results reported by Watanabe and Bannai, (1987). They showed that macrophages exhibit strong membrane transport activity for cystine uptake and are capable of releasing reduced thiol into the extracellular space. DEP exposure increased $\mathrm{AM}$ production of $\mathrm{CYSH}$ and $\mathrm{GSH}$ two-fold. AM from rats exposed to DEP showed a significant increase in GSH-R activity (Figure 22). The DEP exposure did not affect the intracellular level of CYSH in the absence of (added) cystine, but a moderate increase in GSH levels were observed. The mechanism that DEP induces an increase in intracellular GSH levels is not yet clear, but the enhancement of GSH-R activity appears to play a major role in AM responses to DEP exposure. In the presence of cystine, the intracellular levels of CYSH and GSH in DEP-exposed cells were markedly higher than the controls, which can be attributed primarily to increased production of CYSH through increased GSH-R activity.

In lymphocytes, the DEP effect on thiol regulation was quite different from that observed in macrophages. These cells exhibited a moderate capacity in the uptake and conversion of 
cystine to CYSH. Studies by Ishii et al., (1987) have shown that lymphocytes exhibit strong membrane transport activity for $\mathrm{CYSH}$, but only a weak transport activity for cystine. Unlike its effect on AM, the DEP exposure strongly increased the level of CYSH in LNC with or without added cystine. This may be in part due to the fact that DEP also induce GSH-R activity in these cells (Figure 22). It is possible that DEP-exposed lymphocytes contain oxidized thiols that were produced during the exposure. These compounds were subsequently reduced to CYSH through increased GSH-R activity. But, despite the increase in CYSH level and GSH-R activity, the intracellular concentration of GSH in lymphocytes was significantly decreased by DEP exposure when cultured ex vivo. The mechanism by which DEP depletes GSH in lymphocytes is not yet clear. DEP may have increased catabolism of GSH by the lymphocyte, which was not able to replenish its intracellular stores when cultured in thiol free media. These possibilities are currently under investigation.

It is known that GSH levels affect the activation of NFkB (Droge et. Al., 1994; Haddad et al., 2000), and that DEP exposure could alter the function of this important intracellular messenger. DEP exposure has been linked to increased IgE production (Diaz-Sanchez et al., 1994) and isotype switching in B cells to produce IgE in human (Fujieda et al., 1998) and in animals (Muranaka et al., 1986). The cellular activity of GSH in regulating B cell functions has not been studied in detail. It is likely, however, that GSH may play an important role in the alteration of both cellular and humoral immune responses by DEP exposure. The BN rat strain which is noted for its Th2 (IgE) phenotypic responses was compared to SD rats. The pattern and magnitude of the inflammatory response to DEP was similar. The thiol response pattern was also similar but the magnitude of the AM-thiol increases after DEP exposure was drastically greater in the SD rats. It is not known if the strain difference in the magnitude of the AM-thiol response is related to differences in antibody isotype production.

In summary, the present study shows that AM and LNC responded to DEP exposure with alteration in their thiol metabolism. Exposure to DEP increased the GSH-R activity of AM and LNC, and thus, increased level of CYSH. The intracellular level of GSH in DEP-exposed AM was moderately increased when compared to the saline control, and was further augmented when cells were incubated with cystine. Lymphocyte from DEP exposed rats also showed a significant 
increase in GSH, but in contrast to AM, DEP exposed lymphocytes were not able to maintain or replenish their GSH when cultured in GSH free media indicating that DEP exposure may decreases either lymphocyte production or uptake of GSH. Other possibilities such as increases GSH catabolism or shunting CYSH to other synthetic pathways such as antibody synthesis should also be considered.

\section{COMBINED IT-DEP AND INHALED-OVA EXPOSURE EFFECT}

Exacerbation of respiratory allergy has long been associated with particulate air pollution exposure. DEP, which consist of carbonaceous particles and aromatic and aliphatic hydrocarbons adsorbed onto the particle surface, is a major air borne pollutant. Both the particulate and the organic components may play a role in their biological effects. Studies have already indicated that DEP induce acute pulmonary inflammatory responses, but suppress AM responses to lipopolysaccharide and bacterial stimulation in the production of nitric oxide, IL-1, and TNF- $\alpha$, thus increasing the susceptibility of the lung to respiratory infection (Yang et al., 1999; Yang et al., 2001). This effect was attributed to the organic component of DEP. The adjuvant effect of DEP through intranasal administration on allergic sensitization has been reported in humans and in mice (Saxon and Diaz-Sanchez, 2000; Rudell et al., 1999; Nordenhall et al., 2000; Fahy et al., 2000). This effect was characterized by an increase in antigen-specific IgE production (DiazSanchez et al., 1994), and the secretion of Th2-type cytokines in the nasal mucosa (Diaz-Sanchez et al., 1997). Recent studies further indicate that carbonaceous particles such as CB also stimulate Th2 responses and exhibit adjuvant activity to allergic sensitization (Van Zijverden et al., 2000). Indeed, through the present study, we have demonstrated that both carbon black and DEP aggravated OVA-induced pulmonary allergic inflammatory responses (Figure 23), enhance anti-OVA IgE and anti-OVA IgG production (Figure 24), and cause an increase in IL-4 $m$ RNA expression in lung tissue (Figure 25). These results suggest that particle composition of diesel exhaust does not play a major role in the adjuvant effect.

CB was found to exhibit similar effects to those of DEP on IFN- $\gamma$ and IL-4 $m$ RNA tissue levels. The $m$ RNA level of IFN- $\gamma$ was not significantly affected by CB, DEP, OVA, or combined particle-OVA exposure. Thus, it is inconclusive whether DEP or CB affects the production of 
IFN- $\gamma$ or other Th1 cytokines in the lung. It should also be mentioned that at four weeks post particle exposure, animals were well recovered from the acute inflammatory stimulation by these particles, however the tissue cytokine message levels were examined $24 \mathrm{hr}$ 's after OVA challenge of sensitized rats. In contrast, DEP and CB exposure, even at four weeks post exposure, resulted in elevated levels of IL-4 in lung tissues from either non-sensitized or OVAsensitized rats (Figure 25), although the data on $\mathrm{CB}$ did not reach statistical significance in the current experiments. Nevertheless, these results indicate that DEP or CB may augment OVAinduced antibody production through enhanced Th2 responses (i.e., IL-4 production). These results are consistent with those of other studies indicating that DEP enhances IL-5 production and IL-4 $m$ RNA level in OVA-sensitized mice (Takano et al., 1997).

The cellular mechanism(s) involved in altered immune response and cytokine production remains unclear. The fact that rats exposed to DEP or CB showed a significant increase in lung damage and inflammation, when further challenged with OVA suggests potential alteration in cells, such as AM and lymphocytes, involved in the immune response. For this reason we have studied the role of CYSH and GSH in pulmonary allergic responses associated with particle, OVA, and the combined particle-OVA exposures. Thiols are important molecules for various lymphocyte functions. Depletion of intracellular GSH inhibits the lectin-induced activation response of T lymphocytes (Hamilos et al., 1991). Studies by Gmunder and Droge, (1991) showed that depletion of intracellular GSH decreases the proportion of CD8+ cells (i.e., it increases the $\mathrm{CD} 4+/ \mathrm{CD} 8+$ ratio), and inhibits the generation of large blast-like CD8+ cells and cytotoxic T lymphocyte activity. CYSH has a strong influence on the intracellular GSH and DNA synthesis of cytotoxic T cell clones (Gmunder et al., 1990). Thiols in fact may play a regulatory role analogous to the hormone-like lymphokines and cytokines in mediating immunologically relevant functions of lymphocytes. Our initial study demonstrated that DEP produced a time dependent increase in GSH and CYSH levels in AM and lymph node lymphocytes which peaked at 4 and $72 \mathrm{hrs}$ post exposure, respectively. Thiol reductase activity was also induced by DEP (Al-Humadi et al., 2002-1). The lack of alteration in the thiol levels 4 wks post exposure (when incubated for $16 \mathrm{hrs}$ in thiol free media) is not surprising. The cultured AM from the Brown Norway rats had only slightly higher levels of CYSH than GSH (on a molar 
basis), while CYSH from cultured pulmonary associated lymph node lymphocytes was approximately 7 times that of GSH. Both cell types displayed a strong capacity for the uptake and reduction of the disulfide, cystine. The OVA exposure to sensitized rats had a marked effect decreasing thiol levels in AM and lymph node lymphocytes, and their ability to take up and reduce cystine. Interestingly, AM, but not lymph node lymphocytes from DEP and CB exposed rats had significantly greater levels of cystine uptake and reduction over saline controls. DEP and CB exposure also significantly restored the capacity of AM from OVA sensitized/challenged rats to take up and reduce cystine (Fig 26A).

The interplay between particle and OVA exposure on lymphocyte GSH levels from the current study is not clear, probably due to the strong OVA effect. Lymphocytes from animals exposed to both DEP and OVA were not able to maintain their intracellular GSH level (vs. OVA-only exposure) when incubated for $16 \mathrm{hrs}$ in thiol-free media (Fig. 27B). This enhanced loss of GSH was not seen when the lymphocytes were cultured with cystine (Fig. 29B). These results suggest that depletion of intracellular GSH and CYSH may have a role in, or be a consequence of allergic pulmonary responses, or as a result of increased reactivity of the lymphocyte (i.e. in hypertonic media) as discussed earlier. This is consistent with the results of our previous work in which in vitro DEP exposure of pulmonary associated lymph node cells resulted in a depletion of intracellular GSH, even at increased CYSH concentrations and glutathione reductase activity (Al-Humadi et al., 2002-1). The role of particulates and antigens in the (altered) thiol regulation in these immunologically relevant cells is not known. Thiols have been suggested to be important in signal transduction pathways involving NFKB activation (Droge et al., 1994; Haddad et al., 2000), which is associated with a number of cytokine genes including interferon, TNF- $\alpha$, IL-4, IL-6, and transforming growth factor- $\alpha$ (Shukla et al., 2000). Modulation of thiol regulation by particulates may thus affect allergic outcomes.

In summary, the present study shows that DEP- and CB-exposed rats exhibit an aggravated allergic response to OVA exposure with markedly enhanced pulmonary inflammation, IL-4 mRNA levels in lung tissue, and serum OVA-specific IgG and IgE levels similar to the effect reported in mice. The results also confirm the finding of other reports that the carbonaceous particles alone induce adjuvant effect on allergic asthma, however the organic 
component of DEP may also contribute in some aspects aggravating the disease. The role of thiols in the adjuvant effect of DEP remains a complicated issue. Both particulate (DEP and CB) and antigen challenge alter thiol parameters. The extent and type of alteration are tissue dependent. AM as a model of APCs and LNC were studied. AM from DEP exposed OVA sensitized rats were less affected with respect to thiol depletion, which may have a role in its $\operatorname{IgE}$ adjuvant effect (or inhibition of tolerance). 


\section{TABLES}

Table 1. Percent $\mathrm{CD}^{+}$and $\mathrm{CD} 8^{+}$Cells in Selected Lymph Nodes

\begin{tabular}{|l|l|l|}
\hline Treatment & \multicolumn{2}{|c|}{ Lymph Nodes } \\
& Tracheal \& Thymic & 1.82 \\
\hline Unstained & 0.03 & 38.21 \\
\hline CD4 $^{+}$ & 26.54 & 18.21 \\
\hline CD8 $^{+}$ & 10.73 & \\
\hline
\end{tabular}


Table 2. Cysteine and Glutathione Levels in the Pulmonary Associated and Axiliary Lymph Nodes and Alveolar Macrophages of Sprague Dawly Rats.

\begin{tabular}{|l|l|l|}
\hline Tissue & Cysteine ng/Million Cell & GSH ng/Million Cell \\
\hline Axiliary Lymph Nodes & 10.53 & 53.28 \\
\hline $\begin{array}{l}\text { Tracheal and Thymic Lymph } \\
\text { Nodes }\end{array}$ & 12.41 & 83.86 \\
\hline Alveolar Macrophages & 305.16 & 170.469 \\
\hline
\end{tabular}


Table 3. Comparison of Lymph Node and BAL Cells at 72 hours after either IT or Inhaled DEP exposure.

\begin{tabular}{|c|c|c|c|c|}
\hline & \multicolumn{2}{|c|}{ IT-DEP 1} & \multicolumn{2}{|c|}{ Inhaled-DEP 1} \\
\hline GSH-LN & \multicolumn{2}{|c|}{$138.22 \pm 18.4 †$} & \multicolumn{2}{|c|}{$128.98 \pm 17.5$} \\
\hline Cysteine-BAL Cells & \multicolumn{2}{|c|}{$148.45 \pm 16.3+$} & \multicolumn{2}{|c|}{$128.0 \pm 19.0$} \\
\hline GSH-BAL Cells & \multicolumn{2}{|c|}{$105.90 \pm 6.3$} & \multicolumn{2}{|c|}{$98.7 \pm 4.5$} \\
\hline PMN-BAL Cells & \multicolumn{2}{|c|}{$383.81 \pm 21.5 * \dagger$} & \multicolumn{2}{|c|}{$108.28 \pm 10.3$} \\
\hline LDH-BAL & \multicolumn{2}{|c|}{$324.04 \pm 15.2 * \dagger$} & \multicolumn{2}{|c|}{$87.9 \pm 13.6$} \\
\hline Total Protein & \multicolumn{2}{|c|}{$224.10 \pm 15.3 * \dagger$} & \multicolumn{2}{|c|}{$95.6 \pm 4.4$} \\
\hline \multirow[t]{2}{*}{ Albumin } & \multicolumn{2}{|c|}{$187.10 \pm 7.3 * \dagger$} & \multicolumn{2}{|c|}{$88.9 \pm 11.1$} \\
\hline & $+\mathbf{L P S}^{2,3}$ & - LPS ${ }^{1,2}$ & $+\mathbf{L P S}^{2,3}$ & - $\mathbf{L P S}^{1}$ \\
\hline$T N F-\alpha$ & $56.3^{*}+10.0$ & $80 \pm 8.8^{\dagger}$ & $82.3^{*} \pm 9.7$ & $58.8^{*} \pm 9.9$ \\
\hline IL-1 & $76.5^{*+} \pm 14.5$ & $94.8^{ \pm 5.9}$ & $117.1 \pm 13.6$ & $82.2 \pm 10.7$ \\
\hline
\end{tabular}

$1 \%$ Control (Control $=$ IT-Saline or Air Sham Nose-Only Exposure)

${ }^{2}$ Ex Vivo addition of LPS $(0.1 \mathrm{ug} / \mathrm{ml})$ to $A M$

3 \% Control (Control = IT-Saline or Air Sham Nose-Only Exposure + ex vivo LPS)

"Different from Control, t-test, $\mathbf{P} \leq \mathbf{0 . 0 5}$

${ }^{\dagger}$ IT Different from Inhalation, Chi-square, $P \leq 0.05$ 
Table 4. Comparison of Brown Norway (BN) and Sprague-Dawley (SD) Rat Responses to DEP exposure.

\begin{tabular}{|c|c|c|c|c|c|c|}
\hline \multicolumn{7}{|c|}{ Exposure Time (hours) } \\
\hline & \multicolumn{2}{|c|}{4} & \multicolumn{2}{|c|}{24} & \multicolumn{2}{|c|}{72} \\
\hline$\overbrace{\text { Analyt }}^{\text {Strain }}$ & $\mathbf{B N}^{*}$ & SD* & $\mathbf{B N}^{*}$ & SD $^{*}$ & $\mathbf{B N}^{*}$ & SD* \\
\hline GSH-LNC & 109.1 & 96.3 & 260 & 130.2 & 159.0 & 95.4 \\
\hline CYSH-AM & 221.7 & 125.0 & 143.3 & 1276.0 & 175.9 & 1551.7 \\
\hline GSH-AM & 147.9 & 79.5 & 121.3 & 330.1 & 115.1 & 392.8 \\
\hline PMN & 206.4 & 148.5 & 526.4 & 671.9 & 477.3 & 696.3 \\
\hline LDH & & & 199.1 & 256.2 & 336.7 & 265.8 \\
\hline $\begin{array}{l}\text { Total } \\
\text { Protein }\end{array}$ & & & 164.7 & 163.1 & 231.3 & 220.0 \\
\hline
\end{tabular}

$*_{\% \text { of Saline Control }}$

(Note: $\mathrm{BN}=$ Brown Norway Rats, $\mathrm{SD}=$ Sprague-Dawley Rats) 
Table 5. Experimental Design

\begin{tabular}{|l|c|c|c|}
\hline \multicolumn{4}{|c|}{ Route of Exposure } \\
\hline & IT & \multicolumn{2}{c|}{ Inhalation** } \\
\hline Day & 0 & $1,8,15,29$ & 30 \\
group & & & \\
\hline Saline/Saline & Saline & Saline & Sacrifice \\
\hline CB/Saline & CB $^{*}$ & Saline & Sacrifice \\
\hline DEP/Saline & DEP* & Saline & Sacrifice \\
\hline Saline/OVA & Saline & OVA & Sacrifice \\
\hline CB/OVA & CB & OVA & Sacrifice \\
\hline DEP/OVA & DEP & OVA & Sacrifice \\
\hline
\end{tabular}

* $5 \mathrm{mg} / \mathrm{kg}$ body weight

** $90 \pm 18 \mathrm{mg} \mathrm{OVA} / \mathrm{m}^{3}$ air or saline vehicle 


\section{FIGURES}

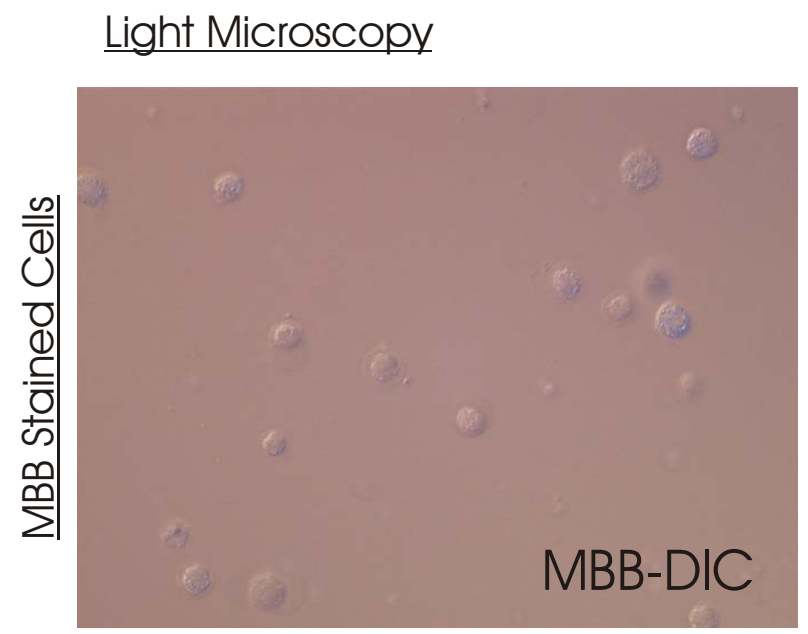

Fluorescent Microscopy
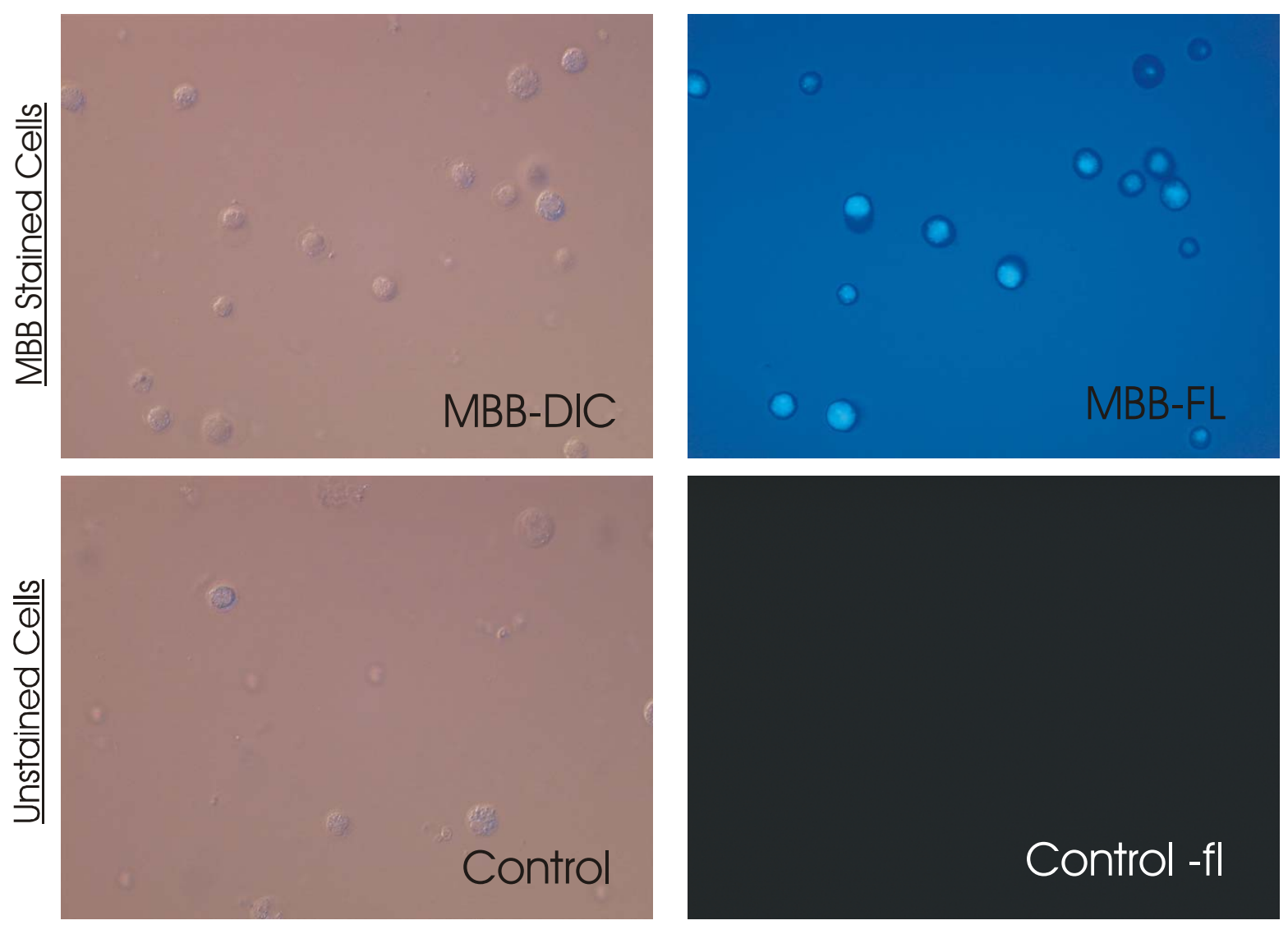

Fig 1. Fluorescent microscopic images of MBB stained rat alveolar macrophage 


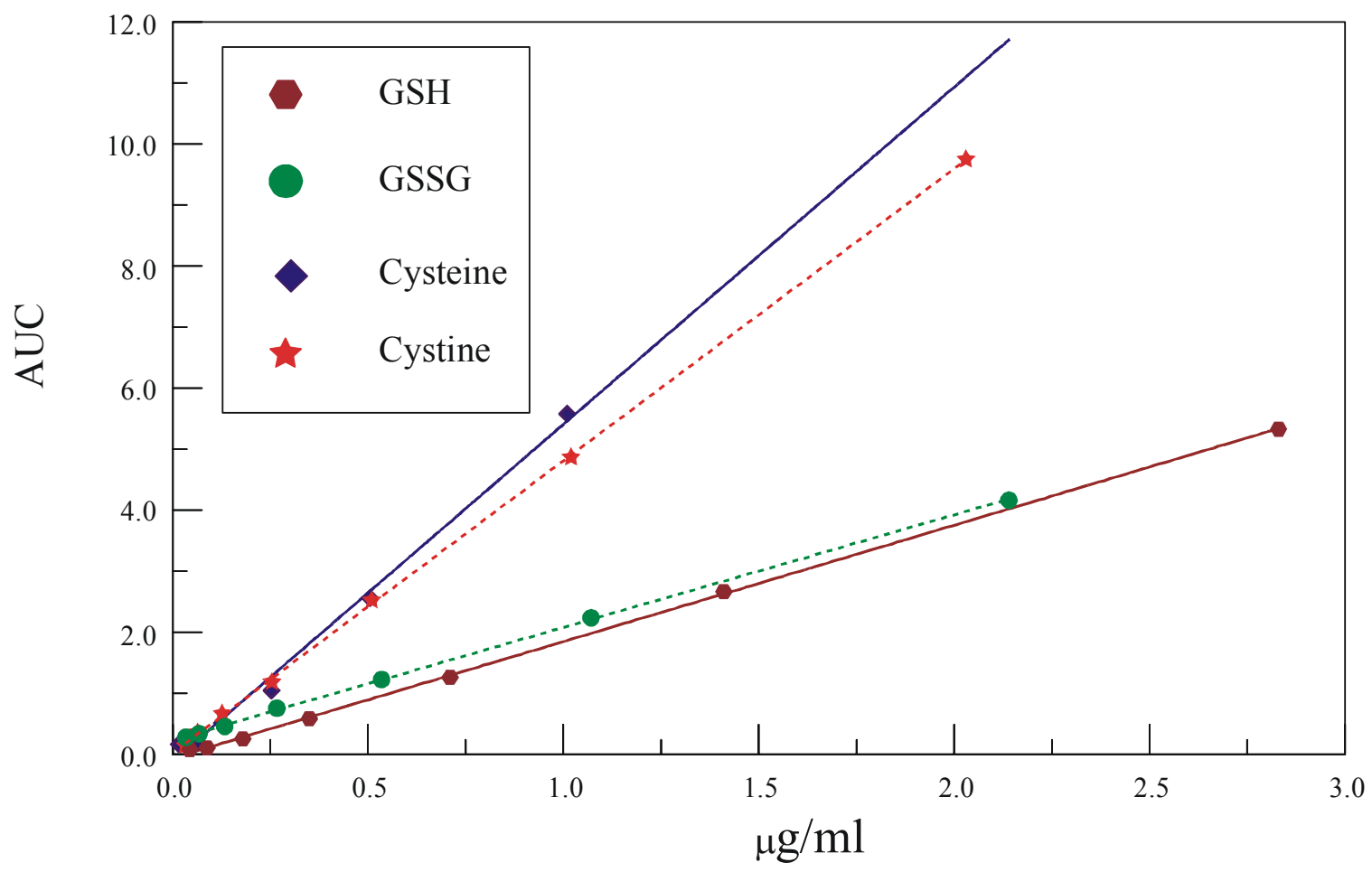

Fig 2. Standard curves for oxidized and reduced glutathione and cysteine 


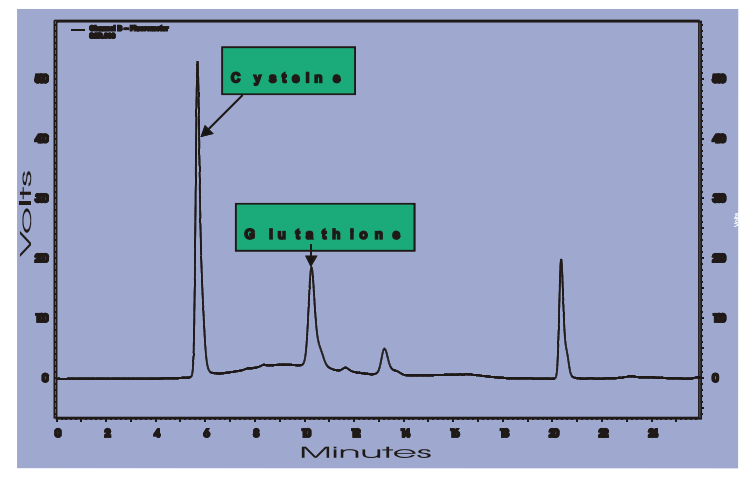

Standard

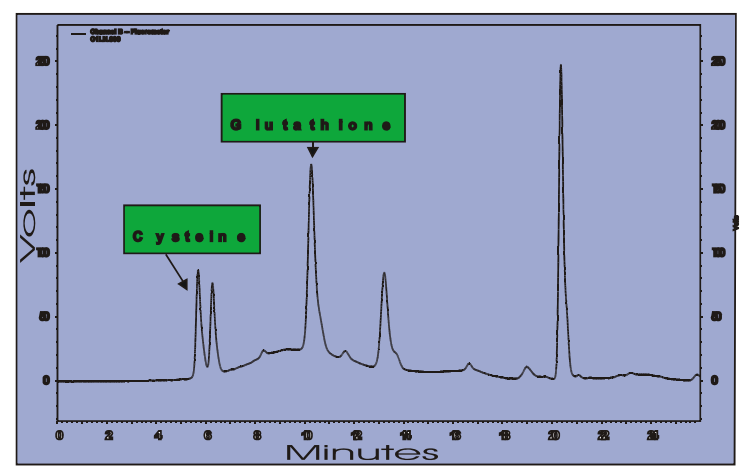

Pulmonary Associated Lymph Nodes

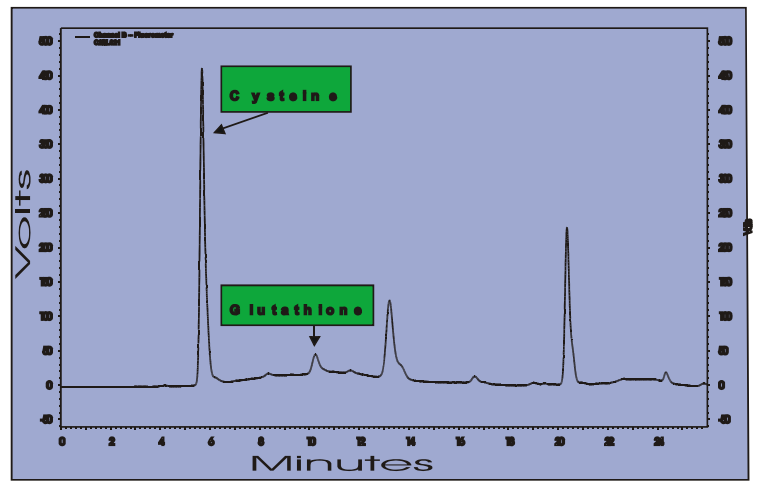

Alveolar Macrophages

Fig 3. Glutathione and cysteine HPLC-Chromatograms 

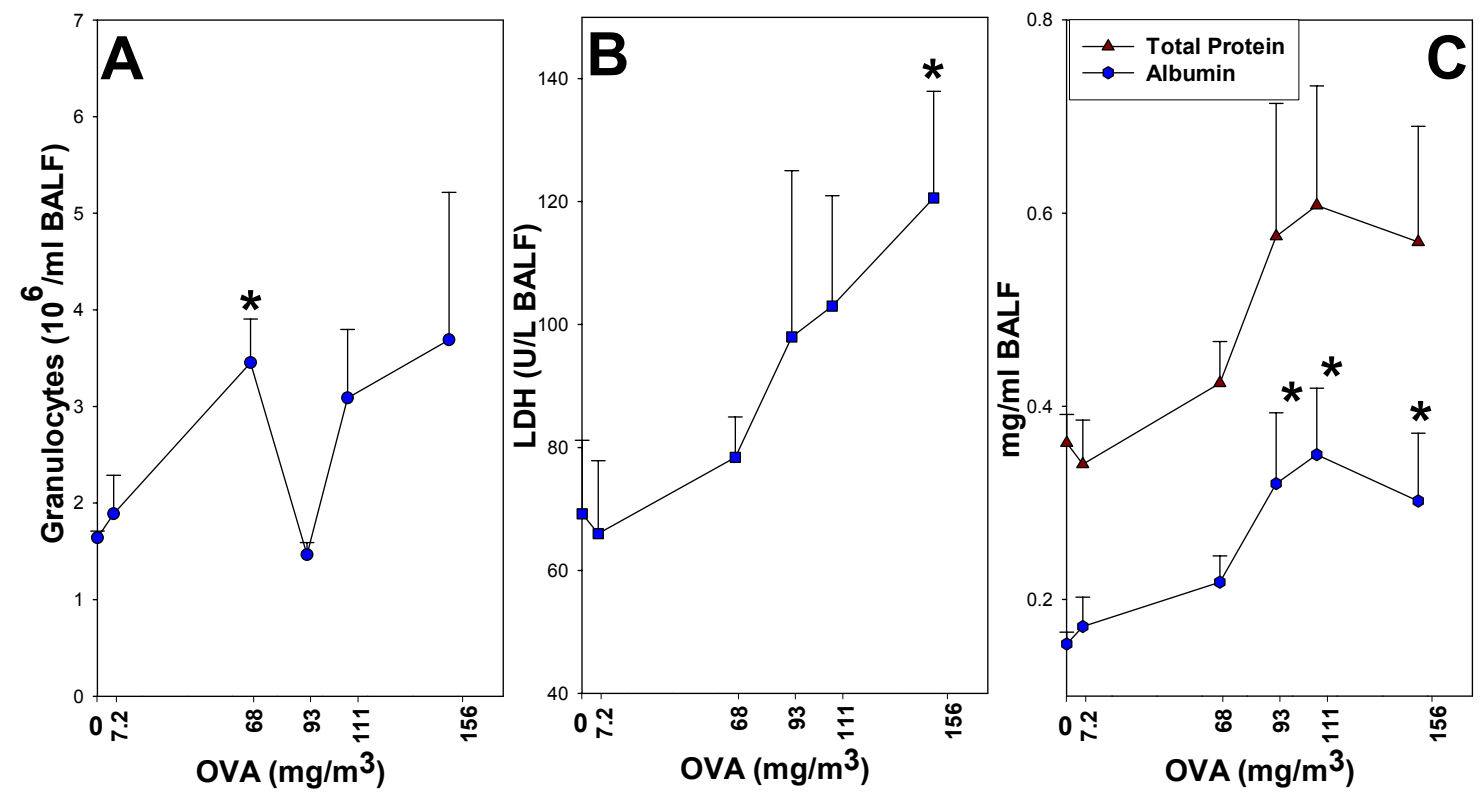

Fig 4. The OVA dose response effect on inflammatory responses in Brown Norway rats as indicated by elevations of granulocytes (A), lactate dehydrogenase activity (B), total protein content and albumin (C) in the bronchoalveolar lavage fluid (BAL).

$\mathrm{n}=5$ /group. Each point represents average \pm SEM.

* Significantly different from saline control at $\mathrm{P}<0.05$, t-test. 

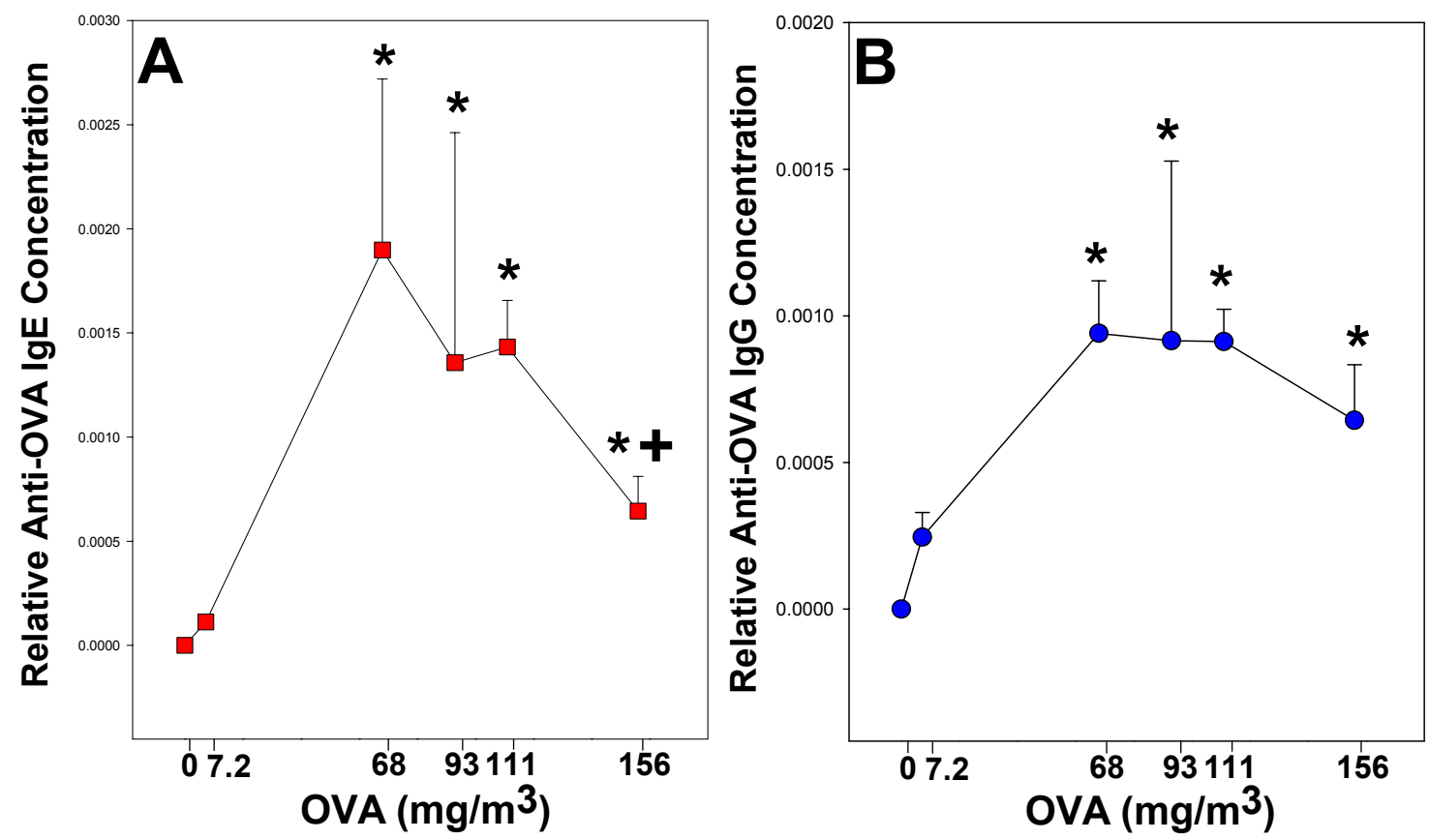

Fig 5. The relative serum anti-OVA $\operatorname{IgE}(\mathrm{A})$ and anti-OVA $\operatorname{IgG}(\mathrm{B})$ concentrations in response to saline, and different doses of OVA-sensitized rats.

$\mathrm{n}=5$ /group. Each point represents average \pm SEM.

* Significantly different from saline control at $\mathrm{P}<0.05, \mathrm{t}$-test.

+ Significantly different from $68 \mathrm{mg} / \mathrm{m}^{3}$ at $\mathrm{P}<0.05$, t-test. 

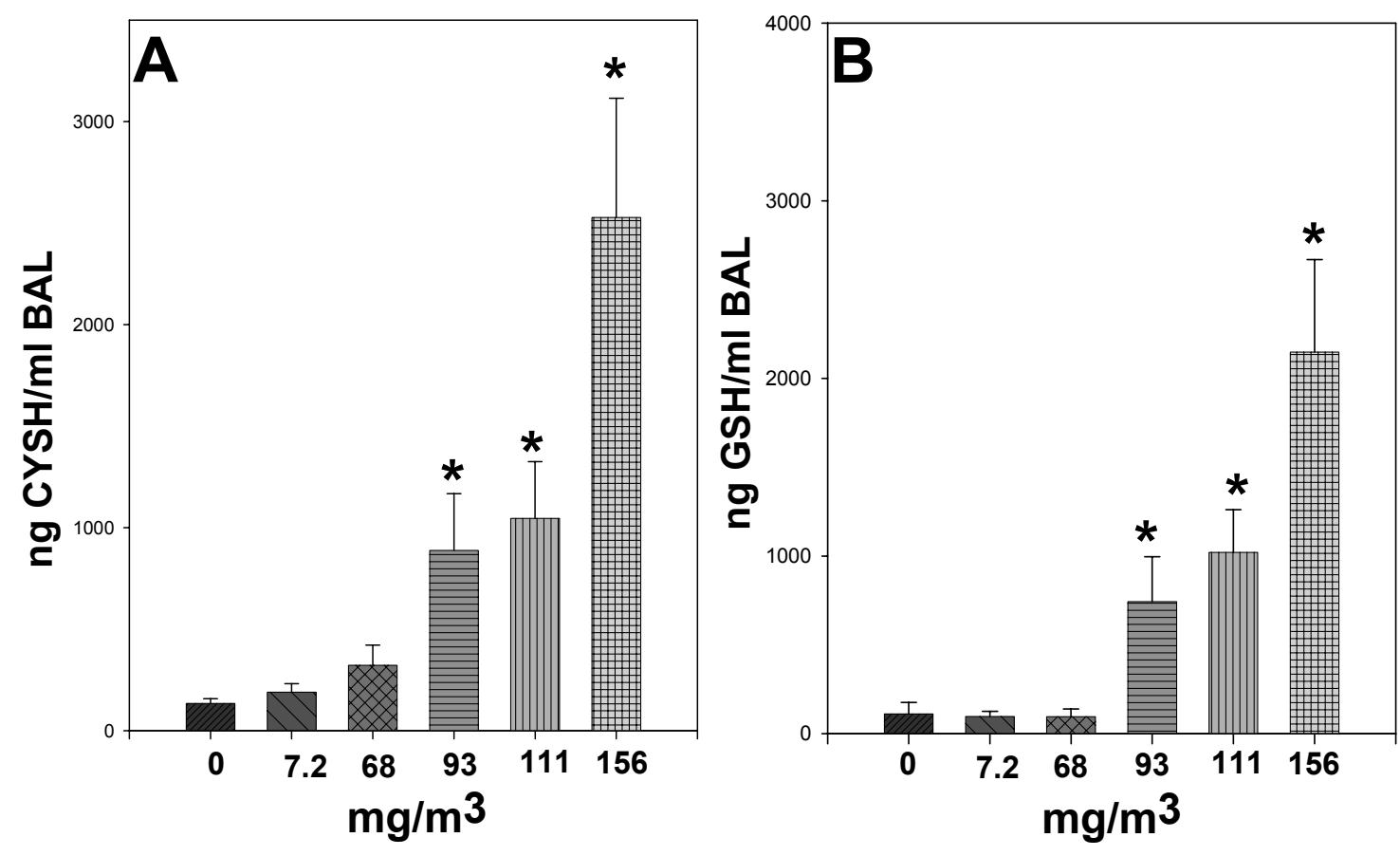

Fig 6. OVA dose dependent effect on Cysteine (A) and GSH (B) levels in rat cell free bronchoalveolar lavage fluid (BAL) at sacrifice.

$\mathrm{n}=5$ /group. Each point represents average \pm SEM.

* Significantly different from saline control at $\mathrm{P}<0.05$, ANOVA. 

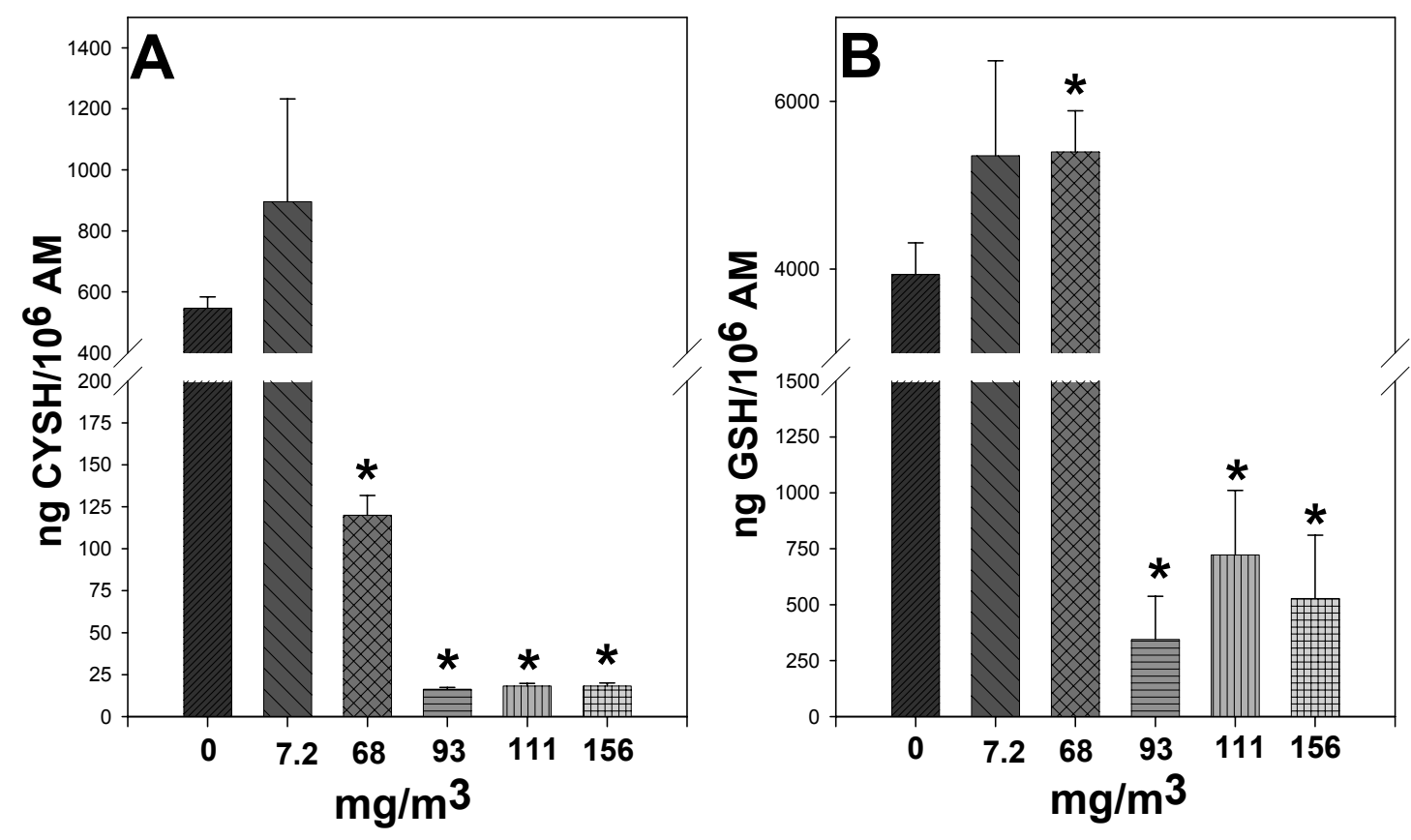

Fig 7. OVA dose dependent effect on intracellular Cysteine (A) and GSH (B) levels in rat AM at sacrifice.

$\mathrm{n}=5$ /group. Each point represents average \pm SEM.

* Significantly different from saline control at $\mathrm{P}<0.05$, ANOVA. 

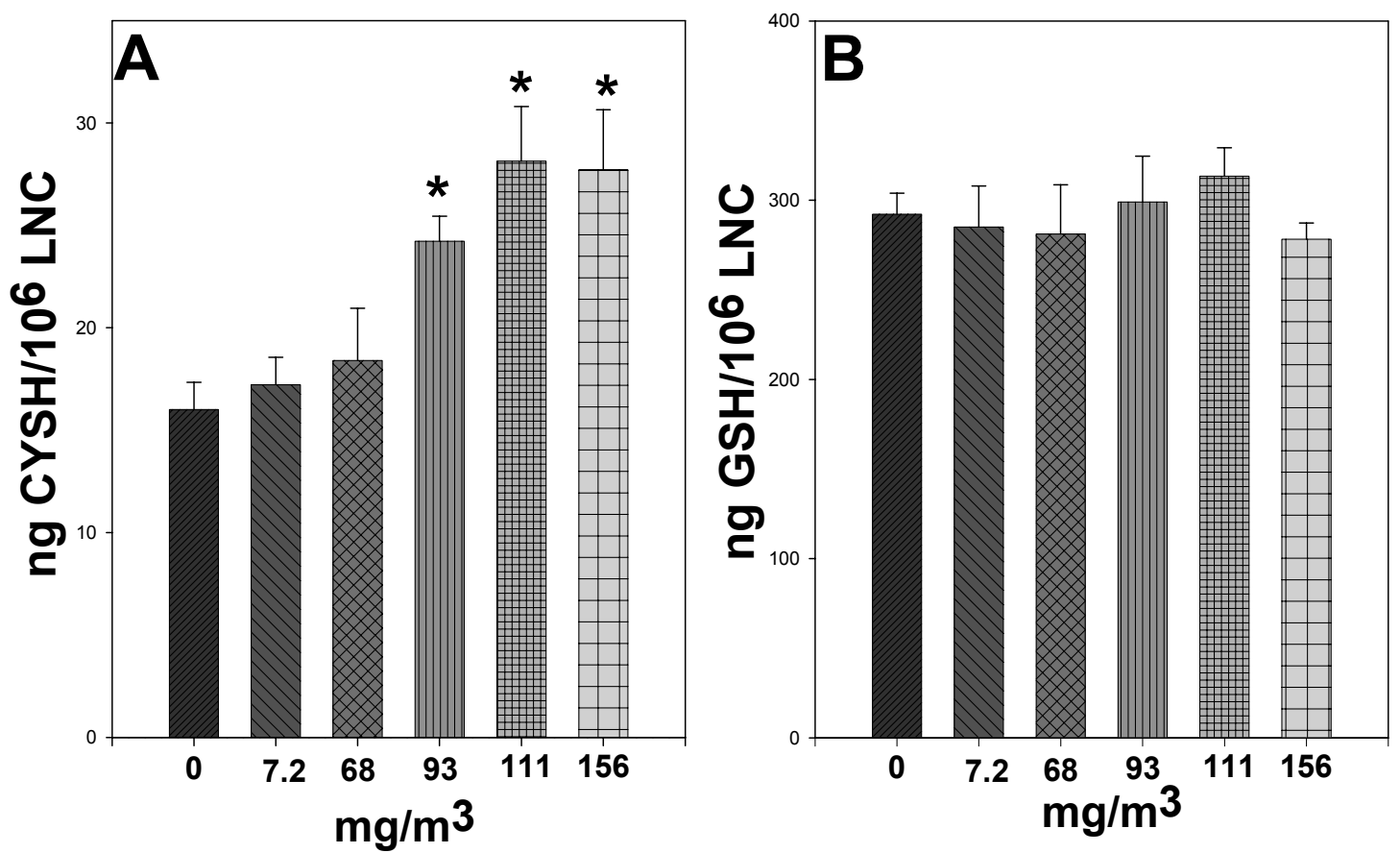

Fig 8. OVA dose dependent effect on intracellular cysteine (A) and GSH (B) levels in rat parathymic and tracheal lymph node lymphocytes at sacrifice.

$\mathrm{n}=5$ /group. Each point represents average \pm SEM.

* Significantly different from saline control at $\mathrm{P}<0.05$, ANOVA. 

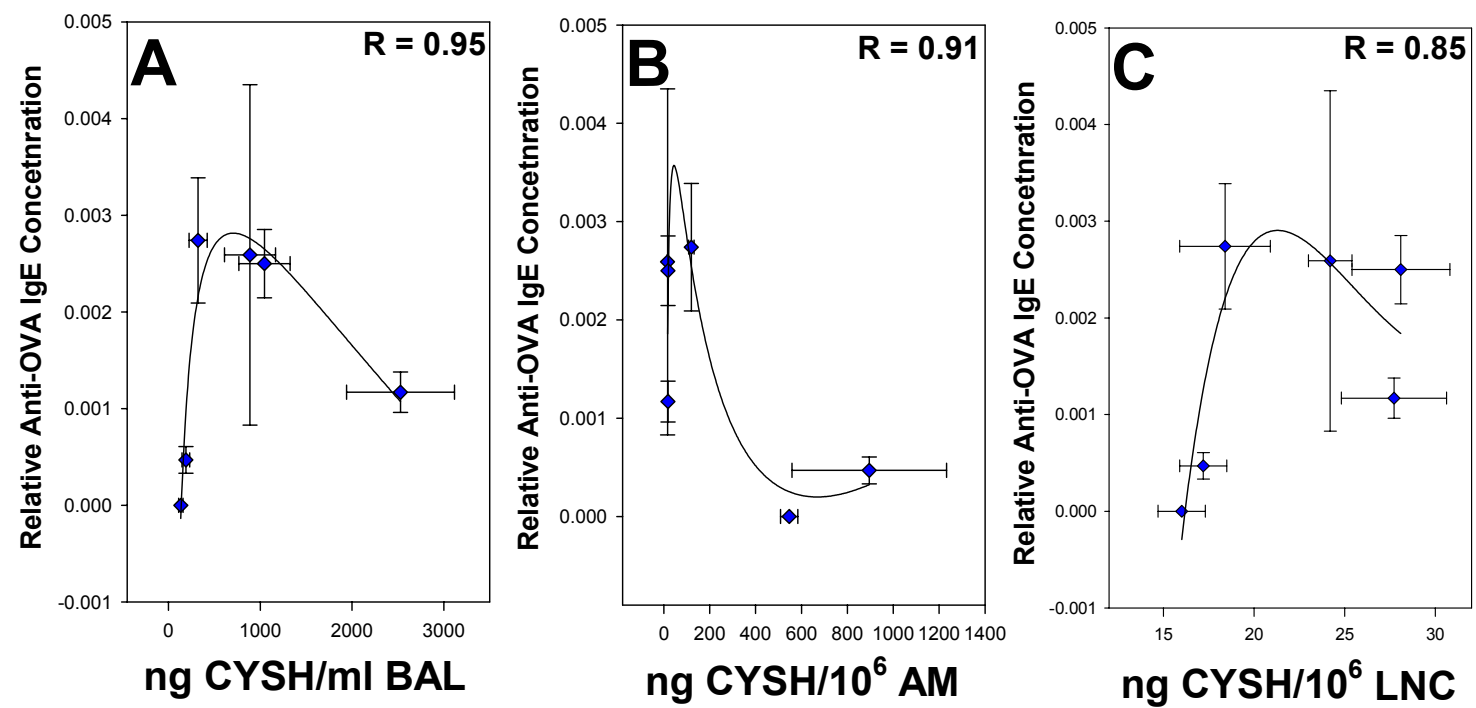

Fig 9. The correlation between CYSH level changes in BAL (A) AM (B), and LNC (C) and antibody (IgE) production. 

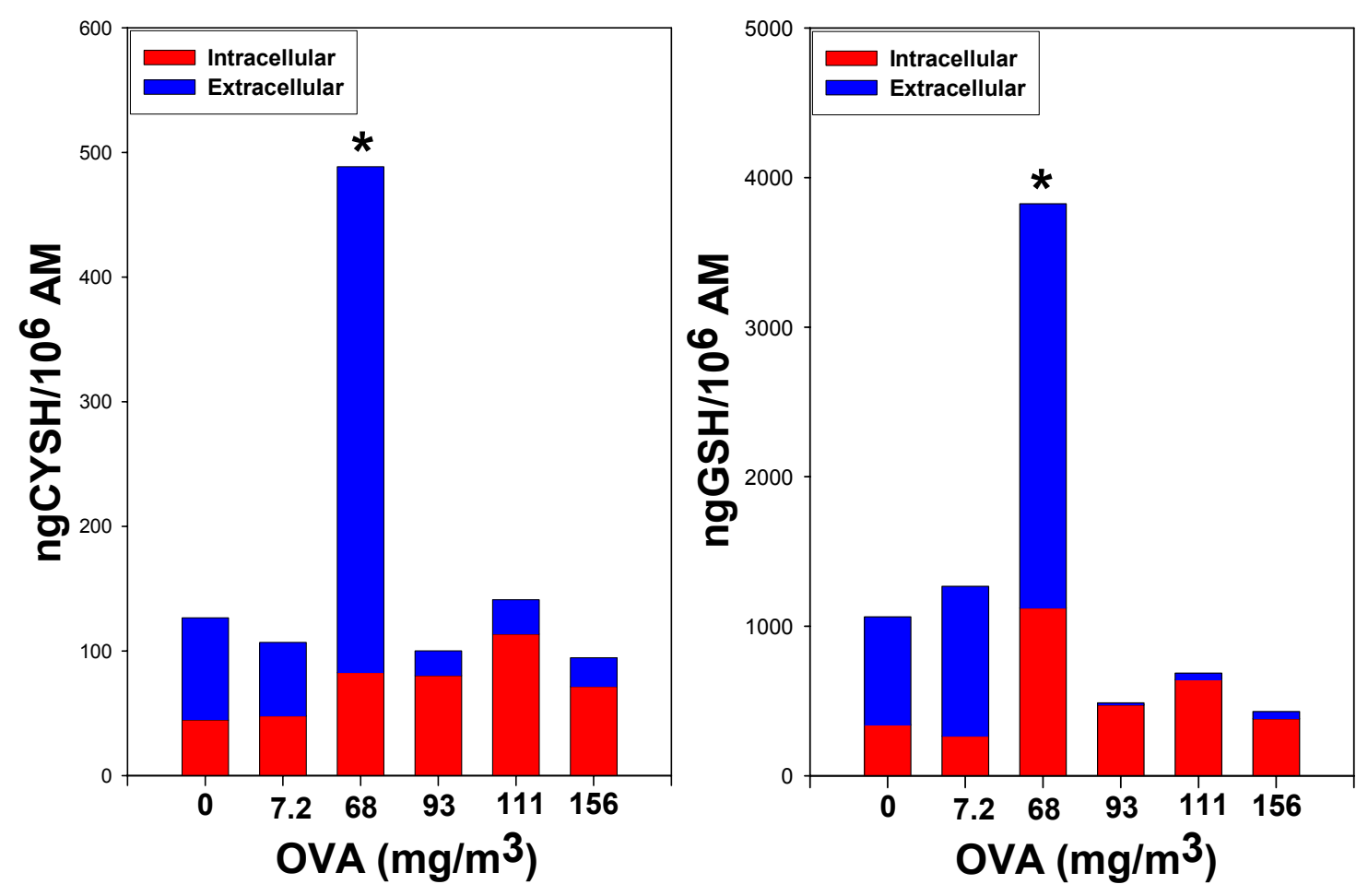

Fig 10. OVA dose dependent effect on the levels of intra- and extra- cellular CYSH (A) and GSH (B) in the alveolar macrophage after 16 hour's ex vivo incubation in thiol free medium. $n=5$ /group. Each point represents average \pm SEM .

* Significantly different from saline control at $\mathrm{P}<0.05$, ANOVA. 

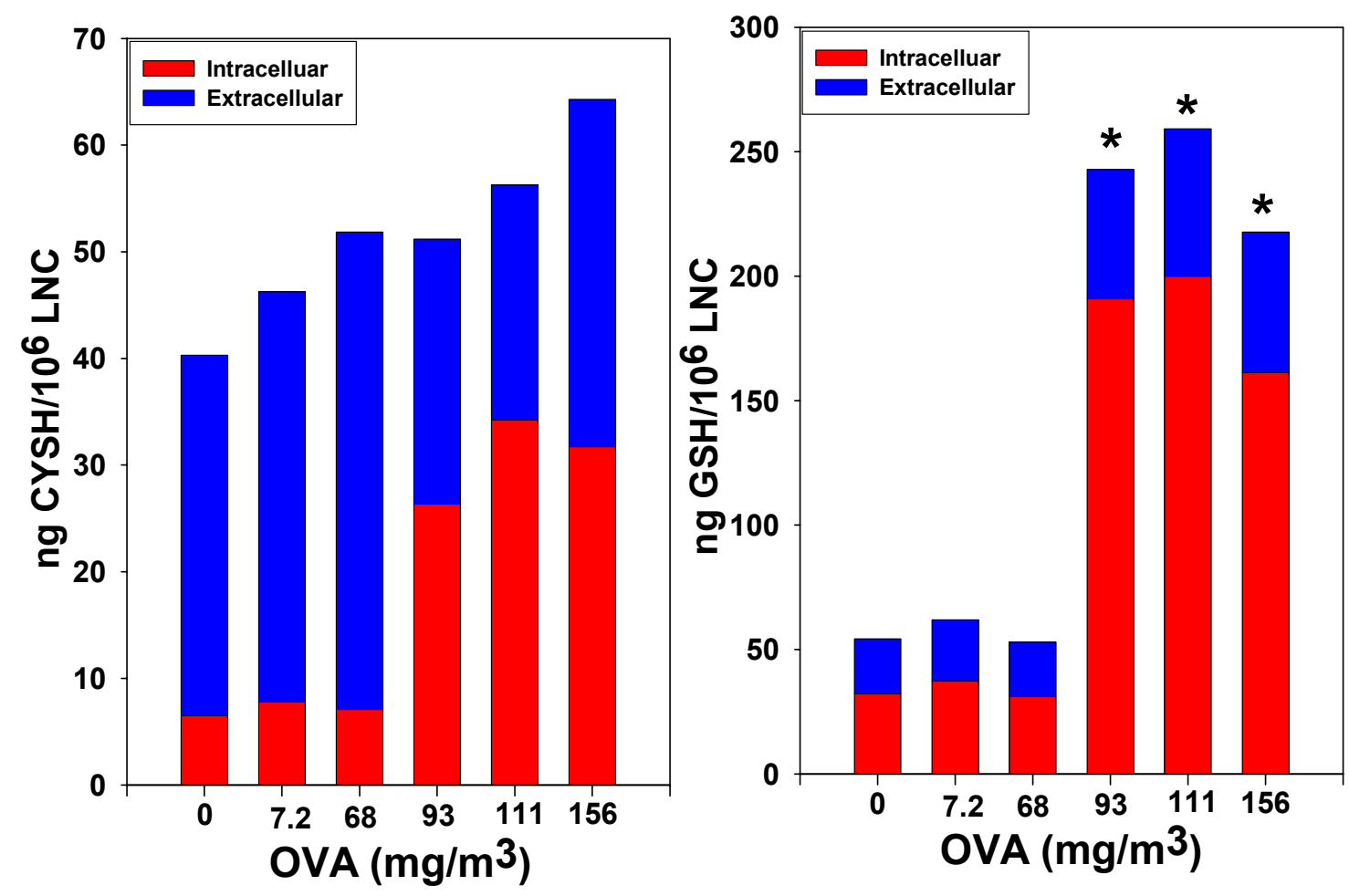

Fig 11. OVA dose dependent effect on the levels of intra- and extra- cellular CYSH (A) and GSH (B) in lymph node cells after 16 hour's ex vivo incubation in thiol free medium.

$\mathrm{n}=5$ /group. Each point represents average \pm SEM.

* Significantly different from saline control at $\mathrm{P}<0.05$, ANOVA. 
(3)

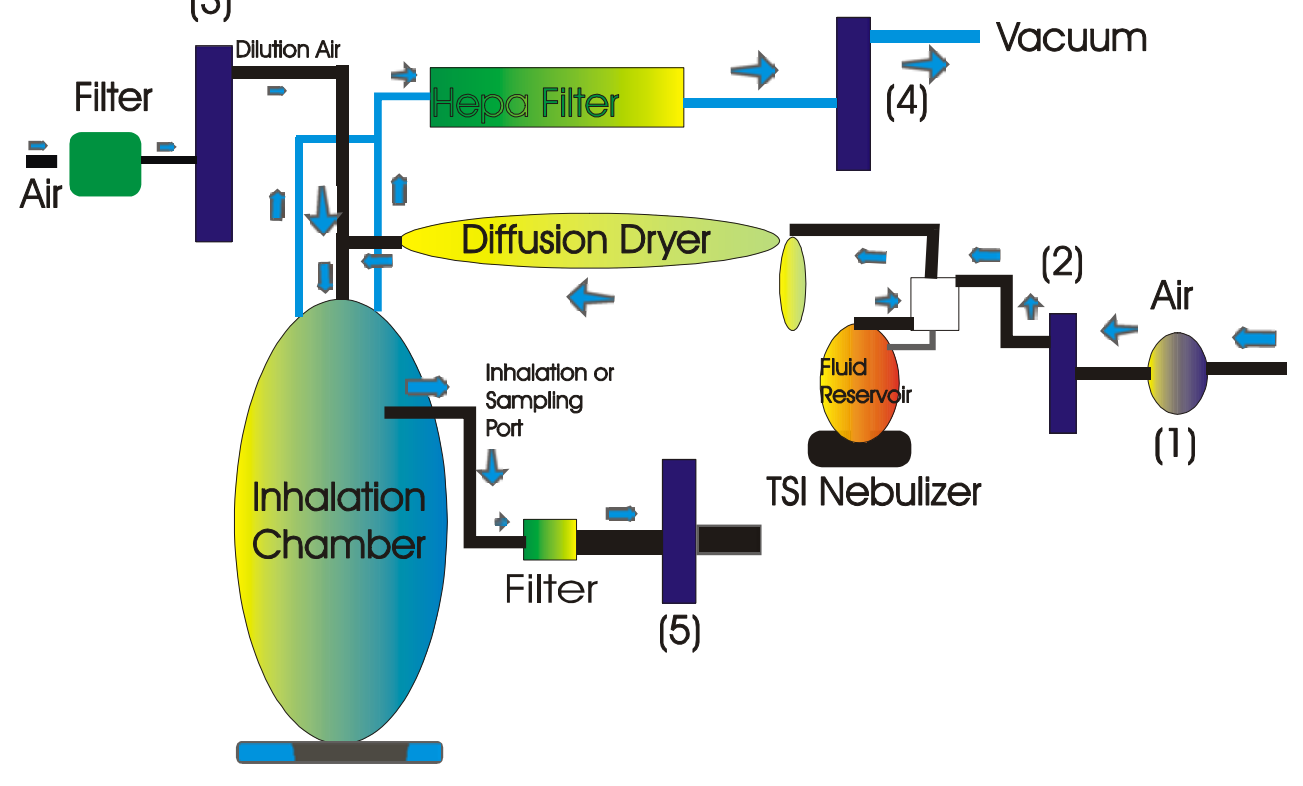

1- Generated Air, 2- In flow air control, 3- Dilution Air Control, 4- Out flow Air control, 5- flow control for air sampling.

Fig 12. Nose only inhalation system for diesel exhaust particles 


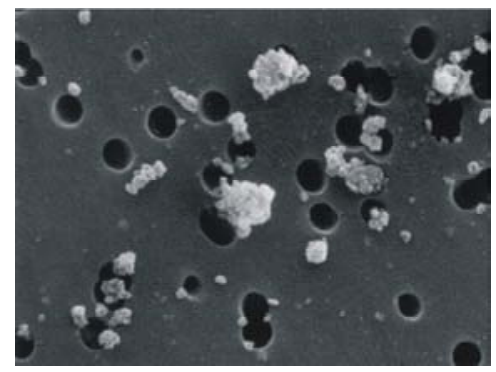

Chamber CB

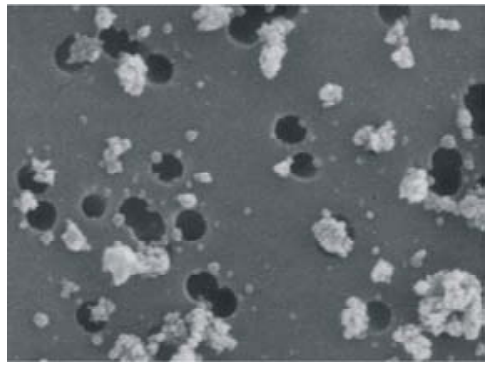

Chamber DEP

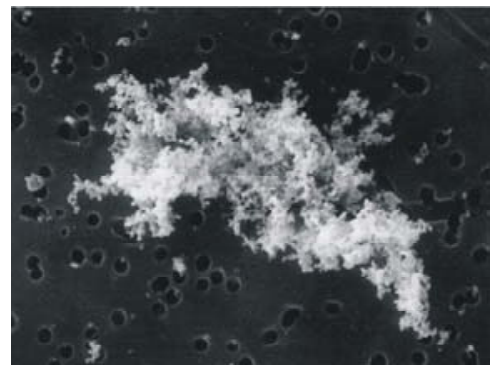

Environmental DEP

Fig 13. Electron micrographs of CB and DEP 


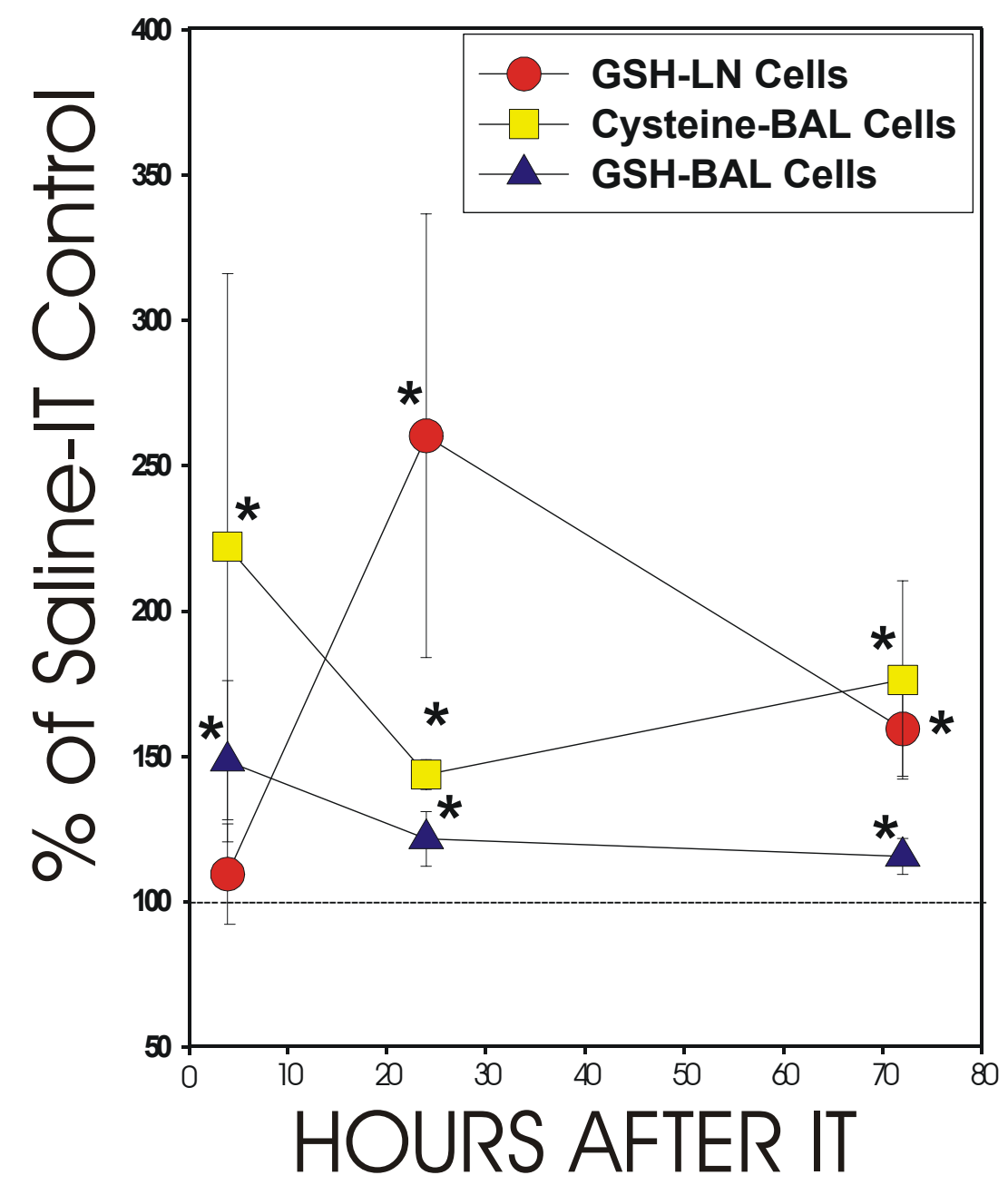

Fig 14. The effect of IT-DEP at 4, 24, 72 hr's on the levels of cysteine and GSH in lymph node and BAL cells

* Significantly different from control $(\mathrm{P}<0.05$, ANOVA) 


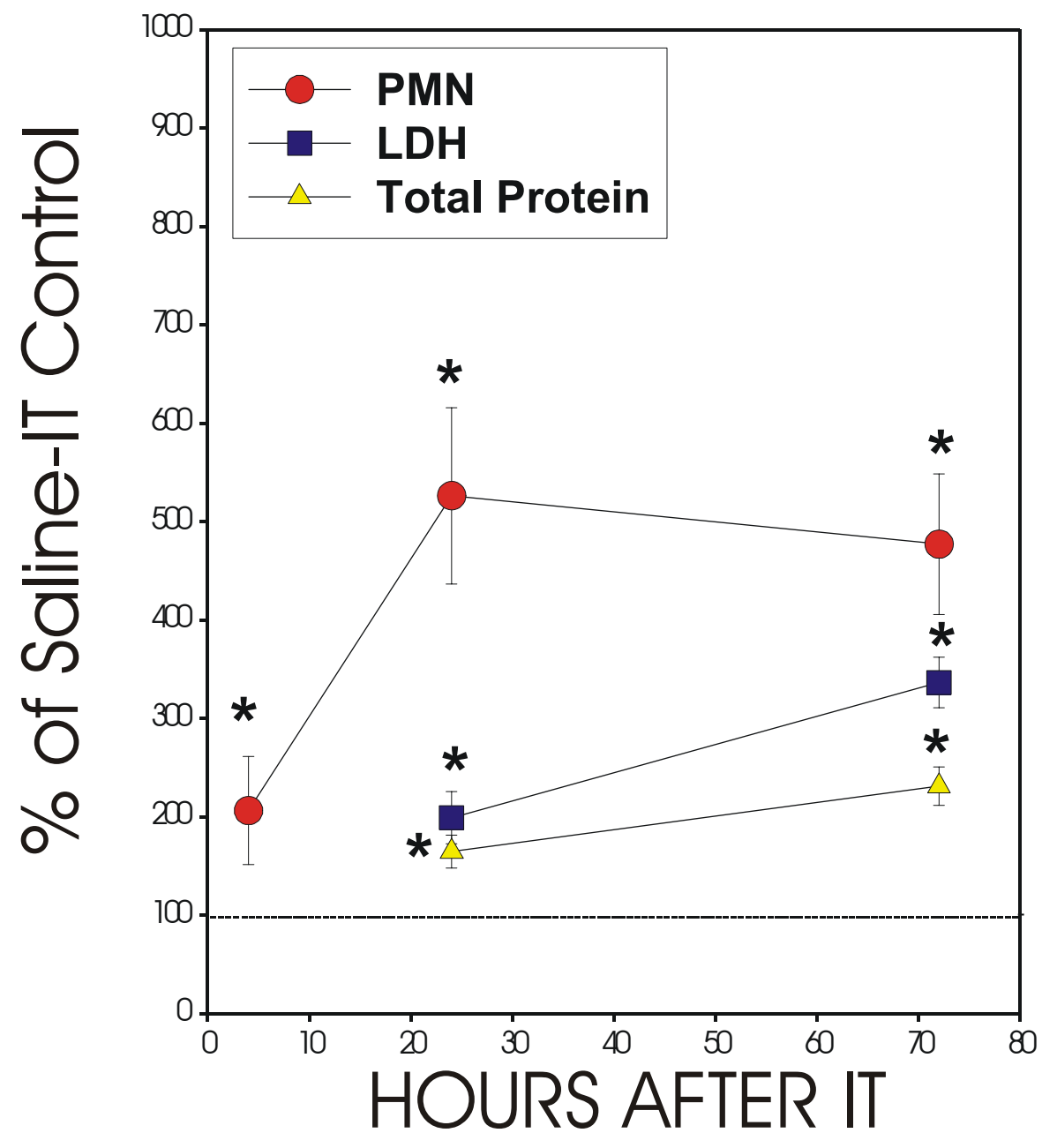

Fig 15. The effect of IT-DEP on PMN, LDH and Total Protein levels in BAL * Significantly different from control (P < 0.05, ANOVA) 

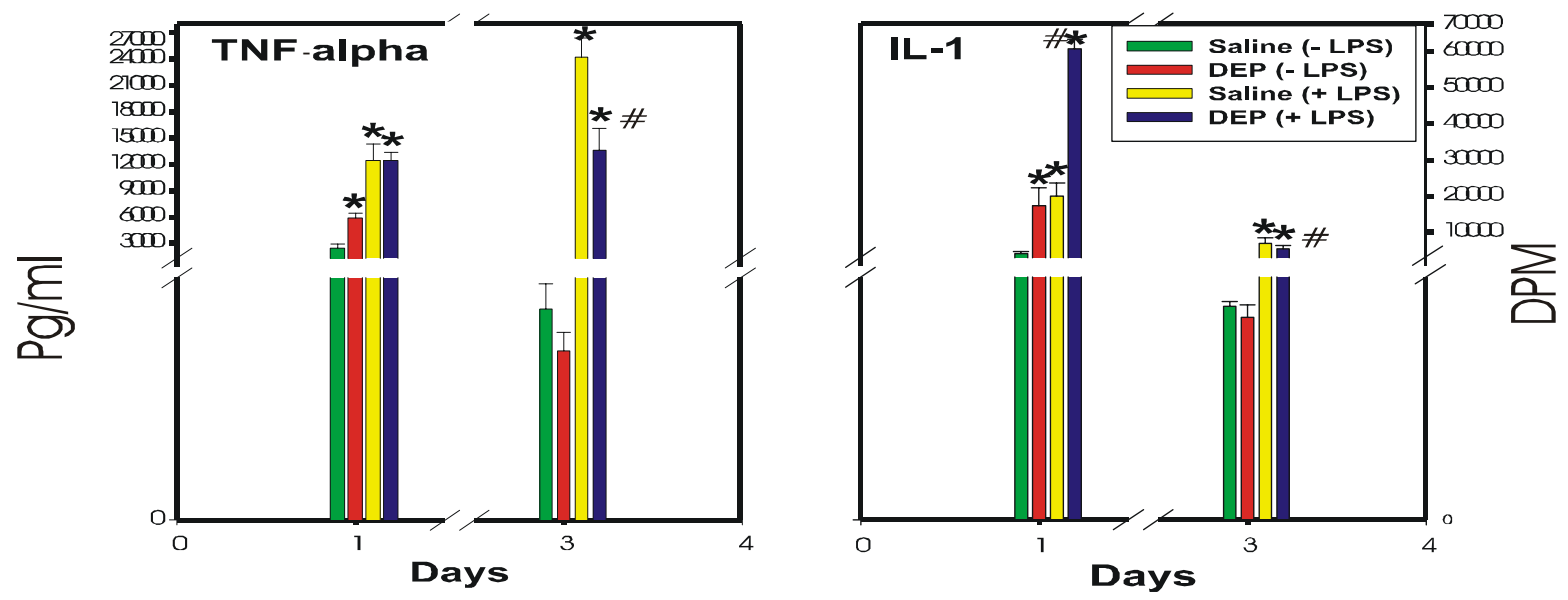

Fig 16. The effect of IT-DEP on the levels of TNF-alpha and IL-1 in AM conditioned medium with and without ex vivo LPS stimulation

* Significantly different from saline control (-LPS) at $\mathrm{P}<0.05$, t-test

\# Significantly different from saline control (+LPS) at $\mathrm{P}<0.05$, t-test 

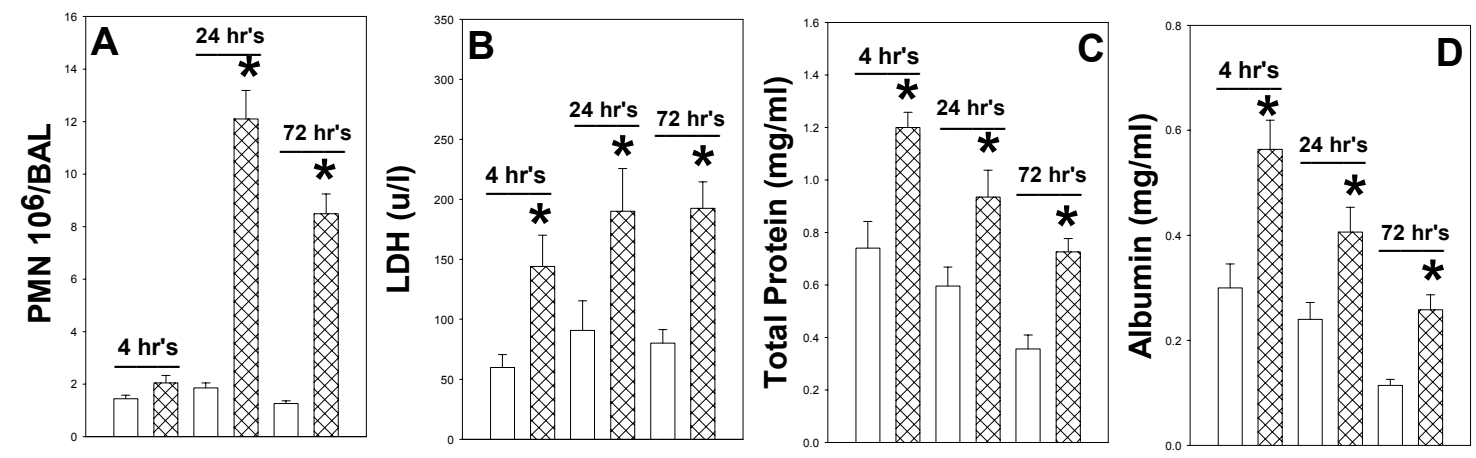

$\square$ Saline Control

$\triangle \times \triangle D$ DEP

Fig 17. The effect of (intratracheally instilled) DEP on neutrophil count (A), lactate dehydrogenase (B), total protein (C), and albumin (D) in BAL of Sprague-Dawley rats. * Significantly different from saline control at $\mathrm{P}<0.05$, t-test. 


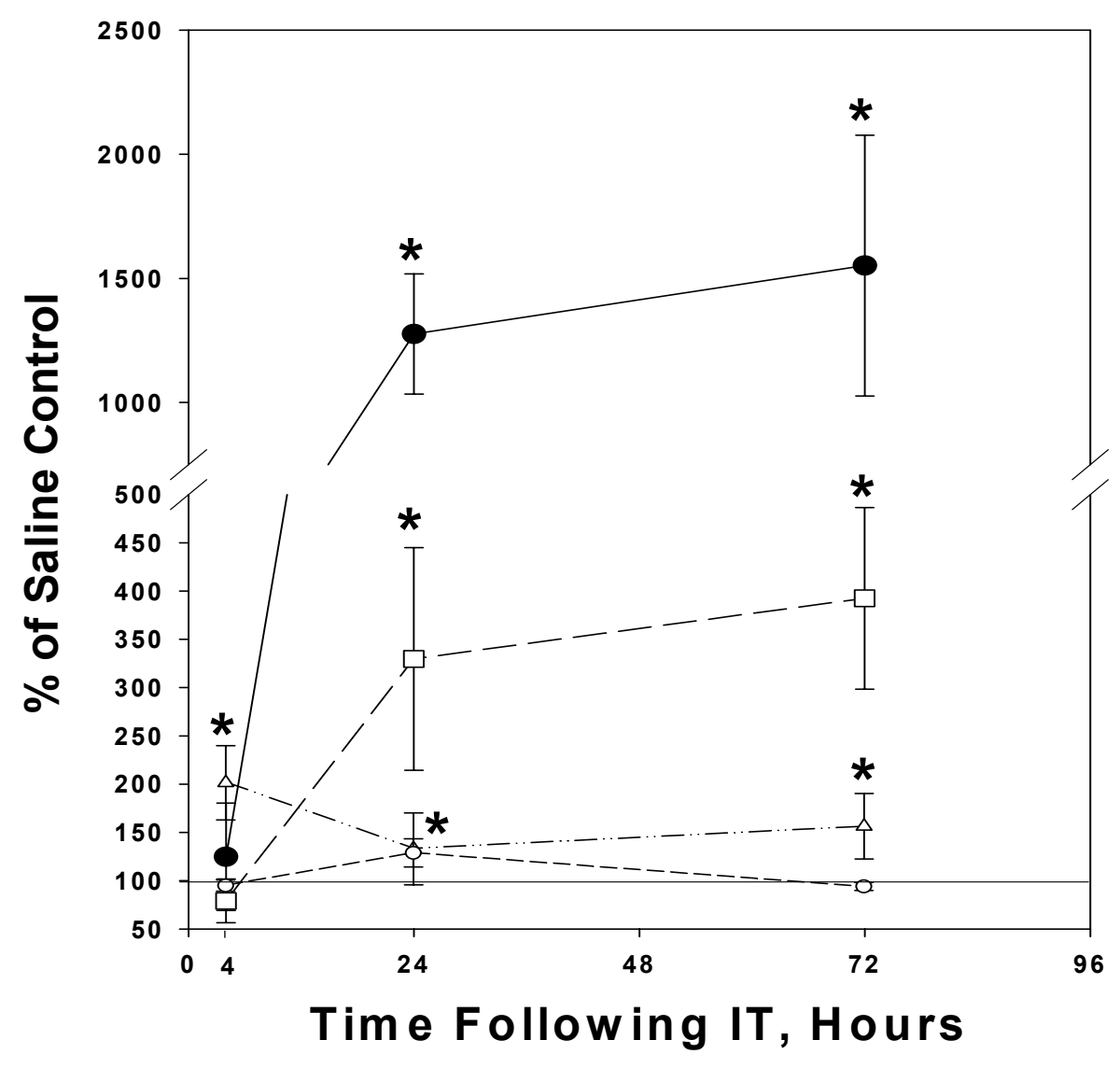

Fig 18. The effect of (intratracheally instilled) DEP on the levels of AM-cysteine ( ) and GSH $(\square)$ and LNC-cysteine ( $\triangle$ ) and GSH ( $O$ ) at 4, 24, and 72 hours post exposure in SpragueDawley rats. Average \% Control SE for the three time points $=7.16,10.4$, and 14.5 for AMGSH, AM-CYSH, and LNC-GSH, respectively.

* Significantly different from saline control at $\mathrm{P}<0.05$, ANOVA. 

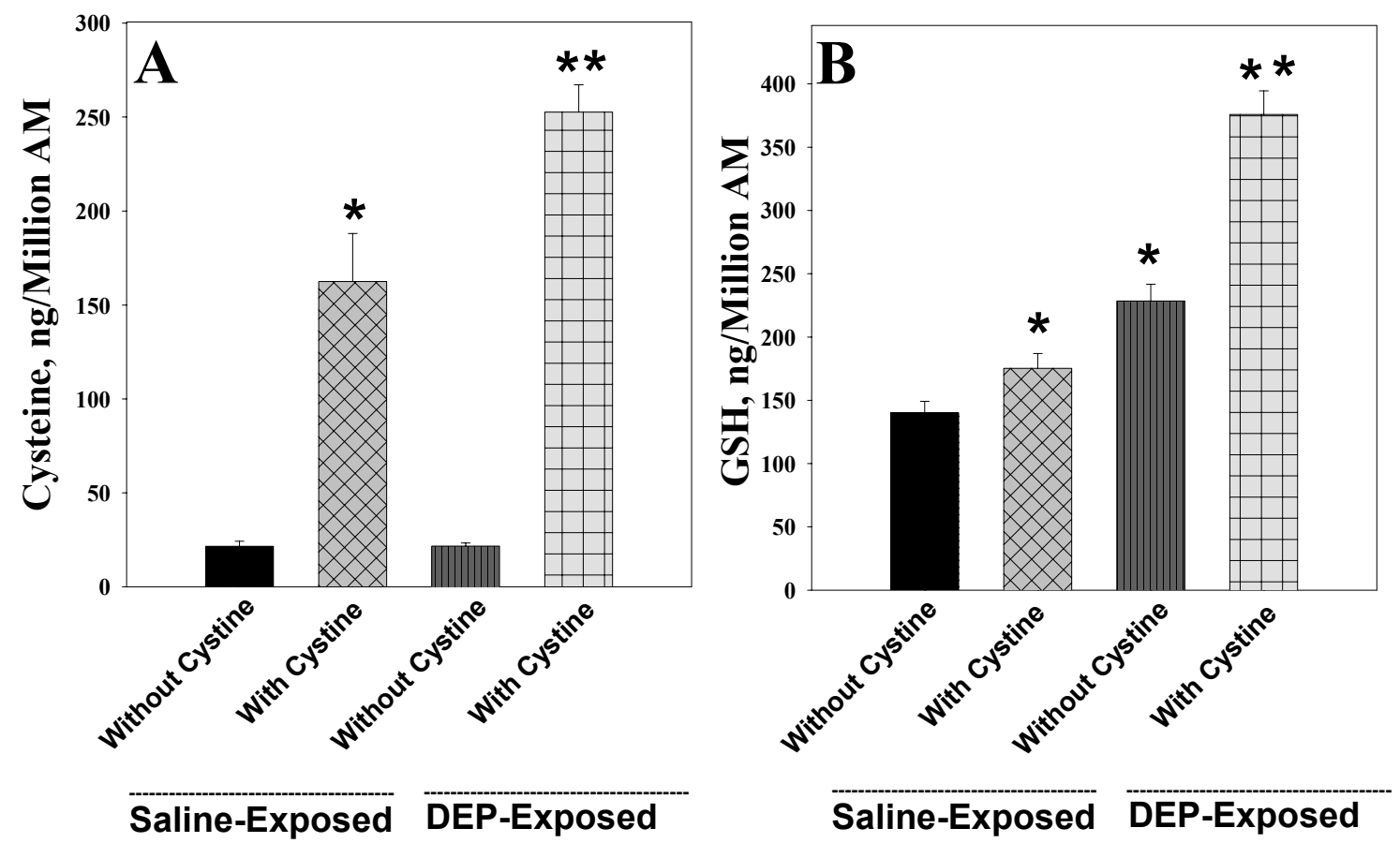

Fig 19. Intracellular Cysteine (A) and GSH (B) levels in alveolar macrophages of SpragueDawley rats after in vivo IT-DEP and 16 hours ex vivo incubation with or without cystine treatment.

* Significantly different from saline control at $\mathrm{P}<0.05$, ANOVA.

** Significantly different from DEP at $\mathrm{P}<0.05$, ANOVA. 

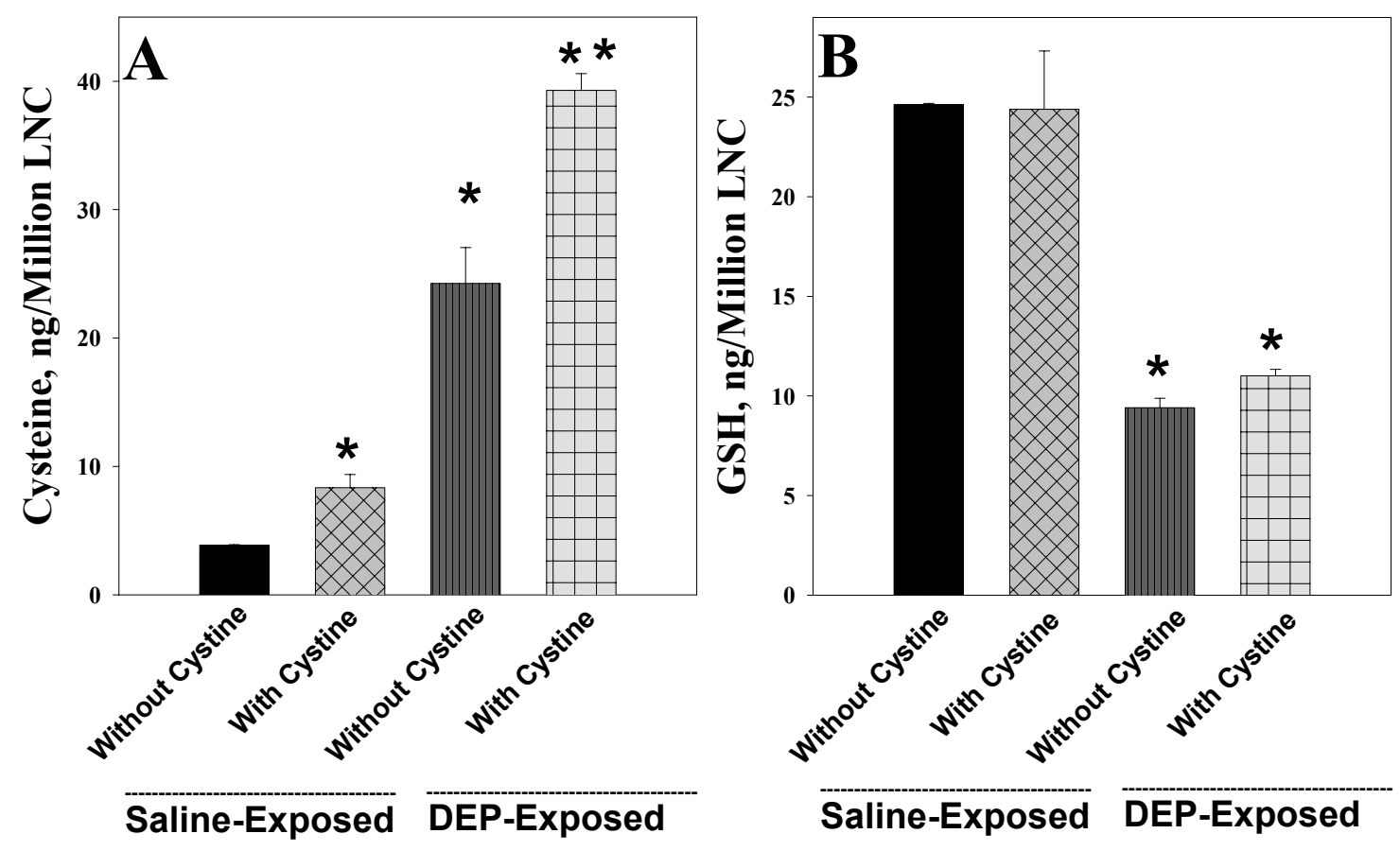

Fig 20. Intracellular Cysteine (A) and GSH (B) level in para-thymic and tracheal lymph node cells of Sprague-Dawley rats after in vivo IT-DEP and 16 hours ex vivo incubation with or without cystine treatment.

* Significantly different from saline control at $\mathrm{P}<0.05$, ANOVA.

** Significantly different from DEP at $\mathrm{P}<0.05$, ANOVA. 


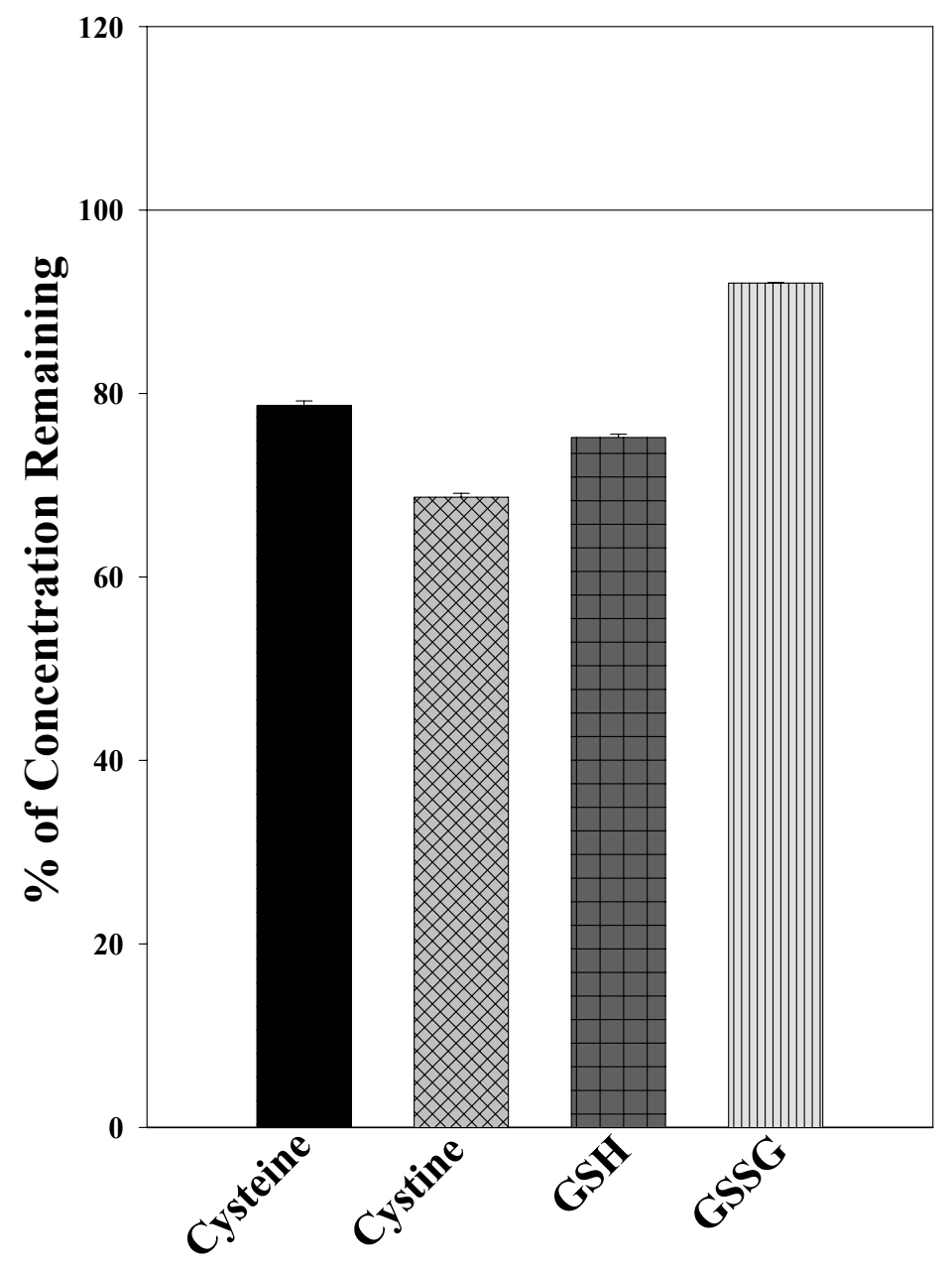

Fig 21. Percent absorption of Cysteine, Cystine, GSH, and GSSG in acellular culture media (no cells added) after 4 hours incubation with (50ug/ml) DEP. 

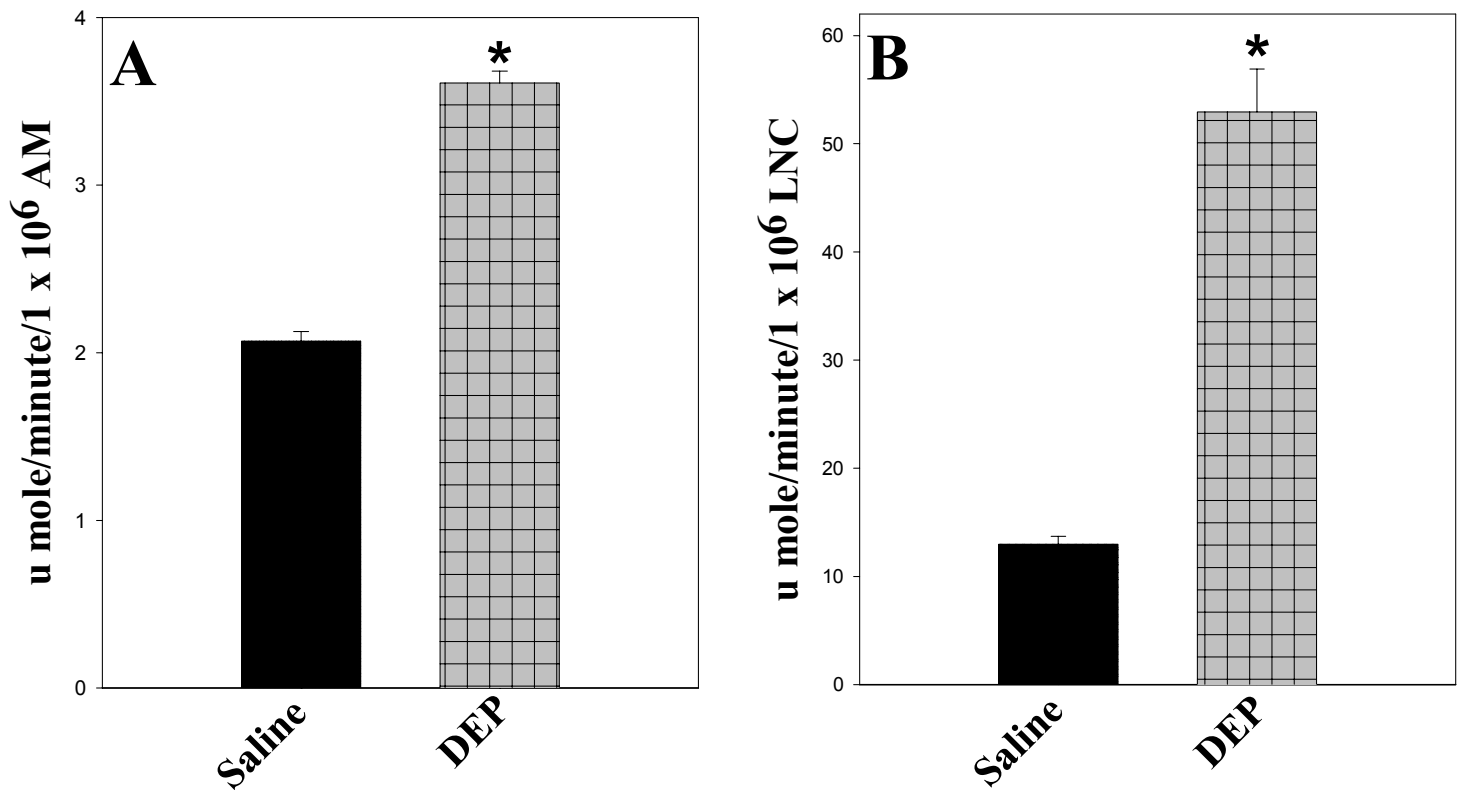

Fig 22. The effect of DEP (3 days after intratracheal instillation) on glutathione reductase activity in alveolar macrophage (A) and para-thymic and tracheal lymph node (B) cells of Sprague-Dawley rats.

* Significantly different from saline control at $\mathrm{P}<0.05$, ANOVA. 

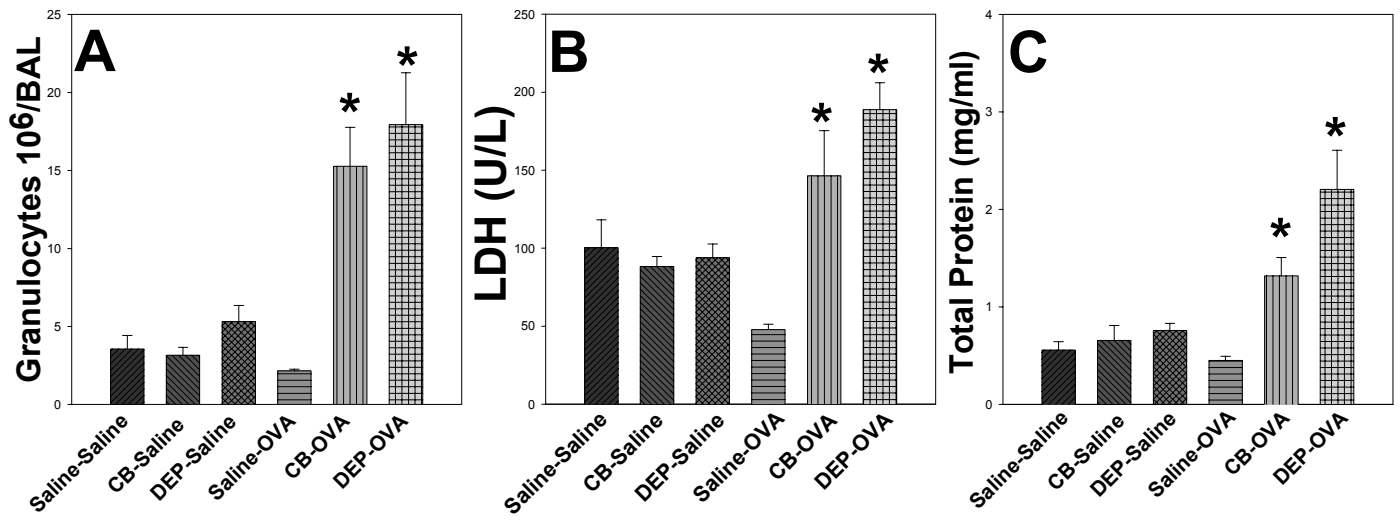

Fig 23. The effect of combined exposure to DEP or CB and OVA on the pulmonary inflammatory responses in Brown Norway rats as indicated by elevations of PMN (A) lactate dehydrogenase (B) activity and total protein (C) content in the bronchoalveolar lavage fluid (BAL).

$\mathrm{n}=5$ /group. Each point represents average \pm SEM.

* Significantly different from saline-saline and saline-OVA controls at $\mathrm{P}<0.05$, ANOVA. 

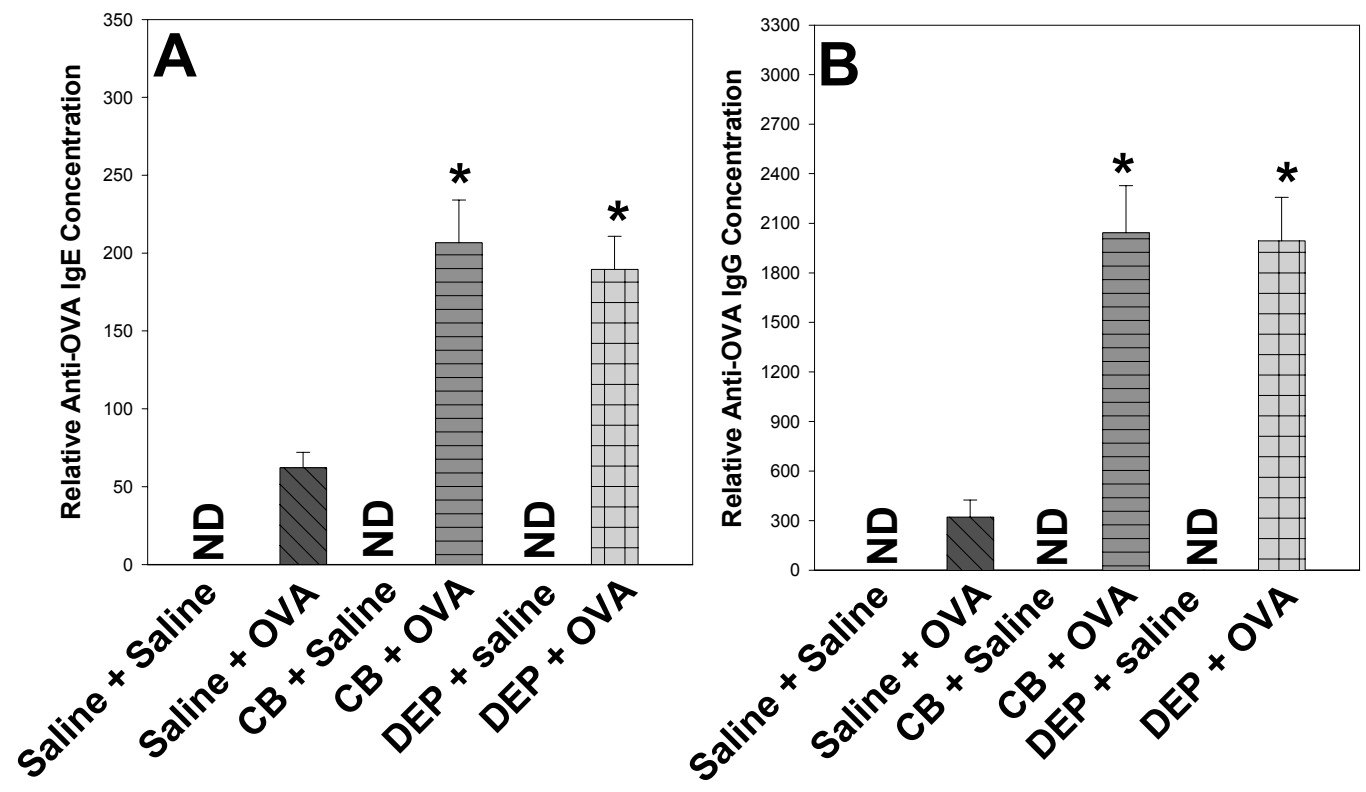

Fig 24. The relative serum anti-OVA IgE (A) and anti-OVA IgG (B) concentration following saline, DEP, or CB exposure in non-sensitized (exposed to saline) and OVA-sensitized rats. $\mathrm{n}=5$ /group. Each point represents average \pm SEM. ND is "not detected". The reported values are relative to a pooled reference standard as noted in materials and methods.

* Significantly different from saline-OVA control at $\mathrm{P}<0.05$, ANOVA. 

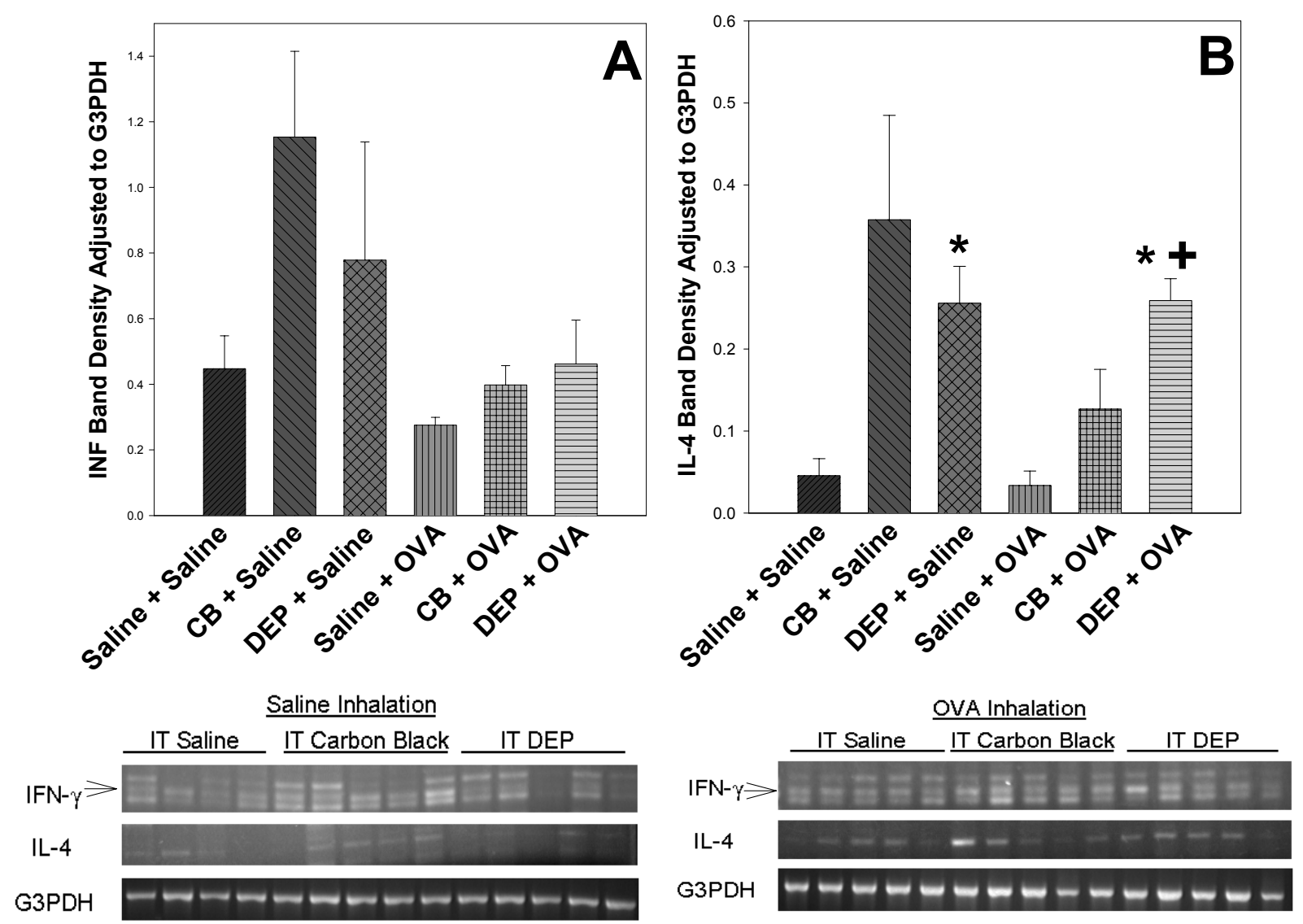

Fig 25. Effect of DEP or CB with or without OVA exposure on $m$ RNA expression for IFN- $\gamma$ (A) and IL-4 (B) in lung tissue. $n=5$ /group. Each point represents average \pm SEM. Note: Agaros gel pictures have been included to show the variation between the individual animals.

* Significantly different from IL-4 value for saline-saline control at $\mathrm{P}<0.05$, ANOVA.

+ Significantly different from IL-4 value for saline-OVA at $\mathrm{P}<0.05$, ANOVA. 

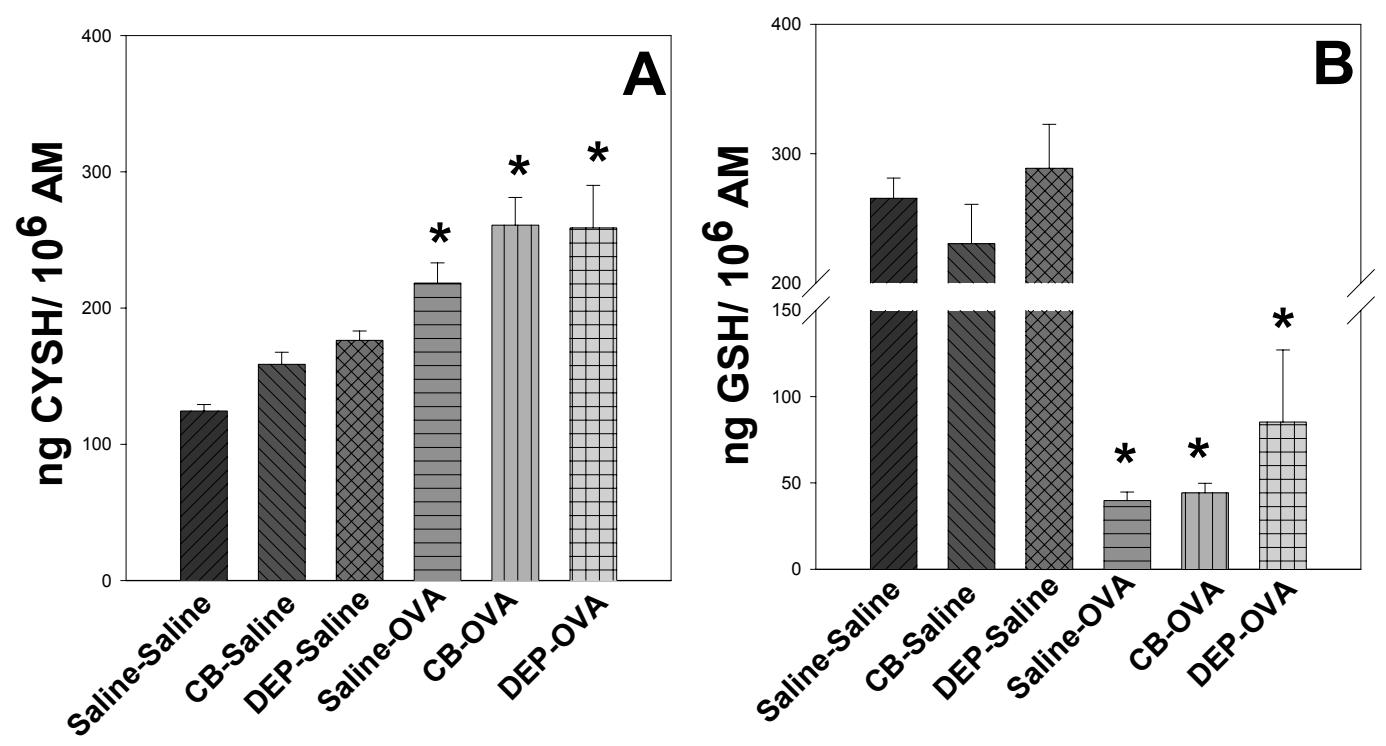

Fig 26. Measurement of intracellular cysteine (A) and GSH (B) levels in AM harvested from rats exposed to saline, CB, DEP, OVA, or both particles (CB or DEP) and OVA, after ex vivo incubation for $16 \mathrm{hr}$.

$\mathrm{n}=5$ /group. Each point represents average \pm SEM.

* Significantly different from saline-saline control at $\mathrm{P}<0.05$, ANOVA. 

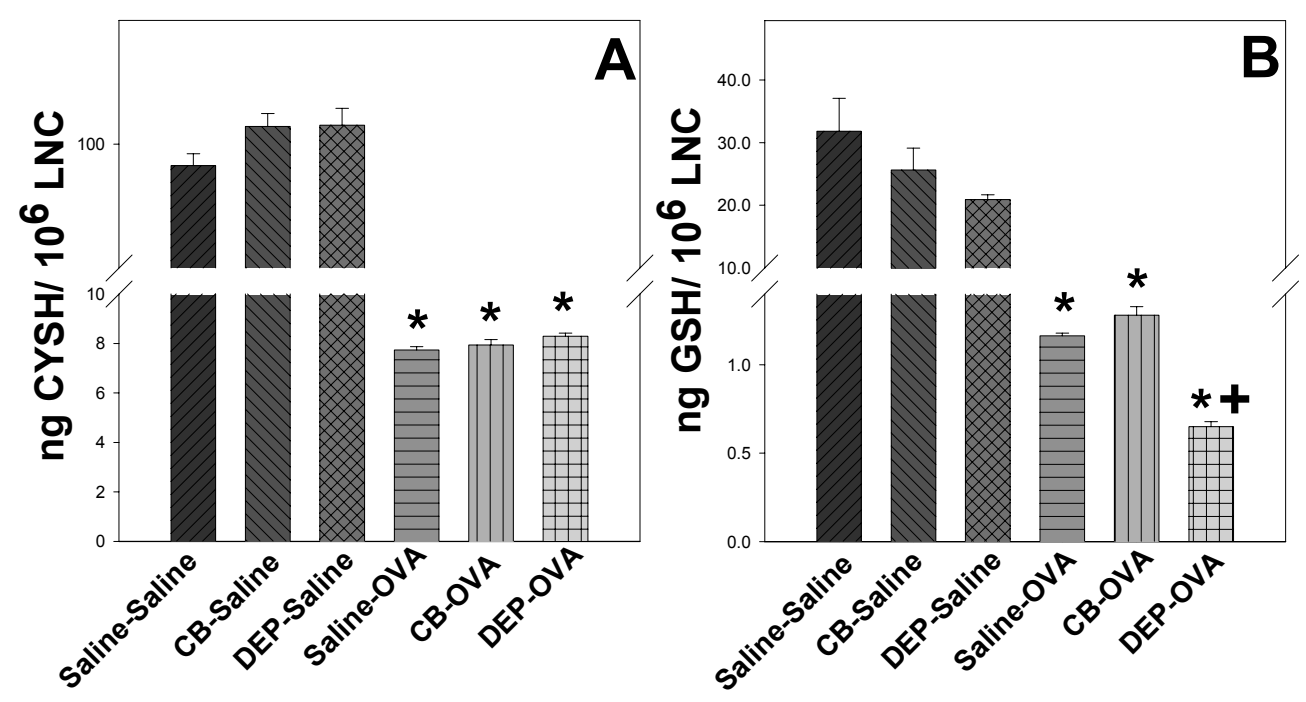

Fig 27. Measurement of intracellular cysteine (A) and GSH (B) levels in para-thymic and tracheal lymph node lymphocytes harvested from rats exposed to saline, $\mathrm{CB}, \mathrm{DEP}, \mathrm{OVA}$, or both particles (CB or DEP) and OVA, after isolation with ficoll-hypaque and ex vivo incubation for 16 hr. $\mathrm{n}=5$ /group. Each point represents average \pm SEM.

* Significantly different from saline-saline control at $\mathrm{P}<0.05$, ANOVA.

+ Significantly different from saline-OVA at $\mathrm{P}<0.05$, ANOVA. 

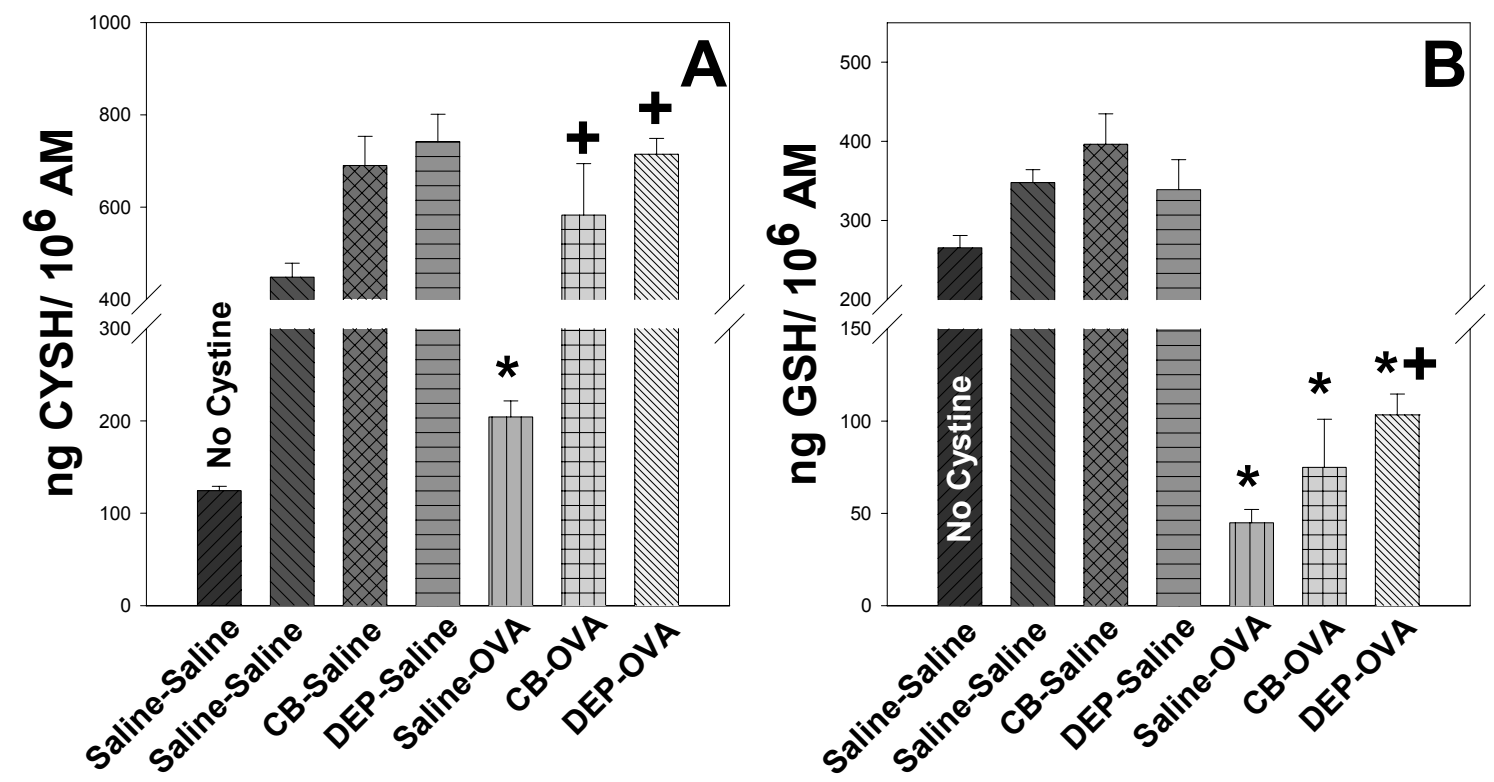

Fig 28. Measurement of intracellular cysteine (A) and GSH (B) levels in AM harvested from rats exposed to saline, $\mathrm{CB}$, DEP, OVA, or both particles (CB or DEP) and OVA, after ex vivo incubation with $24 \mu \mathrm{g} / \mathrm{ml}$ cystine for $16 \mathrm{hr}$.

$\mathrm{n}=5$ /group. Each point represents average \pm SEM.

* Significantly different from saline-saline w/cystine control at $\mathrm{P}<0.05$, ANOVA.

+ Significantly different from saline-OVA w/cystine control at $\mathrm{P}<0.05$, ANOVA. 

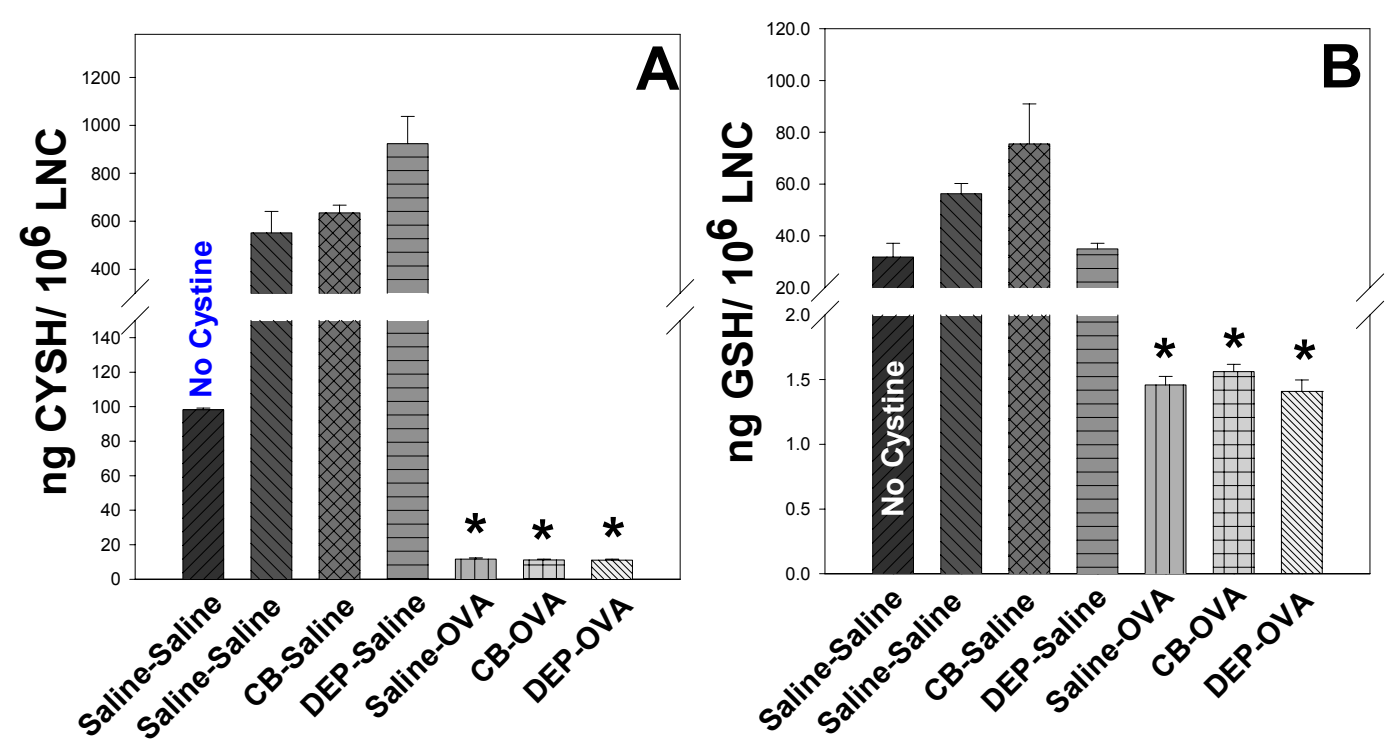

Fig 29. Measurement of intracellular cysteine (A) and GSH (B) levels in para-thymic and tracheal lymph node lymphocytes harvested from rats exposed to saline, $\mathrm{CB}$, DEP, OVA, or both particles (CB or DEP) and OVA, after isolation with ficoll-hypaque and ex vivo incubation with $24 \mu \mathrm{g} / \mathrm{ml}$ cystine for $16 \mathrm{hr}$.

$\mathrm{n}=5$ /group. Each point represents average \pm SEM.

* Significantly different from saline-saline w/cystine control at $\mathrm{P}<0.05$, ANOVA. 


\section{REFERENCES}

1. Al-Humadi NH, Siegel PD, Lewis DM, Barger MW., Ma JYC, Weissman DN, and Ma JKH (2002-1). Alteration of Intracellular Cysteine and Glutathione Levels in Alveolar Macrophages and Lymphocytes by Diesel Exhaust Particle Exposure. Environ. Health Perspect. 110: 349-353.

2. Al-Humadi NH, Seigel PD, Lewis DM, Barger MW, Ma JYC, Weissman DN, and Ma JKH (2002-2). The Effect of Diesel Exhaust Particles (DEP) and Carbon Black (CB) on Thiol Changes in Pulmonary Ovalbumin Allergic Sensitized Brown Norway Rats. Experimental Lung Research, 28: 333-349.

3. American Thoracic society Workshop (1999). Immunobiology of asthma and rhinitis. Am. J. Crit. Care Med. 160: 1778-1787.

4. Andersson P (1980). Antigen-induced bronchial anaphylaxis in actively sensitized guinea pigs. Allergy 35: 61-71.

5. Bai Y, Suzuki AK, and Sagai M (2000). The cytotoxic effects of diesel exhaust particles on human pulmonary artery endothelial cells in vitro: role of active oxygen species. Free Radical Biology \& Medicine 30: 555-562.

6. Bayer E, and Wilchek M (1978). The avidin-biotin complex as a tool in molecular biology. Trends Biochem Sci 3: 257-259.

7. Boland S, Baeza-Squiban A, Fournier T, Houcine O, Gendron MC, Chevrier M, Jouvenot G, Coste A, Subier M, and Marano F, (1999). Diesel exhaust particles are taken up by human airway epithelial cells in vitro and alter cytokine production. Am. J. Physiol. 276: L604-L613. 
8. Brain JD, and Valberg PA (1979). Deposition of aerosol in the respiratory tract. Am Rev Respir Dis 120: 1325-1373.

9. Cammer P, Perschagen G, Ahlborg U, Ljungvist S, and Victorin K (1988). Health effects of diesel exhaust emissions. Stockholm, Nordic Council of Ministers.

10. Cass GR, and Gray HA (1995). Regional Emissions and Atmospheric Concentrations of Diesel Engine Particulate Matter: Los Angeles as a Case Study. In: Diesel Exhaust: A Critical Analysis of Emissions, Exposure, and Health Effects. Cambridge, MA: Health Effects Institute, pp. 125-137.

11. Chow JC (1995). Measurement methods to determine compliance with ambient air quality standards for suspended particles. J Air Waste Manag Assoc 45: 320-382.

12. Constant SL and Bottomly K (1997). Induction of Th1 and Th2 CD+4 T cell responses: The alternative approaches. Annu. Rev. Immunol. 15: 297-322.

13. Diaz-Sanchez D, Dotson AR, Takenaka H, Saxon A (1994). Diesel exhaust particles induce local IgE production in vivo and alter the pattern of $\operatorname{IgE}$ messenger RNA isoforms. J. Clin. Invest. 94; 1417.

14. Diaz-Sanchez D, Tsien A, Casillas A, Dotson AR, and Saxon A (1995). Enhanced nasal cytokine production in human beings after in vivo challenge with diesel exhaust particles. J. Allergy Clin. Immunol. 98: 114-123.

15. Diaz-Sanchez D, Tsien A, Fleming J, and Saxon A (1997). Combined diesel exhaust particulate and ragweed allergen challenge markedly enhances human in vivo nasal ragweedspecific IgE and skew cytokine production to a T helper cell 2-Type pattern. J. Immunol. 158: 2406-2413. 
16. Dolphin D, Avramovic O and Poulson R (1989). Glutathione: Chemical, Biochemical, and Medical Aspects. Coenzymes and Cofactors. Vols. 3A: 476-517 and 3B: 45-85. John Wiley. New York.

17. Driscoll KE, Lindenschmidt RC, Maurer JK, Higgins JM, Ridder G (1990). Pulmonary response to silica or titanium dioxide: Inflammatory cells, alveolar macrophage-derived cytokines, and histopathology. Am J Respir Cell Mol Biol 2: 381-390.

18. Droge W, Schulze-Osthoff K, Mihm S, Galter D, Schenk H, Eck H, Roth S, and Gmunder H (1994). Functions of glutathione and glutathione disulfide in immunology and immunopathology. FASEB J. 8: 1131-1138.

19. Eggleston PA, Buckley TJ, Breysse P, Wills-Harp M, and Kleeberger Jaakkola JJK (1999). The environment and asthma in U.S. inner cities. Environ. Health Perspect. 107:Suppl 3: 439450.

20. Engvall E, and Perlmann P (1971). Enzyme-linked immunosorbent assay (ELISA). Quantitative assay of immunoglobulin G. Immunochemistry 8: 871-874.

21. Fahy O, Hammad H, Senechal S, Pestel J, Tonnel A, Wallaert B, Tsicopoulos A (2000). Synergistic effect of diesel organic extracts and allergen Der $\mathrm{p} 1$ on the release of chemokines by peripheral blood mononuclear cells from allergic subjects. Am J Respir Cell Mol Biol 23: 247254.

22. Fanger MV, Hart DA, Wells JV, and Nisonoff A (1970). Enhancement by reducing agents of the transformation of human and rabbit peripheral lymphocytes. J. Immunol. 105; 1043-1045. 
23. Fujieda S, Diaz-Sanchez D, Saxon A (1998). Combined nasal challenge with diesel exhaust particles and allergen induces in vivo IgE isotype switching. Am J Respir Cell Mol Biol 19: 507512.

24. Fujimaki H, Ushio H, Nohara K, and Ui N (2001). Induction of the imbalance of helper Tcell functions in mice exposed to diesel exhaust. Sci. Total Environ. 270: 113-121.

25. Gainy D, Short S, and McCoy K (1996). Intracellular location of cysteine transport activity correlates with productive processing of antigen disulfide. J. Cell. Physiol. 168: 248-254.

26. Gay RJ, McComb RB, Bowers GN (1968). Optimum reaction conditions for human lactate dehydrogenase isoenzymes as they affect total lactate dehydrogenase activity. Clin Chem 14: 740-753.

27. Gmunder H, and Droge W (1991). Differential Effects of Glutathione Depletion on T Cell Subsets. Cellular Immunologey 138; 229-237.

28. Gmunder H., Eck HP, Benninghoff B, Roth S, and Droge W (1990). Macrophages regulate intracellular Glutathione Levels of Lymphocytes. Evidence for an Immunoregulatory Role of Cysteine. Cellular Immunology 129; 32-46.

29. Haddad JJE, Olver RE, Land SC (2000). Antioxidant/Pro-oxidant equilibrium regulates HIF1 alpha and NFkB redox sensitivity. J Biol Chem 275: 21130-21139.

30. Hamilos DL, Mascali JJ, and Wedner HJ (1991). The role of glutathione in lymphocyte activation-II. Effects of buthionine sulfoximine and 2-cyclohexene-1-one on early and late activation events. Int. J. Immunopharmacol. 13: 75-90. 
31. Hiura TS, Li N, Kaplan R, Horwitz M, Seagrave JC, Nel AE (2000). The role of a mitochondrial pathway in the induction of apoptosis by chemicals extracted from diesel exhaust particles. J Immunol 165: 2703-2711.

32. Huisingh J, Bradow R, Jungers R, Claxton L, Zweidinger R, Tejada S, Bungarner J, Duffield F, Waters M, Simon VF, Hare C, Rodriguiz C, Snow L (1978). Application of bioassay to the characterization of diesel particle emission. In: Sandhu SS, Claxton L eds. Application of shortTerm Bioassay in the Fractionation and Analysis of Complex Environmental Mixtures. New York: Plenum; 381-418.

33. Ishii T, Sugita Y, Bannai S (1987). Regulation of glutathione levels in mouse spleen lymphocytes by transport of cysteine. J Cell Physiol 133: 330-336.

34. Iwai K, Adachi S, Takahashi M, Moller L, Udagawa T, Mizuno S, Sugawara I (2000). Early oxidative DNA damages and late development of lung cancer in diesel exhaust-exposed rats. Environ Res 84; 255-264.

35. Kang J.H., Lewis D.M., Castranova V., Rojanasakul Y., Banks D.E., Ma J.Y.C. and Ma J.K.H. (1992). Inhibitory action of tetrandrine on macrophage production of interleukin-1 (IL1)-like activity and thymocyte proliferation. Exp. Lung Res.18; 715-729.

36. Kasai H, Nishimura S (1984). Hydroxylation of deoxyguanosine at the C-8 position by ascorbic acid and other reducing agents. Nucl. Acid Res. 12: 2137-2145.

37. Knox, WE, In “The Enzymes," $2^{\text {nd }}$ ed. (PD Boyer, HA Lardy, and K Myback, Eds.), Vol. 2, part A pp. 253-294, Academic Press, New York, 1960.

38. Koren HS, and Utell MJ (1997). Asthma and the environment. Environ. Health Perspect. 105: 534-537. 
39. Kosower EM and Kosower NS (1969). Lest I forget thee, glutathione. Nature 224: 117-120.

40. Kotin P, Falk H, Thomas M (1995). Aromatic hydrocarbons. III. Presence in the particulate phase of diesel engine exhausts and the carcinogenicity of exhaust extracts. Arch. Ind. Health 11: 113-120.

41. Kumagai Y, Arimoto T, Shinyashiki M, Shimojo N, Nakai Y, Yoshikawa T. Sagai M (1997). Generation of reactive oxygen species during interaction of diesel exhaust particle components with NADPH-cystochrome P450 reductase and involvement of the bioactivation in the DNA damage. Free Rad. Biol. Med. 22: 479-487.

42. Lambert AL, Dong W, Winsett DW, Selgrade MK, and Gilmour MI (1999). Residual fly ash exposure enhances allergic sensitization to house dust mite. Toxicol. Applied Pharmacol. 158: 269-277.

43. Lambert AL, Dong W, Selgrade MK, and Gilmour MI (2000). Enhanced allergic sensitization by residual oil fly ash particles is mediated by soluble metal constituents. Toxicol. Applied Pharmacol. 165: 84-93.

44. Lane, FC, and Mehta, JR (1990). In vitro human tumor sensitivity assay using cell counting and sizing. Am. Biotech. Lab. 8: 12-27.

45. Lawrence BP, Will Y, Reed DJ, and Kerkvliet NI (2000). $\gamma$-Glutamyltranspeptidase knockout mice as a model for understanding the consequences of diminished glutathione on $\mathrm{T}$ cell-dependent immune responses. Eur. J. Immunol. 30: 1902-1910.

46. Layne E (1957). Spectrophotometric and turbidimetric methods for measuring proteins. Methods Enzymol 10: 447-455. 
47. Li AP (1981). Antagonistic effects of animal sera, lung and liver cytosols, and sulfhydryl compounds on the cytotoxicity of diesel exhaust particle extracts. Toxicol. Appl. Pharmacol. 57: $55-62$.

48. Lovik M, Hogseth A, Gaarder PI, Hagemann R, and Eide I (1997). Diesel exhaust particles and carbon black have adjuvant activity on the local lymph node response and systemic IgE production to ovalbumin. Toxicology 121: 165-178.

49. Luster MI, Munson AE, Thomas P, Holsapple MP, Fenters J, White KL, Lauer Jr., LD, and Dean JH (1988). Development of a testing battery to assess chemical-induced immunotoxicity. Fund. Appl. Toxicol. 10; 2.

50. Maejima K, Tamura K, Taniguchi Y, Nagase S, and Tanaka H (1997). Comparison of the effects of various fine particles on IgE antibody production in mice inhaling Japanese cedar pollen allergens. J. Toxicol. Environ. Health 52: 231-248.

51. McMenamin C, Girn B, and Holt PG (1992). The distribution of IgE plasma cells in lymphoid and non-lymphoid tissues in high-IgE responder rats: Different localization of antigenspecific and "bystander" components of the IgE response to inhaled antigen. Immunology 77: 592-596.

52. Mizuochi T, Yee ST, Kasai M, Kakiuchi T, Muno D, and Kominami E (1994). Both cathepsin B and cathepsin D are necessary for processing of ovalbumin as well as for degradation of class II MHC invariant chain. Immunol Lett. Immunol. Lett. 43; 189-193

53. Muranaka M, Suzuki S, Koizumi K, Takafuji S, Miyamoto T, Ikemori R, et.al. (1986). Adjuvant activity of diesel exhaust particulates for the production of IgE antibody in mice. J. Allergy Clin. Immunol. 77; 616-23. 
54. Nagashima M, Kasai H, Yokota J, Nagamachi Y, Ichinose T, Sagai M (1995). Formation of an oxidative DNA damage, 8-hydroxydeoxyguanosine, in mouse lung DNA after intratracheal instillation of diesel exhaust particles and effects of high dietary fat and beta-carotene on this process. Carcinogenesis 16: 1441-1445.

55. National Institute for Occupational Safety and Health (1988). Health Hazard Evaluation. Report HETA 86-447-1919. Cincinnati, OH: NIOSH.

56. Nel AE, Diaz-Sanchez D, David NG, Hiura T and Saxon A (1998). Enhancement of allergic inflammation by the interaction between diesel exhaust particles and the immune system. J. Allergy Clin. Immunol. 102; 539-554.

57. Noble A, Macary PA, and Kemeny DM (1995). IFN- $\gamma$ and IL-4 regulate the growth and differentiation of CD8+ T cells into subpopulations with distinct cytokine profiles. J. Immunol. 155: $2928-2937$.

58. Nordenhall C, Pourazar J, Blomberg A, Levin JO, Sandstrom T, Adelroth E ((2000). Airway inflammation following exposure to diesel exhaust: a study of time k using induced sputum. Eur Respir J 15: 1046-1051.

59. O'Garra A, and Muphy K (1996). Role of cytokines in development of Th1 and Th2 cells. In Romangnani S (ed) chemical Immunology: Th1 and Th2 cells in Health and Disease. Karger, Basel, PP 1-13.

60. Oliveira DBG, Gillespie K, Wolfreys K, Mathieson PW, Qasim F, and Coleman JW (1995). Compounds that induce autoimmunity in the Brown Norway rat sensitize mast cells for mediator release and interleukin-4 expression. European Journal of Immunology 25: 2259-2264. 
61. Peat JK (1994). The rising trend in allergic illness: which environmental factors are important? Allergy 24, 797-800.

62. Pederson TC (1981). DNA-binding studies with diesel exhaust particle extract. Environ. Int. 5: 299-305.

63. Pederson TC, and Siak J-S (1981). The role of nitroaromatic compounds in the direct-acting mutagenicity of diesel particulate extract. J. Appl. Toxicol. 1: 54-60.

64. Peterson JD, Herzenberg LA, Vasquez K, and Waltenbaugh C (1998). Glutathione levels in antigen presenting cells modulate Th1 versus Th2 response patterns. Proc. Natl. Acad. Sci. USA 95: 3071-3076.

65. Reed P.W. (1969). Glutathione and the hexose monophosphate shunt in phagocytizing and hydrogen peroxide-treated rat leukocytes. J. Biol. Chem. 244; 2459-2464.

66. Renz H, Smith HR, Jenson JE, Ray BS, Irvin CG and Gelfand EW (1992). Aerosolized antigen exposure without adjuvant causes increased $\operatorname{IgE}$ production and increased airway responsiveness in the mouse. J. Allergy Clin. Immunol. 89 (6): 1127-1138.

67. Rudell B, Blomberg A, Helleday R, Ledin C, Lundback B, Stjernberg N, Horstedt P, Sandstrom T (1999). Bronchoalveolar inflammation after exposure to diesel exhaust: comparison between unfiltered and particle trap filtered exhaust. Occup Environ Med 56: 527-534.

68. Sagai M, Saito H, Ichinose T, Kodama M, Mori Y (1993). Biological effects of diesel exhaust particles. I. In vitro production of superoxide and in vivo toxicity. Free Rad. Biol. Med. 14: $37-47$. 
69. Salvi S, Frew A, and Holgate S (1999). Is diesel exhaust a cause for increasing allergies? Clin. Exp. Allergy 29: 4-8.

70. Salvi S, and Holgate S (1999). Mechanisms of particulate matter toxicity. Clin. Exp. Allergy 29: 1187-1194.

71. Salvi S, Blomberg A, Rudell B, Kelly F, Sandstrom T, Holgate ST, and Frew A (1999). Acute inflammatory responses in the airways and peripheral blood after short-term exposure to diesel exhaust in healthy human volunteers. Am. J. Respir. Crit. Care Med. 159: 702-709.

72. Saxon A, Diaz-Sanchez D (2000). Diesel exhaust as a model xenobiotic in allergic inflammation. Immunopharmacology 48: 325-327.

73. Schuetzle D (1983). Sampling of vehicle emissions for chemical analysis and biological testing. Envriron. Health Perspect. 47: 65-80.

74. Schuetzle D, Lee FSC, Prater TJ, and Tejada SB (1980). In: Proceedings of the $10^{\text {th }}$ Annual Symposium on the Analytical Chemistry of Pollutants. New York: Gordon and Breach Science Publishers; 193-244.

75. Schwartz J, Dockery DW, and Neas LM (1996). Is daily mortality associated specifically with fine particles? J Air Waste Manag Assoc 46: 927-939.

76. Seaton A, MacNee W, Donaldson K, and Godden D (1995). Particulate air pollution and acute health effects. Lancet 345: 176-178.

77. Sedgwick JD, and Holt PG (1983). Induction of IgE-isotype specific tolerance by passive antigenic stimulation of the respiratory mucosa. Immunology 50 (4): 625-630. 
78. Shahan TA, Siegel PD, Sorenson WG, Kuschner WG, and Lewis DM (1994). A sensitive new bioassay for tumor necrosis factor. J. Immunol. Methods 175: 181-187.

79. Short S, Merkel BJ, Caffrey R, and McCoy KL, (1996). Defective antigen processing correlates with a low level of intracellular glutathione. Eur. J. Immunol. 26: 3015-3020.

80. Shukla A, Timblin C, BeruBe K, Gordon T, Mckinney W, Driscoll D, Vacek P, and Mossman BT (2000). Inhaled particulate matter causes expression of Nuclear Factor (NF)-кBrelated genes and oxidant-dependent NF- $\kappa$ B activation in vitro. Am. J. Respir. Cell Mol. Biol. 23: $182-187$.

81. Siegel PD, Al-Humadi NH, Nelson ER, Lewis DM, and Hubbs AF (1997). Adjuvant effect of respiratory irritation on pulmonary allergic sensitization: Time and Site Dependency. Toxicol. Applied Pharmacol. 144: 356-362.

82. Siegel PD, Al-Humadi NH, Millecchia LL, Robinson VA, Hubbs AF, Nelson ER, Fedan JS (2000). Ovalbumin aeroallergen exposure-response in Brown Norway rats. Inhal. Toxicol. 12: $245-261$.

83. Staal F.J., Roederer M., Herzenberg L.A., and Herzenberg L.A. (1992). Glutathione and Immunophenotypes of T and B lymphocytes in HIV-infected individuals. Ann. N. Y. Acad. Sci. $4 ; 651 ; 453-463$.

84. Sydbom A, Blomber A, Parnia S, Stenfors N, Sandstrom T, and Dahlen SE (2001). Health effects of diesel exhaust emissions. Eur Respir J 17: 733-746.

85. Takano H, Yoshikawa T, Ichinose T, Miyabara Y, ImaokaK, and Sagai M (1997). Diesel exhaust particles enhance antigen-induced airway inflammation and local cytokine production in mice. Am. J. Resp. Crit. Care Med. 156: 36-42. 
86. Takizawa H, Ohtoshi T, Kawasaki S, Kohyama T, Desaki M, Kasama T, Kobayashi K, Nakahara K, Yamamoto K, Matsushima K, and Kudoh S (1999). Diesel exhaust particles induce NF-kappa B activation in human bronchial epithelial cells in vitro: importance in cytokine transcription. J. Immunol. 162: 4705-4711.

87. Taniguchi N, Higashi T, Sakamoto Y, and Meister A (1989). Glutathione centennial: molecular properties and clinical applications. Academic Press. New York.

88. Van Zijverden M, van der Pijl A, Bol M, van Pinxteren A, de Haar C, Penninks AH, van Loveren H, and Pieters R (2000). Diesel exhaust, carbon black, and silica particles display distinct Th1/Th2 modulating activity. Toxic. Appl. Pharmacol. 168: 131-139.

89. Voller A, and Bidwell D; Enzyme-linked immunosorbent assay. In Manual of clinical laboratory immunology, $3^{\text {rd }}$ ed., eds. N. R. Rose, H. Friedman, and J. L. Fahey; 1986; 99-110. Washington, DC: American Society for Microbiology.

90. Watanabe H, and Bannai S (1987). Induction of cystine transport activity in mouse peritoneal macrophages. J Exp Med 165: 628-640.

91. Watzl B, Abrahamse SL, Treptow-Van Lishaut S, Neudecker C, Hansch GM, Rechkemmer G. and Pool-Zobel BL (1999). Enhancement of ovalbumin-induced antibody production and mucosal mast cell response by mercury. Food and Chemical Toxicology 37: 627-637.

92. Wolfreys K and Oliveira DBG (1997). Alterations in intracellular reactive oxygen species generation and redox potential modulate mast cell function. European Journal of Immunology 27: 297-306.

93. Woolcock AJ, and Barnes PJ: Asthma. In Lippincott-Raven Publishers. Philadelphia; 1997 : Chapter 3: 3-32. 
94. Yang HM, Ma JYC, Castranova V, and Ma JKH (1997). Effect of diesel exhaust particles on the release of interleukin-1 and tumor necrosis factor-alpha from rat alveolar macrophages. Exp Lung Res, 23: 269-284.

95. Yang HM, Barger MW, Castranova V, Ma JKH, Yang JJ, and Ma JYC (1999). Effects of diesel exhaust particles (DEP), carbon black, and silica on macrophage responses to lipopolysaccharide: Evidence of DEP suppression of macrophage activity. J Toxicol Envir Health 58: 261-278.

96. Yang HM, Antonini JM, Barger MW, Buterworth L, Roberts JR, Ma JKH, Castranova V, and Ma JYC (2001). Diesel exhaust particles suppress macrophage function and slow the pulmonary clearance of Listeria monocytogenes in rats. Environ. Health Perspect. 109: 515-521.

97. Yoshino S, and Sagai M (1999). Enhancement of collagen induced arthritis in mice by diesel exhaust particles. J Pharmcol Exp Ther 290: 524-529. 


\section{OVERALL CONCLUSION}

In this study the effect of OVA sensitization and challenge on the levels of CYSH and GSH in BAL, AM, and LNC were shown. OVA challenge may have caused an oxidative stress, increasing the demand on antioxidants systems. A concomitant change in the blood serum immunoglobulin levels was also reported. The relationship between thiol and immunological changes is not conclusive from these studies. DEP, indeed, affects the levels of thiols in both AM and LNC and also affected the thiol regulation behavior of these two cell populations. This, in part, may be related to the effect of DEP on the GSH-reductase activity, which was increased in both cell types.

Cells, like alveolar macrophages, control their GSH levels by at least three different enzymes. These are involved in controlling the redox status and the synthesis of GSH. These enzymes are: $\gamma$-glutamylcysteine synthetase, a rate limiting enzyme for GSH synthesis; $\gamma$ glutamyl transpeptidase which breaks down the extracellular GSH and makes cysteine available for the intracellular usage for GSH synthesis; and GSH-reductase, which reduces disulfide bonds. Affecting the activity of any of these enzymes might perturb the levels of GSH available for the cells. A xenobiotic may alter thiol regulation by directly or indirectly interacting with one or more of these enzymes. Alteration of cellular thiol transport is another potential target.

OVA challenge and DEP exposures caused significant changes in thiol levels in both AM and LNC with a concomitant increase in the immunoglobuline levels. Allergic challenge caused major changes in cellular thiol levels, which were partially alleviated by pre exposure to DEP. In addition, the combined exposure increased the levels of IL-4 mRNA expression in lung tissue. Both OVA and DEP separately affected the level of thiols in both AM and LNC. DEP increased OVA specific IgE (a Th2 type response) level in the serum of OVA sensitized rats. The results of these studies demonstrate that both allergic sensitization/challenge and particulate effect alter thiols in target tissues. The alterations by DEP seem to be particulate mediated as similar affects were caused by CB. While direct ties between DEP effects on thiol regulation and immune alterations can not be determined from these studies, it is interesting to note the seemingly protective affect of DEP on AM thiols following allergic challenge. It could be speculated that this may help preserve its antigen presentation ability and prevent the IgE tolerance noted. 


\title{
CURRICULUM VITAE
}

\author{
NABIL H. AL-HUMADI \\ 106 ESTATE DRIVE, \\ MORGANTOWN, W.V., 26508 \\ PH \# Home: (304) 292-1358 \\ Work: (304) 285-6065 \\ e-mail: naa9@cdc.gov \\ U.S. Citizen
}

EDUCATION

* Ph.D. in Pharmacy

West Virginia University, Morgantown, 2002.

Dissertation: Modulation of Thiols and Pulmonary Immune Responses due to Diesel Exhaust Particle (DEP) Exposure.

* M.S. in Human Nutrition West Virginia University, Morgantown, 1992.

* M.S. in Food Technology Baghdad University, Baghdad, 1985.

* B.S. in Agricultural Biology Baghdad University, Baghdad, 1979.

\section{EMPLOYMENT HISTORY}

Employer

US Dept. Of Health, NIOSH

R.O.W. Sciences, Inc.

Grain Processing Industry

Bakeries \& Ovens Industry $\underline{\text { Title }}$

Research Biologist

Bio/Lab Technician

Agriculture Engineer

Agriculture Engineer $\underline{\text { Dates }}$

09, 1996- Present.

12, 1992- 09, 1996.

06, 1987-11, 1989.

06, 1985-06, 1987.

\section{EXPERIENCE}

US Department of Health and Human Services, NIOSH-CDC, Morgantown, $W . V$.

Research Biologist (09/ 1998- present): HPLC method development have been used in my research. Labeling thiols such as cysteine and glutathione in two cell populations (alveolar macrophages and lymph node lymphocytes) with fluorescence label (monobromobimane) and a picomole detection limits were achieved. I have measured Cytokine levels (such as IFN $\gamma$ and 
IL-4 $m$ RNA) in lung tissues and cranial lymph nodes by RT-PCR. I have used ELISA in measuring the levels of specific $\operatorname{IgE}$ and $\operatorname{IgG}$ in the rat serum. I have used my previous experience in inhalation toxicology (Bio-aerosol exposure) to expose rats to diesel exhaust particulate, carbon black, and ovalbumine. Comparing the difference between two routes of exposure (inhalation and instillation) to DEP and CB was part of my study. The enzyme activity which is involved in regulating the thiols (e.g. GSH and Cysteine) in both AM and LN lymphocytes were also investigated. I have collected different lymph nodes (axiliary, Inguinal, para-thymic, cranial .....etc) and studied their thiol and cytokine levels. I have trained students and fellow scientists on different analysis systems and techniques.

US Department of Health and Human Services, NIOSH-CDC, Morgantown, W.V. Biological-Laboratory Technician (09/ 1996- 09/1998): I am applying all of my Immunological and Biochemical experience to my current Pathology section work. Beside the animal treatments and animal necropsy that comprise the main part of my responsibilities, I utilize the Liver and Testes Cytochrome P450, Ascorbic Acid, Malondialdehyde, Alcohol Dehydrogenase, Glutathione and the skin histamine assays as part of my investigations. I also serve as a primary user of the High Pressure Liquid Chromatography (HPLC) system, and assist other investigators run their samples for analyses on the system.

R.O.W. Sciences, Inc., Morgantown, W.V. Biological-Laboratory Technician (12/ 1992- 09/ 1996): I have considerable experience working in both the Biochemistry and the Immunology sections of NIOSH/DRDS. Responsibilities included gas chromatography for solvents (Ethane, Pentane, and Isoprene) to study their toxicokinetics, Inhalation toxicological techniques, Chemical analysis of bulk and air environmental samples (FMLP, Histamine, Ammonia, NO2), and hydrogen peroxide assay from primary cell cultures. Fluorescent, Ultra Violet, Visible, and Infrared spectrophotometry, Enzyme assays from biological samples (myeloperoxidase kinetic assay), Enzymeimmuno Assay (EIA), and Radioimmune Assay (RIA). Protein, LTC4, PGD2, tryptase, ECP, radio receptor-ligand binding assays. Conducting nasal and lung lavage techniques as well as Immunological techniques such as passive cutaneous anaphylaxis in animal studies. Cell isolation using density gradients and cytocentrifugation, Solid and liquid phase extractions and Chemical purification have been performed. I have 
Sensitized rats and guinea pigs and subsequently collected sera by cardiac puncture or through the tail vein. I also have an extensive work experience with the automated ELISA, and the HPLC coupled to three different detectors (UV, Fluorometer and Electrochemical). I have acquired a good working knowledge of several additional instruments including the gamma and beta counters, Coulter counter with channelizer, and lyophilizer. These analyses were performed to identify and quantitate biomarkers of disease and exposure in animal models and from human occupational disease studies.

Grain Processing Industrv, Agriculture Engineer (06/ 1985- 11/ 1989): Duties included; setting imported wheat and flour specifications, oversaw the quality of flour and wheat in private sector factories. I have also used the Amylograph, Pharinograph, and Extensograph Instruments to evaluate the quality of the produced flour. Furthermore, I have supervised more than 50 laborers. Other responsibilities included operating and adjusting the flour production equipment. Setting the flour and the ingredients (improver, salt, sugar, yeast, and water) specifications. I have operated and adjusted the bread production equipment.

\section{Computer Experience:}

Word Perfect 5.1, 6.0, 6.1 and 9, Microsoft World, Microsoft Excel, Microsoft Power Point, Corel Draw9, Sigma Plot, Sigma Stat, Instat, figP, and Draw Perfect.

\section{Awards:}

1- Outstanding Effort in promoting the goals of NIOSH 1998-1999.

2- Performance award for the year 1999.

3- Performance award for the year 2000.

4- Performance award for the year 2001.

\section{ABSTRACTS}

* NH Al-Humadi, PD Seigel, DM Lewis, MW Barger, JYC Ma, DN Weissman, and JKH Ma. Thiol and Immune Exposure Dependent Response to Ovalbumin in Sensitized Rats. The Toxicologist, March 17-21, 2002. 
* NH Al-Humadi, PD Seigel, DM Lewis, MW Barger, JYC Ma, DN Weissman, and JKH Ma. Adjuvant Effect of Diesel Exhaust Particles (DEP) and Carbon Black (CB) on Pulmonary Allergic Sensitization. Submitted to the $3^{\text {rd }}$ International Conference on Oxygen/Nitrogen Radicals: Cell injury and Disease Conference. Morgantown, WV, June 2002.

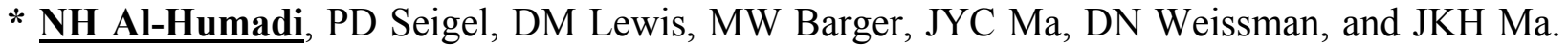
Role of Thiols in Pulmonary Immune Response to Allergic Sensitization: Adjuvant Effect of Diesel Exhaust Particulate (DEP). AAPS Pharm Sci., Abstract No. T3449, pp 196, 2001.

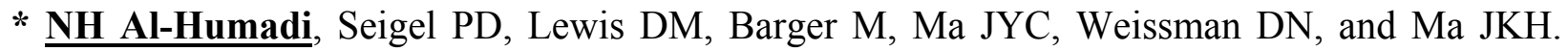
Effect of Exposure to Diesel Exhaust Particles (DEP) on Pulmonary Allergic Sensitization. Presented at the International Congress of Society of Toxicology. Australia, Brisbane, July 8-12, 2001.

* NH Al-Humadi, PD Siegel, DM Lewis, JYC Ma, and JKH Ma. Diesel Exhaust Particulate (DEP) Affected Thiol Levels in Both Alveolar Macrophages (AM) and Lymph Node Cells (LNC). The Toxicologist, 60 (1): 167, 2001.

* C Kommineni, A Shvedova and NH Al-Humadi. Used Semi-synthetic Metal Working Fluid (UMWF): Dermal and Systemic Effect in B6C3F1 Mice. The Toxicologist, 60 (1): 59, 2001.

* NH Al-Humadi, P.D. Siegel, JYC Ma, WJ Jones, MW Barger, D Lewis and JKH Ma. Comparison of Pulmonary Response to Inhaled and Inratracheally Instilled Diesel Exhaust Particulate. The Toxicologist, 54 (1): 14, 2000.

* C Kommineni, Elena Kisin, NH Al-Humadi, V Castranova and AA Shvedova,. Elevated Oxidative Stress in Skin of B6C3F1 Mice Affects Dermal Exposure to Machine Working Fluid. The Toxicologist, 54 (1): 141, 2000. 
* NH Al-Humadi, P.D. Siegel, JYC Ma, JC Mull, LF Butterworth and JKH Ma. Fluorometeric Determination of Thiol Concentrations in Cells from Pulmonary Associated Lymph Nodes and Alveolar Macrophages. AAPS Pharm Sci. 1: 2748, 1999.

* C Kommineni, Elena Kisin, NH Al-Humadi, V Castranova and AA Shvedova,. Elevated Oxidative Stress in Skin of B6C3F1 Mice Affects Dermal Exposure to Machine Working Fluid. Presented in the $14^{\text {th }}$ Annual Conference of the Developmental Immunotoxicology: Research and Risk Issues, Morgantown, WV, September 8-10, 1999.

* NH Al-Humadi, C Kommineni, AA Shvedova, L Battelli, and V Castranova. Adverse Responses to Semi-synthetic Metal Working fluids in B6C3F1 mice. The Toxicologist, 48 (1-S): $76,2000$.

* M. Iqbal, PB Kenney, H. Klandorf, and Nabil H. Al-Humadi. Effect of Age, Diet Restriction and Aminoguanidine on Mechanical Properties and Pentosidine in Tendon of Broiler Breeder Hens. Presented in the FASEB Experimental Biology Meeting, April 17-21, 1999, Washington, DC.

* M. Iqbal, L.L. Probert, PB Kenney, H. Klandorf, and Nabil H. Al-Humadi. Effect of Age, Diet Restriction and Aminoguanidine on Skin Pentosidine and Meat Tenderness in Broiler Breeder Hens. The Southern Poultry Science Society, Volume 77, Supplement I, P. 103 Abstract \# 392. Presented in the Poultry Science Association $19^{\text {th }}$ Annual Meeting ,Pennsylvania State University, PA, August 2-5, 1998.

* M. Iqbal, L.L. Probert, H. Klandorf, K Van Dyke, and Nabil H. Al-Humadi. Effect of Age, Diet Restriction and Aminoguanidine on Pentosidine in the Skin of Broiler Breeder Hens. The FASB Journal, Volume 12, Number 5, Part II, P. A879, Abstract \# 5088. Presented in FASB Annual Meeting, San Francisco, CA, April 18-22, 1998. 
* Nabil H. Al-Humadi, C. Kommineni, L. Batteli, P. Willard, D. Schwegler-Berry, and V. Castranova. MWF Effects on the B6C3F1 Mice Skin. Metal Working Fluids Symposium II, PP 398-401, 1997 (Detroit, Michigan).

* Nabil.H. Al-Humadi, P.D. Siegel. Fluorometric and Electrochemical FMLP HPLC Analysis. Eighth Annual Meeting of the Allegheny-Erie Regional Chapter of the Society of Toxicology, May 31, 1996.

* Nabil H. AL-Humadi, M.Z.A. Nomani, Amy B. Schrecengost, and Wendy L. Stuhldreher. Nutritive value and acceptability of wheat flour bread supplemented with chickpea and triticale flour. The FASB Journal, Volume 7, Number 4, Part II, P. A582, Abstract \# 3372, February 23, 1993.

* M.Z.A. Nomani, Amy B. Schrecengost, Nabil H. AL-Humadi, and Wendy L. Stuhlderher. Wheat flour cookies supplemented with chickpea and triticale flours. The FASB Journal, Volume 7, Number 4, Part II, P. A582, Abstract \# 3373, February 23, 1993.

* P.D. Siegel, N.H. AL-Humadi, P.R. Clark, and E.A. Ronk. Biological considerations in the use of breath alkanes (and alkenes) as markers of lipid peroxidation. Oxygen Radicals and Lung Injury Conference, August 30 - September 2, Morgantown, West Virginia, 1993.

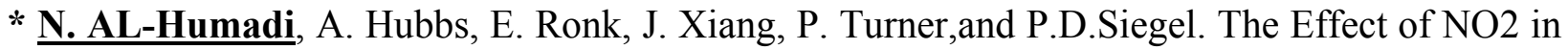
Acute Lower Lung Irritation in Pulmonary Allergic Sensitization. (Presented in the local AESOT meeting, June, 1994).

* P.D. Siegel, N. Al-Humadi, A. Hubbs, E. Ronk, J. Xiang, and P. Turner. Adjuvant effect of acute lower lung irritation in pulmonary allergic sensitization. The International Toxicologist, 71, P.3, 1995. 
* Nabil H. AL-Humadi, and S. Toma. To Investigate the use of Dry Milk in the Manufacturing of Dairy Products, Journal of Agricultural Sciences, Baghdad, Iraq, 1985.

\section{PUBLICATIONS}

* NH Al-Humadi, PD Seigel, DM Lewis, MW Barger, JYC Ma, DN Weissman, and JKH Ma (2002). The Effect of Diesel Exhaust Particles (DEP) and Carbon Black (CB) on Thiol Changes in Pulmonary Ovalbumin Allergic Sensitized Brown Norway Rats. Experimental Lung Research, 28: 333-349.

* NH Al-Humadi, PD Siegel, DM Lewis, Mark W. Barger, JYC Ma, and JKH Ma (2002). Alteration of Intracellular Cysteine and Glutathione Levels in Alveolar Macrophages and Lymphocytes by Diesel Exhaust Particle Exposure. Environmental Health Perspective, 110: 349353.

* Nabil H. Al-Humadi, Shvedova A., Battelli L., Diotte N., Castranova V., and Kommineni C (2000). Dermal and Systemic Toxicity after Application of Semi-synthetic Metal Working Fluids in B6C3F1 Mice. J. Toxic. Envir. Health, part A, 61: 579-589.

* Nabil H. Al-Humadi, C. Kommineni, L. Batteli, P. Willard, D. Schwegler-Berry, and V. Castranova (2000). MWF Effects on the B6C3F1 Mice Skin. Journal of Toxicology and Industrial Health, 16: 203-210.

* Muhammad Iqbal, P.B. Kenney, N.H. Al-Humadi, and H. Klandorf (2000). Relationship between Mechanical Properties and Pentosidine in Tendon: Effect of Age, Diet Restriction and Aminoquanidine in Broiler Breeder Hens. J. Poultry Sci., 79: 1338-1344.

* Paul D. Siegel, Nabil H. Al-Humadi, L.L. Millecchia, V.A. Robinson, A.F. Hubbs, E.R. Nelson, and J.S. Fedan (2000). Ovalbumin Aeroallergen Exposure-Response in Brown Norway Rats. Inhalation Toxicology, 12: 245-261. 
* M. Iqbal, L.L. Probert, N.H. Al-Humadi, and H. Klandorf (1999). Protein Glycosylation and Advanced Glycosylated End product (AGE) Accumulation: An Avian Solution? Journal of Gerontology: Biological Science, 54A: B171-B176.

* Nabil.H. Al-Humadi, P.D. Siegel (1997). Fluorometric and Electrochemical FMLP HPLC Analysis. Proceedings-Beltwide Cotton Conferences.(Eds Paul Dugger, and Debbie Richter). Volume 1 PP 202-205.

* Paul D. Siegel, Nabil H. Al-Humadi, Elizabeth R. Nelson, Daniel M. Lewis, and Ann F. Hubbs (1997). Adjuvant Effect of Respiratory Irritation on Pulmonary Allergic Sensitization: Time and Site Dependency. Toxicology and Applied Pharmacology 144, 356-362.

* P.D. Siegel, S. Short, W.G. Jones, N.C. Leppla, D.M. Lewis, B. Ducatman, E.A. Ronk, T. Bledsoe, B. Husberg, E. Jennison, E. Janotkova, J.C. Mull, T.A. Shahan, ․H. Al-Humadi, D. Freeland, J. Odencrantz, E.L. Petsonk (1995). Nasal Lavage for Exposure and Health Assessment. People and Work. Research Report 3, pp.81-87.

* D.G. Frazer, V.A. Robinson, P.D. Siegel, N. Al-Humadi, A.A. Afshari, W.T. Goldsmith, S. Olenchock, M.P. Whitmer and V. Castranova (1996). Response of An Animal Model to Mixtures of Endotoxin and N-Formyl-Methionyl-Leucyl-Phenylalanine (FMLP) Aerosols. Proc. Of the twentieth Cotton \& Other Organic Dusts Res. Conf. (eds. PJ Wakelyn, RR Jacobs and R. Rylander). PP 360-363.

\section{SEMINARS ATTENDED}

* 08/ 07/ 97- 08/ 10/ 97, 3-Day Millennium System with 996 PDA course (HPLC, by Waters), Cincinnati, Ohio.

* 10/ 28/ 89- 11/2/ 89, Conference of the America Association of Cereal Chemists (AACC) meeting in Washington, D.C. 
* 02/ 23/ 89- 02/ 26/ 89, Seminar in grain storage and handling, held in Baghdad, Iraq by the U.S. Wheat Associates.

\section{PROFESSIONAL AFFILIATIONS}

* American Association of Pharmaceutical Scientist.

* Allegheny-Erie Regional Chapter of the Society of Toxicology.

\section{COMMUNITY SERVICE}

* Registered referee with the United States Soccer Federation (Grade 8) and with the National Federation Interscholastic Officials Association. Officiating recreational, local tournaments and high school games.

\section{REFERENCES}

* Dr. Paul Siegel, Research Chemist; NIOSH/ALOSH, Immunology Section, 1095 Willowdale Road, Morgantown, WV 26505. Phone \#: (304) 285-5855.

* Dr. Daniel Lewis, Branch Chief; NIOSH/ALOSH, Immunology Section, 1095 Willowdale Road, Morgantown, WV 26505. Phone \#: (304) 285-5720.

* Dr. Joseph Ma, Professor; West Virginia University, School of Pharmacy, Basic Pharmaceutical Sciences, Morgantown, WV 26506-6124. Phone \#: (304) 293-1449.

* Dr. Vincent Castranova, Branch Chief; NIOSH/ALOSH, Pathology \& Physiology Branch, 1095 Willowdale Road, Morgantown, WV 26505. Phone \#: (304) 285-6032.

\section{LANGUAGE SKILLS}

* English: Near Native fluency in speaking, reading and writing.

* Arabic: Native fluency in speaking, reading and writing. 